\title{
5 Vom Zerstören und Befreunden: THE LAST GUARDIAN, PYRE, HELLBLADE: SENUA'S SACRIFICE
}

\section{Lob des Serienkillers}

Warum muss es immer Mord sein? Man wird ja kaum einen Krimi finden, der darauf verzichtet, mindestens einen mehr oder weniger Unschuldigen ums Leben zu bringen. Das ist keineswegs eine Selbstverständlichkeit. Denn es könnte, wie Peter von Matt anmerkt, „doch eigentlich genauso spannend sein, herauszufinden, wer ein Auto gestohlen hat oder in eine Konditorei eingebrochen ist“. ${ }^{1}$ Doch von Matt weiß natürlich, dass die Vorstellung, einer der ebenso brillanten wie zerquälten Kommissare, die in Skandinavien, Großbritannien, Frankreich, Deutschland oder auch der Schweiz offenbar zu Hunderten anzutreffen sind, würde sich wegen der Ersparnisse eines Tortenbäckers die Nächte um die Ohren schlagen dass eine derartige Vorstellung den versierten Krimikenner eher zum Schmunzeln anregt. Nein, das Mordopfer, gerne auch im Plural, ist der raison d'être dieses Genres.

Was erneut die Frage aufwirft: Warum ist das so? Wenn von Matt recht hat, geht es weniger um das Blutige und Gewaltsame der Tat. Nicht „die menschliche Grausamkeit“ als solche steht in Rede, sondern: „Die menschliche Schuld. Und ihre Sühne.“2 Folglich gehört zweierlei zum Krimigenuss: der Mord und die Bestrafung des Mörders. Beides ist unabdingbar. Denn das Genre folgt einer affektpoetischen Bewegung, welche die Tat mit ihrer Vergeltung zusammenschließt. Der Krimi sorgt dafür, dass wir, wie von Matt schreibt, „das Böse erleben“, doch dabei darf es nicht bleiben; „das eigentümliche Gefühl der Zufriedenheit“, das uns der Krimi verschafft, muss vielmehr am Bösen sein Maß nehmen, um die entsprechende Strafe ins Werk zu setzen:

Je größer die Schuld war, umso tiefer die Genugtuung. Genau deshalb braucht es den Mord, genau deshalb reicht ein Fahrraddiebstahl nicht aus und auch ein erschossener Hund nicht. Der Mord an einem Menschen ist für das spontane Empfinden das Verbrechen schlechthin; dessen angemessene Bestrafung erleben wir daher als Konsolidierung unseres immer gefährdeten Grundvertrauens in die Weltordnung. Wir fühlen uns wieder ein bisschen besser zuhause auf dem Erdboden. ${ }^{3}$

1 Peter von Matt: Skizze zum Kriminalroman. Am Beispiel von Hansjörg Schneiders Tod einer Ärztin. In: ders.: Das Kalb vor der Gotthardpost. Zur Literatur und Politik der Schweiz. München 2012, S. 340-344, hier: S. 340.

2 von Matt: Skizze zum Kriminalroman, S. 341.

3 von Matt: Skizze zum Kriminalroman, S. 341.

כ Open Access. (C) 2020 Daniel Illger, publiziert von De Gruyter. (cc) BY-NC-ND Dieses Werk ist lizenziert unter der Creative Commons Attribution-NonCommercial-NoDerivatives 4.0 International Lizenz.

https://doi.org/10.1515/9783110695380-005 
Man könnte vielleicht noch einen Schritt weitergehen und sagen: Wer einen Krimi liest, erhofft sich eine Art Wiedergutmachung. Wir halten uns schadlos an den fiktiven Tätern, da wir wissen, dass die Sache in der Wirklichkeit allzu oft anders abläuft. Sicher, das Böse verlangt nach Strafe, im Leben wie in der Kunst, nur dass es das Leben weit weniger eilig hat, jenem Verlangen nach Gerechtigkeit zu genügen. Und abgesehen davon sind die meisten Mörder, die in unseren Städten und Dörfern ihr Unwesen treiben, ja gerade keine psychopathischen Serienkiller oder Genies des Verbrechens, sondern - arme Teufel.

Umgekehrt mag das der Grund dafür sein, warum der populäre Krimi schon seit längerem nicht mehr mit jenen gewöhnlichen Mördern auskommt, sondern eben den psychopathischen Serienkiller braucht. Hier findet eine merkwürdige Verschiebung statt. Es ist, als würden uns die immer bizarreren, elaborierteren und überaus blutrünstigen Methoden des Serienkillers in ihrer Zurschaustellung einer sehr handfesten Form des Bösen irgendwie auch beruhigen. Immerhin kann man einen durchgeknallten Mörder verhaften oder nötigenfalls erschießen.

Sehr viel schwerer tut man sich damit, ein Wirtschaftssystem vor Gericht zu stellen, das offenbar nicht auskommt ohne Kriege, Ausbeutung, Waffenexporte, Umweltzerstörung und künstlich erzeugte Hungersnöte - und das dabei einen winzigen Teil der Menschheit in einer Weise immer reicher und mächtiger macht, dass man leicht zu dem Schluss kommen könnte, die naturrechtliche Verfasstheit unserer Spezies ziele in Wahrheit auf die Entlohnung des Verbrechens, und im Streben nach Anstand offenbare sich allein die mangelnde Tauglichkeit zu einem Erfolg, der nicht nur sprichwörtlich über Leichen geht. ${ }^{4}$

Nun gehört eine Portion Kapitalismuskritik fast ebenso obligatorisch zum zeitgenössischen Krimi wie die Zeugenbefragung oder das verkrachte Privatleben der Ermittler. Aber möglicherweise wird das Paradoxon, das die genannte Verschiebung begründet, gerade durch diese, mitunter ja durchaus ernstzunehmende, politische Ambition des Genres vervollständigt. Die Missstände, in deren Schilderung sich die Krimis ergehen - von Armut und häuslicher Gewalt bis hin zu Menschenhandel und High-Society-Korruption -, sind unleugbar

\footnotetext{
4 Luc Boltanski vertritt in diesem Zusammenhang die These, dass der Krimi eine Störung der Realität selbst inszeniert. Das Insistieren auf der Untersuchung sieht er als eine der äußerlich sichtbaren Formen, „die eine allgemeinere und tiefere Störung annimmt, deren Gegenstand die Realität selbst ist. Einerseit hat sich die Realität zweifellos niemals als so organisiert, robust und dadurch so vorhersehbar dargestellt wie in den modernen westlichen Gesellschaften. Aber andererseits, und zwar vielleicht aus denselben Gründen, tritt ihre Fragilität oder das, was man dafür hält, in den Vordergrund und scheint eine noch nie dagewesene Verunsicherung hervorzurufen.“ Luc Boltanski: Rätsel und Komplotte. Kriminalliteratur, Paranoia, moderne Gesellschaft. Berlin 2015, S. 46.
} 
real. Je nachdem, welche Stellung man selbst in der Welt einnimmt, mag die Realität, der sie zugehören, aufdringlich und störend, letztlich jedoch harmlos sich anfühlen, ähnlich wie das Stück Hundekot an der Schuhsohle; oder aber sie gleicht einem wuchernden Tumor im eigenen Schädel. Davon unabhängig legitimiert der Wirklichkeitsstatus jener sozialen und politischen Schrecknisse das nahezu Fantastische der Killerfigur.

Im Gegenzug verwandelt das Übersteigerte in der wahnhaften Grausamkeit des Serienmörders die ganz gewöhnliche Menschen- und Lebensfeindlichkeit einer Gesellschaft, die, bis zu einem gewissen Grad losgelöst vom individuellen Wollen und Streben, bereit scheint, alles der Profitmaximierung unterzuordnen. Wer war zuerst da, das Huhn oder das Ei? Der Krimi sorgt dafür, dass mitunter noch die Leiden der alleinerziehenden Mutter, die sich mit diversen Dreckjobs über die Runden quält, ihren Kindern dennoch kaum das Nötigste bieten kann und obendrein von einem machistischen Geliebten verprügelt wird, als Emanation der Boshaftigkeit des Serienkillers erscheinen. Oder er projektiert ein Kontinuum zwischen den Übeln verschiedener Größenordnung, die ihre Wurzel zwar in derselben politischen, sozialen und ökonomischen Misere haben mögen, in dem psychopathischen Mörder aber ihre Personifikation finden. So oder so macht dieses Genre noch die Ohnmacht angesichts einer aus den Fugen geratenen Welt genussfähig, ${ }^{5}$ indem es sie, vermittels der Exzessivität des Killers, seiner Methodik und seiner Motive, zum Teil eines epischen Kampfes zwischen Gut und Böse erhebt, aus dem die Helden zwar nicht als Sieger hervorgehen können, den sie aber ebensowenig verlieren, da sie ja zumindest diesen einen, gerade in seiner singulären Grausamkeit exemplarischen Vertreter der Gegenseite zur Strecke bringen.

Ist die „menschliche Grausamkeit“ also von zweitrangiger Bedeutung in dem Drama von Schuld und Sühne, welches der Krimi inszeniert? Vielleicht hat von Matt mit dieser Behauptung zugleich recht und unrecht, in dem Sinn, dass vor dem Hintergrund des allgemeinen Zustands der Welt noch der gewöhnliche Mord wie ein Fahrraddiebstahl oder ein Einbruch in die Konditorei anmutet. Um jene Erschütterung des Weltgefühls zu erzeugen, auf deren Grundlage sich die Wiederherstellung eines wie immer fragilen Vertrauens vollziehen kann, braucht der Krimi schon ein bisschen mehr. Und dieses Mehr besteht eben oft genug in den bizarren Folter- und Mordpraktiken sowie der nicht minder bizarren Psychologie des Serienkillers.

5 Der - durchaus abstrakt-philosophische - Genuss des Krimilesens oder -schauens besteht unter anderem auch darin, zu erfahren, wie die Textur einer vernünftig verfassten Realität sich auflöst. Vgl. Christine Lötscher: Der Abgrund im Alltag. Der Regionalkrimi als Genre der Globalisierung. Unveröffentlichtes Vortragsmanuskript, 2018, S. 1-2. 
Die Hartnäckigkeit, mit der das Genre in stets denselben Abgrund starrt, ${ }^{6}$ mag im Einzelfall viel mit künstlerischer Faulheit oder Gedankenarmut zu tun haben. Dessen ungeachtet lässt sich das existenzialistische Pathos des Krimis zumindest, was die Gegenwart betrifft - kaum denken ohne die Kübel von Blut, die gemarterten Körper und die nach und nach sich aufreihenden Leichen, die der Fleiß des psychopathischen Mörders bereitstellt.

Hier offenbart sich eine überraschende Verwandtschaft zwischen dem Krimi und einem Genre, das, hinsichtlich des Verhältnisses zur sozialen Wirklichkeit eher als sein Antipode erscheint. Die Rede ist natürlich von der Fantasy.

\section{Eine kleine Fantasy?}

Beginnen wir mit folgender Behauptung: Was dem Krimi der Mord, ist der Fantasy der Kampf.

Ganz offensichtlich kommt dieses Genre kaum je aus ohne Waffengeklirr. Das reicht vom Zweikampf über das Scharmützel bis hin zur Schlacht. Schwerter, Säbel, Dolche, Äxte und Beile, Kriegshämmer und Streitkolben, Lanzen und Speere sind wohl die beliebtesten unter den archaischen Mordwerkzeugen, die zum Einsatz kommen, wenn Mann gegen Mann steht (seltener: Frau gegen Mann; noch seltener: Frau gegen Frau). Dafür, dass sich die Leute auch aus der Ferne umbringen können, sorgen etwa Schleudern, Bögen und Armbruste; nicht zu vergessen Magie, deren Wirkung mitunter jener von Flammenwerfern oder Giftbomben ähnelt. Den wüsten Mitteln entspricht eine Sprache, die sich bei der Darstellung des Gemetzels nicht unbedingt in Diskretion übt. Seit den Anfängen der Fantasy als populäres Genre ist das so. Beispielsweise triefen die Erzählungen des Conan-Erfinders Robert E. Howard, auf den ich im folgenden Kapitel zu sprechen komme, regelrecht vor Blut und Hirnmasse. Freilich geht es nicht überall so rabiat zu wie bei Howard. Doch selbst die Fantasy, die sich ausdrücklich an junge Menschen richtet, ist voller tödlicher Auseinanderset-

6 Ich vermute, dass sich nichts Wesentliches an dieser poetischen Logik ändert, wenn an die Stelle des Serienkillers ein bis ins Mark verdorbener Politiker oder Wirtschaftsboss tritt. In solchen Fällen wird vielleicht das Systemische stärker betont als das Individuelle, und es sind keine Kindheitstraumata, keine aberwitzigen moralischen, religiösen oder politischen Vorstellungen, sondern der unbedingten Anhäufung von Geld und Macht dienende Geschäftspraktiken, welche die grausigen Morde herbeiführen. Bei dieser Spielart des Krimis werden die Morde selbst wohl auch eher von Handlangern ausgeführt, denen es freilich nicht an psychopathischer Verve gebricht. In jedem Fall kann man sagen, dass der Krimi die affektpoetische Dialektik von Erschütterung und partieller Wiederherstellung des Weltvertrauens auch dann ins Werk setzt, wenn er sein Böses nicht in der Gestalt eines prototypischen Serienkillers sucht. 
zungen und brutaler Kämpfe - und kulminiert gerne in gewaltigen Schlachten, die Reiche, Völker und Zeitenläufe erschüttern.

Wie beim Krimi stellt sich auch hier die Frage: Warum muss das sein?

Wenn eine fantastische Welt sorgfältig gebaut ist und in ihrer räumlichen wie zeitlichen Entfaltung jenen Zauber von Ahnung und Geheimnis spürbar macht, auf dessen Realisierung die Genrepoetik wesentlich abzielt - reicht das nicht? Könnte man, wenn dies gegeben ist, nicht genügend Spannung und Aufregung in kleineren und zudem friedfertigeren Geschichten finden dem Fantasy-Äquivalent zum Fahrraddiebstahl oder dem Einbruch in die Konditorei, sozusagen?

Tatsächlich kann man sich das schön vorstellen. Wir hätten es dann zu tun mit Bauern, Fischern und Jägern, reisenden Händlern und verarmten Adeligen, die einfach nur versuchen, ein anständiges Dasein zu führen und mit ihren gewöhnlichen Sorgen, Nöten, Freuden und Abenteuerchen vollauf beschäftigt sind. Die entsprechenden Geschichten würden sich vielleicht wirklich um den Diebstahl von ein paar Säcken Getreide drehen; oder um einen Schatz, der im benachbarten Wald versteckt sein soll; oder um heikle Liebschaften; oder um einen Geist, der keine Ruhe findet, solange ein bestimmtes Unglück nicht aus der Welt geschafft ist. Sie wären verwurzelt in einer alltäglichen Sozietät, deren Darstellung grosso modo den Gesetzen des literarischen Realismus verpflichtet ist; zugleich würden sie sich freimütig bei den Reichtümern der Fantastik bedienen und gerne auch auf Gestalten und Vorkommnisse, Handlungsfigurationen und ästhetische Modalitäten zurückgreifen, die in der romantischen Tradition der Neudichtung (angeblich) alter Märchen, Sagen oder Chroniken vorgebildet sind. Und was den Kampf betrifft: Eine solche Geschichte würde wohl mit der gelegentlichen, freundschaftlichen Kneipenschlägerei auskommen; im Extremfall müssten sich die Helden den Knüppeln von Wegelagerern oder Strauchdieben erwehren.

Wer nach Vorbildern für eine solche kleine Fantasy sucht, ${ }^{7}$ könnte bei gewissen Autoren des 19. Jahrhunderts fündig werden, deren Erzählungen zwar nicht in einer Sekundärwelt angesiedelt sind, die vermeintlich gewohnte Wirklichkeit

7 Nicht zufällig klingt hier das von Deleuze und Guattari an der Person und am Werk Kafkas entwickelte Konzept einer „kleinen Literatur“ an. Bezogen auf die Fantasy würde es vielleicht bedeuten, nicht nur die Mythologeme und Stereotype des Genres - die sich eben um Kampf, Krieg, Heldentum und Weltrettung drehen -, sondern auch die ihnen korrespondierende Sprache zu dekonstruieren. Wirklich wissen kann man das freilich nicht, da es nun mal kein Werk gibt, an dem sich eine kleine Fantasy exemplifizieren ließe. Allgemein scheint mir aber, dass die Fantasy nicht das ungeeigneteste Genre für die Herausbildung einer kleinen Literatur ist ihr Hang, eigene Sprachen, Historien, Religionen, Völker und Geografien zu entwickeln, zeigt ja schon, dass ihr recht eigentlich die ganze Welt eine Fremdsprache ist. Vgl. Gilles Deleuze/ Félix Guattari: Kafka. Für eine kleine Literatur [1975]. Frankfurt a. M. 1976. 
aber - ohne dabei die Alltäglichkeit preiszugeben - auf eine Weise fantastisch aufladen, dass der Unterscheid verwischt. Man denke beispielsweise an das Frühwerk von Nikolai Gogol, seine Abende auf dem Weiler bei Dikanka (1831/32), oder Jeremias Gotthelfs verwegenere, um nicht zu sagen wilde, wüste ${ }^{8}$, Erzählungen, etwa Die schwarze Spinne (1842) oder Kurt von Koppingen (1844/50); wobei in letzterer freilich gekämpft wird, dass die Schwarte kracht.

Auch bei Autoren, deren Werke der Unterhaltungsliteratur zugerechnet werden und mithin im heute geläufigen Sinne als Genreprodukte gelten, gibt es derartige Ansätze. Und zwar mitunter an Orten, wo man es nicht unbedingt erwarten würde, so in den Romanen Ulrich Kiesows, die in der maßgeblich von ihm entwickelten Welt des Rollenspiels Das Schwarze Auge spielen, namentlich Der Scharlatan (1996) und Das zerbrochene Rad (1997), oder im dritten Band der Rigante-Tetralogie von David Gemmell, Ravenheart (2001), ${ }^{9}$ der ganz offensichtlich an Walter Scott sein Maß nimmt, wobei der schottische Nationaldichter zweifelsfrei ebenfalls einen Platz in der Ahnengalerie jener kleinen Fantasy fände. Des Weiteren will ich Robin Hobb erwähnen - eine Autorin, deren Werk immer wieder den Eindruck erweckt, sie würde am liebsten ganze Buchreihen mit kleiner Fantasy füllen. Vor allem bei der Lektüre ihrer Liveship-Trader-Trilogie ${ }^{10}$ ist es, als würde sich die Erzählung selbst dagegenstemmen, von den wundervollen Beschreibungen des Alltagslebens in der Küstenstadt Bingtown und auf den Schiffen der Familie Vestrit abzukommen, um stattdessen den Plot-Mechaniken von Intrige, Machtkampf und Bürgerkrieg das Wort zu reden. Nicht zuletzt sollte Patrick Rothfuss in diesem Zusammenhang genannt werden; schließlich hat er den weltweiten Erfolg der ersten zwei Bände seiner Kingkiller Chronicle, The Name of the Wind (2007) und The Wise Man's Fear (2011), tatsächlich genutzt, um sich mit der Novelle The Slow Regard of Silent Things (2014) an kleiner Fantasy zu versuchen. ${ }^{11}$ Ein Werk, womit er daran erinnert, dass Fantasy auch

\footnotetext{
8 Peter von Matt hat eine Auswahl der einschlägigen Arbeiten Gotthelfs unter diesem Titel versammelt. Vgl. Jeremias Gotthelf: Wilde, wüste Geschichten, hg. von Peter von Matt. München 2012.

9 Die übrigen drei Titel der Reihe - Sword in the Storm (1999), Midnight Falcon (2000) und Stormrider (2002) - sind zwar in der gleichen Welt angesiedelt, folgen aber (bedauerlicherweise, würde ich sagen) einer anderen Poetik.

10 Bestehend aus den Bänden Ship of Magic (1998), The Mad Ship (1998) und Ship of Destiny (2000).

11 Die Kingkiller Chronicle selbst ist bis auf Weiteres unvollendet. Einstweilen lässt sich sagen, dass sie nicht nur, was die Verkaufszahlen, sondern auch, was ihre Machart betrifft, eine Sonderstellung einnimmt. Rothfuss schwelgt hier in einer poetisch ausgemalten Alltäglichkeit, die mitunter an Dickens gemahnt, strebt aber andererseits nach einer Fantasy, wie sie gewaltiger nicht sein könnte: Sein Protagonist Kvothe ist der größte Held, der größte Kämpfer, der größte
} 
dies sein kann und vielleicht sein sollte: eine Sprache, die die Magie der Sekundärwelt in sich selbst trägt und dort, im Rhythmus der Worte, zum Klingen bringt.

Allein die Ansätze sind eben - Ansätze. Früher oder später übernimmt für gewöhnlich (nicht allerdings bei Rothfuss' Novelle) die große Fantasy das Ruder, und mit ihr die Logik der martialischen Auseinandersetzung, des Kampfes auf Leben und Tod, der epochalen Konflikte. Im Sinne eines durchgeführten poetologischen Prinzips findet man die kleine Fantasy am ehesten in sogenannten Kinderbüchern - hier denke ich etwa an Tove Janssons Geschichten um die Mumin-Trolle (1945-1970), Otfried Preußlers Krabat (1971) oder Astrid Lindgrens Ronja Rövardotter (1981) - oder bei avantgardistischen Genreautoren, deren kommerzieller Erfolg sich umgekehrt proportional zu ihrer Experimentierfreude verhält. Als Beispiele seien J. M. McDermotts Dogsland-Trilogie; ${ }^{12}$ oder die Romane von Sofia Samatar genannt. ${ }^{13}$ Nicht zufällig wird diese Autorin mit Ursula K. Le Guin verglichen, von der ebenfalls noch $\mathrm{zu}$ reden sein wird. Aber, wie gesagt, die Fantasy, die Verlage gerne verlegen, Leser gerne lesen und (die meisten) Autoren gerne schreiben, ist von anderem Schlag.

Zum Teil mag das in der Funktionsweise des Literaturbetriebs begründet sein. Fantasy ist nun mal ein Genre, das mit dem Eselshut in der Ecke des Klassenzimmers sitzt. Und das heißt eben auch, dass es keinen nennenswerten Diskurs gibt, der Verlage, Leser oder Autoren ermutigen würde, das ungenutzte Potenzial des Genres zu erkunden; und der überdies den Raum schaffen würde, die Produkte dieses Bemühens zu würdigen. ${ }^{14}$

Doch wahrscheinlich greift es zu kurz, die tendenzielle Einsinnigkeit der Fantasy mit bourdieuschen Kategorien zu begründen; obgleich ihre Lage sicher nicht zufällig der des Arbeiterkindes in einer Schulklasse voller Akademiker-Sprösslinge

Magier und der größte Barde seines Zeitalters und als solcher für ein kataklysmisches Unglück verantwortlich - was es mit diesem Unglück und Kvothes Schuld auf sich hat, lässt sich am Ende des zweiten Bandes freilich nur erahnen. Jedoch steht zu befürchten, dass Rothfuss einer jener Fantasy-Autoren werden könnte, denen, wie Robert Jordan oder möglicherweise George R. R. Martin, das Große allzu groß geraten ist.

12 Bestehend aus den Bänden Never Knew Another (2011), When We Were Executioners (2012) und We Leave Together (2014).

13 A Stranger in Olondria (2013) und The Winged Histories (2016).

14 Mit dieser Einschätzung will ich keineswegs die Arbeit der zahlreichen Bloggerinnen und Blogger schmähen, die regelmäßig die Neuerscheinungen der Fantasy rezensieren. Aber abgesehen davon, dass die meisten Blogs vorwiegend von den Verfassern anderer Blogs gelesen werden, müsste ein Diskurs, der die Stellung der Fantasy effektiv hinterfragt, auf der Grundlage einer überzeugenden literarischen Programmatik erfolgen; und Blogs sind wohl kaum der Ort, eine solche zu entwickeln oder zu diskutieren. 
ähnelt. Dessen ungeachtet muss man einräumen, dass der martialische Furor der Fantasy maßgeblich in ihrer Poetik begründet ist. Das Genre strebt ja nicht nur nach dem Zauber, der in der Auffaltung einer Welt zahlloser Geschichten - erzählter und unerzählter - zur Geltung kommt. Es will zudem das Pathos der gefallenen Welt, welches es erlaubt, mit metaphysischer Entschiedenheit die Konfrontation zwischen Gut und Böse zu gestalten. Und eben eine Entscheidung herauszufordern, nicht nur von den handelnden Figuren, sondern auch von den Leserinnen und Lesern (beziehungsweise den Spielern und Zuschauerinnen). Kurz gesagt verlangt die Fantasy, dass wir selbst, in der ästhetischen Erfahrung, Position beziehen, eine Haltung einnehmen, nicht einfach nebendran stehen, sondern uns als Teil des geschilderten Konflikts begreifen.

\section{Die Notwendigkeit von Kampf und Krieg}

Ich habe all das bereits zu Anfang der vorliegenden Studie ausgeführt. Das knappe Resümee soll dabei helfen, zu begreifen, warum sich in nahezu aller Fantasy irgendwann jene Bewegung vollzieht, die dafür sorgt, dass an die Stelle der kleinen Geschichten und des alltäglichen Lebens der Kampf tritt.

Das ist buchstäblich zu verstehen. Soweit ich sehe, gleichen sich die Fantasy-Epen von Tolkien bis Martin darin, dass eine gelungene Alltäglichkeit, in der Shire oder bei den Starks, zwar durchaus liebevoll ausgemalt wird, dies aber nicht zuletzt mit dem Ziel geschieht, den Leserinnen und Lesern die Grauen des Krieges, die Verheerungen jener Alltäglichkeit, späterhin umso eindrücklicher vor Augen zu stellen. In Hinblick auf die grundlegenden Strebungen der Genre-Poetik ist das durchaus verständlich. Denn die Fantasy braucht das Verlorene, um sowohl ihre Melancholie als auch ihre Idee von Heroismus wirkungsvoll zu entfalten. Dem metaphysischen Sturz des Weltalters entspricht hierbei das persönliche Unglück der Heldinnen und Helden, die im Lauf der Geschichte auf die eine oder andere Weise um ihre Heimat gebracht werden, oder diese verlassen müssen, wenn sie ihre Queste antreten. Freilich muss die verlorene Heimat kein Ort sein; es kann sich auch um die Kindheit, eine Erinnerung, oder die liebevolle Geborgenheit in einer Gemeinschaft handeln ... was häufig auf dasselbe hinausläuft.

Wichtig ist nicht so sehr, wie das im Einzelnen geschieht, sondern welches Gefühl auf diese Weise erzeugt werden soll: Ein innerer Raum der Wehmut, des Schmerzes und des Abschieds öffnet sich, und was da an Leidvollem ist, dient in der Folge dazu, die Größe der heroischen Tat erfahrbar zu machen. Aber zugleich eine letzte Vergeblichkeit, die darin besteht, dass es etwas gibt, das, einmal verloren, durch keinen Heldenmut wiederhergestellt werden kann. 
Vor diesem Hintergrund wird deutlich, dass die eingangs aufgestellte These einer Zuspitzung bedarf. Was dem Krimi der Mord, ist der Fantasy der Krieg - so muss es eigentlich heißen. Denn der Kampf als solcher, wie blutig und grausam er sein mag, genügt dem Genre nicht, solange ein soziales Gefüge bestehen bleibt, das von dem Konflikt zwar möglicherweise erschüttert, nicht jedoch zerstört oder beseitigt wird. Der Krieg hingegen treibt das Verhängnis der gefallenen Welt zum Äußersten. Er bezeichnet einen Zustand, in dem rohe Brutalität an die Stelle aller moralischen und ethischen Verbindlichkeit tritt. Somit geht es weniger um den Krieg als, wie Clausewitz schreibt, ,bloße Fortsetzung der Politik mit andern Mitteln“15; sondern um die Schrecknisse der entfesselten, triumphierenden und ubiquitären Gewalt, die eben keinen Alltag, keine freie Entfaltung der Lebensmöglichkeiten mehr zulässt. Darum kann der Krieg in der Fantasy etwas sein, das sich zwischen Nationen, Reichen oder Mächten abspielt, aber auch etwas, das sich als allgemeines Weltgesetz realisiert. Denn diesem Genre ist es eben vor allem um die poetologische Funktion des Krieges zu tun: Sie besteht darin, Räume zu eröffnen, innerhalb derer sich der Fall des Menschen vollziehen kann, hinab in die tiefste Teufelei - gleichfalls jedoch der Aufstieg zu den Höhen eines selbstlosen Opfers, das um Willen der Liebe oder der Gerechtigkeit geschieht. Es geht hier um Handlungsfigurationen, die in der Fantasy immer auch Hobbits, Elben, Zwerge und andere Nicht-Menschen in ihre Pathetik hineinnehmen können; und in diesen Nicht-Menschen nicht selten gar ein Ideal der Menschlichkeit gestalten. Das ist, wie wir sehen werden, mehr als nur ein Notabene.

Wo der Krimi nach der Erschütterung und partiellen Wiederherstellung des Weltvertrauens strebt, zielt die Fantasy somit auf die Gestaltung der unhintergehbaren Wahrheit von Gut und Böse, und zwar in einer Weise, dass sich die Leserinnen und Leser als Teil des Konflikts beider Prinzipien empfinden.

Vorhin sagte ich, angesichts des Zustands der heutigen Welt benötige der Krimi mehr als einen gewöhnlichen Mord, um sein affektpoetisches Ziel zu

15 Es lohnt sich, die entsprechende Passage ausführlich zu zitieren: „Der Krieg ist eine bloße Fortsetzung der Politik mit andern Mitteln. So sehen wir also, daß der Krieg nicht bloß ein politischer Akt, sondern ein wahres politisches Instrument ist, eine Fortsetzung des politischen Verkehrs, ein Durchführen desselben mit andern Mitteln. Was dem Kriege nun doch eigentümlich bleibt, bezieht sich bloß auf die eigentümliche Natur seiner Mittel. Daß die Richtungen und Absichten der Politik mit diesen Mitteln nicht in Widerspruch treten, das kann die Kriegskunst im allgemeinen und der Feldherr in jedem einzelnen Fall fordern, und dieser Anspruch ist wahrlich nicht gering; aber wie stark er auch in einzelnen Fällen auf die politischen Absichten zurückwirkt, so muß dies doch immer nur als eine Modifikation derselben gedacht werden; denn die politische Absicht ist der Zweck, der Krieg ist das Mittel, und niemals kann das Mittel ohne den Zweck gedacht werden.“ Carl von Clausewitz: Vom Kriege. Erftstadt 2003 [1832-1834], S. 21. 
erreichen. Diese Behauptung muss nun ebenfalls korrigiert werden. Denn es geht nicht um den objektiven Zustand der äußeren Welt. Sondern um den wahrgenommenen Zustand dieser Welt, der in den Gesetzmäßigkeiten ihrer künstlerischen Nachgestaltung sich niederschlägt. Und wie man die Welt wahrnimmt, hängt wiederum in hohem Maße davon ab, ob man Gegenkräfte auszumachen vermag, die der allseitigen Zerstörung, Ausbeutung und Korruption potenziell Einhalt gebieten oder wenigstens Grenzen setzen könnten.

Das gilt bezogen auf den Krimi. Es gilt nicht weniger in Hinblick auf die Fantasy. The Lord of the Rings entstand ja im Schatten des Zweiten Weltkriegs, der Naziherrschaft, des Holocaust. Und ohne die Grauen der vergangenen fünfundsiebzig Jahre kleinreden $\mathrm{zu}$ wollen - es ist wohl unbestritten, dass die Menschheit, einstweilen zumindest, noch in keine dunklere Nacht hinabsteigen musste; obwohl es seit 1945 wahrlich nicht an dunklen Menschheitsnächten gefehlt hat. Worauf ich hinauswill, ist das Folgende: Wenn die Schrecknisse der äußeren Welt tatsächlich den Ausschlag gäben, hätte Tolkien allen Grund gehabt, sein Werk in verzweifelte oder gar nihilistische Grausamkeit einzusenken. Bekanntlich hat er das nicht getan. Das lässt sich nicht mit allgemeinen Tendenzen der Populärkultur - im Sinn einer teleologischen Gerichtetheit - erklären, wie das Beispiel von Robert E. Howard zeigt. Dieser Autor, der starb, ehe Tolkien The Hobbit veröffentlichte, schrieb ja nicht nur eine äußerst gewalttätige, sondern obendrein und vor allem eine in mehrfacher Hinsicht erschreckend hoffnungslose Fantasy.

Müsste man also fragen nach den konkreten Lebensumständen, dem kulturellen Herkommen, der Bildung und dem Geschmack einer Autorin oder eines Autors? Vielleicht, aber was heißt das? Wenn die Poetik eines Werkes in Rede steht, zielt die Frage, so meine ich, letztlich auf das Vorhandensein der erwähnten Gegenkräfte.

Sprechen wir also nicht vom Schreibenden, sondern vom Geschriebenen. Meine Vermutung wäre, dass ein Text, der Gegenkräfte der Liebe, der Solidarität, der Gerechtigkeit, kurzum: des Guten, auszumachen in der Lage ist und ihnen obendrein lebens- und weltgestaltende Kraft zutraut - dass ein solcher Text zwar überaus brutal und grausam sein kann, sich aber weigern wird, der Brutalität und Grausamkeit in seiner Affektpoetik das Feld zu überlassen. Ich gebe $z u$, dass diese Vermutung, die ja eigentlich ganz unabhängig vom Genre gilt, durch keine Empirie jenseits meiner eigenen Leseerfahrung gedeckt ist. Einen Indikator, dass etwas an ihr dran sein könnte, mag man darin erkennen, dass der Autor, der ohne jeden Zweifel die trostloseste Fantasy aller Zeiten schreibt, R. Scott Bakker, die literarische Gewalt in all ihren Formen nahezu beispiellosen Extremen zugetrieben hat - und immer beispielloser werden die Extreme, wenn hier ein Komparativ möglich ist, je weiter die Second Apocalypse 
voranschreitet. ${ }^{16}$ Der Third Way der Fantasy, sozusagen zwischen Tolkien und Bakker, wäre wahrscheinlich der blutig-vergnügte Zynismus, dem (weitgehend) die Romane von Joe Abercrombie und anderen „Grimdark“-Autoren frönen. Aber auch dieser Third Way hat in eine Sackgasse geführt - vielleicht sogar aus vergleichbaren Gründen wie jener, den Tony Blair und Gerhard Schröder einstmals beschreiten wollten. ${ }^{17}$

Kurz und gut, in der Fantasy dient die Drastik der Gewaltdarstellungen häufig dazu, die Leserinnen und Leser am eigenen Leib spüren zu lassen, wie überaus bedrohlich sich die Hoffnungslosigkeit der gefallenen Welt und der

16 Die Second Apocalypse-Serie besteht aus sieben Büchern, die sich auf die Prince-of-Nothing-Trilogie und The-Aspect-Emperor-Tetralogie verteilen; im Einzelnen handelt es sich um die Bände: The Darkness That Comes Before (2004), The Warrior-Prophet (2005), The Thousandfold Thought (2006), The Judging Eye (2009), The White-Luck Warrior (2011), The Great Ordeal (2016) und The Unholy Consult (2017). Ihre Trostlosigkeit verdanken Bakkers Bücher übrigens nicht nur der exzessiven Grausamkeit ihrer Gewaltdarstellungen (die schon mal gerne Kannibalismus und Vergewaltigung kombinieren), sondern zuvörderst dem nihilistischen Blick auf den Menschen im Allgemeinen, Geschlechterverhältnisse im Speziellen, sowie alle Formen von sozialer und politischer Ordnung. Schließlich wäre ihre metaphysische Hoffnungslosigkeit zu erwähnen. Was letztere betrifft, merkt Jakob Schmidt treffend an: „Of course, there is a strong - maybe absolute - moral perspective within the series: The eponymous Judging Eye in one of its earlier books. It looks from the vantage point of the God(s) and marks the sinner. But there is really no reason to accept its moral code as anything remotely akin to a humanist outlook. In the eyes of the God(s), all sorcerers are sinners, which means that the one character in the series who acts and feels consistently like a human being, the sorcerer Achamian, is irrevocably damned to dwell in hell.“ Jakob Schmidt: Oh Well, Yet Another Hell. In: The Otherlander's Blog, 29. September 2016, https://otherland-berlin.blogspot.com/2016/09/ oh-well-yet-another-hell.html [letzter Zugriff: 12.05.2020].

17 An dieser Stelle sei nur Abercrombies bekanntestes Werk genannt, die The-First-Law-Trilogie mit ihren drei Bänden The Blade Itself (2006), Before They Are Hanged (2007) und Last Argument of Kings (2008). Übrigens muss man einräumen, dass dieser Autor durchaus zu mehr als jenem blutig-vergnügten Zynismus in der Lage ist, wie seine wahrscheinlich eindrucksvollste Schöpfung zeigt, der Inquisitor Sand dan Glokta, der sich deshalb so hervorragend mit dem Foltern auskennt, weil er selbst aufs Grausamste gequält und misshandelt wurde.

Was nun „Grimdark“ betrifft, so stammt der Begriff aus der anglo-amerikanischen Fantasyszene und wurde von Autoren und Bloggern geprägt - und ist entsprechend wenig präzise. Allgemein soll damit wohl eine Fantasy bezeichnet sein, die einem düsteren Realismus verpflichtet ist und moralisch ambivalente Heldinnen und Helden favorisiert. Das alles im Gegensatz zur Tradition der, noch ein wenig präziser Begriff, sogenannten High Fantasy. Abgesehen davon, dass es schon bei Tolkien reichlich moralische und sonstige Ambivalenzen gibt - wie eigentlich jeder merken sollte, der The Lord of the Rings mit wachem Geist liest -, beißt sich die Katze hier in den Schwanz. Denn was „realistisch“ ist und was nicht, hängt eben immer davon ab, welche Wirklichkeit man zu sehen willens und in der Lage ist. 
mit ihr einhergehende Triumph zerstörerischer Mächte ausnehmen können. ${ }^{18}$ Das war schon in Howards Conan-Geschichten so, und wenn die Fantasy seit den neunziger Jahren immer brutaler geworden ist, könnte das sehr wohl damit zusammenhängen, dass unterdessen auch vielen Autorinnen und Autoren der Fortschrittsoptimismus, die politischen Utopien und der metaphysische Trost abhandengekommen sind. Sogar solchen, deren Geschäft es ist, sich andere Welten auszudenken.

Das ändert allerdings nichts daran, dass noch die pessimistische, verzweifelte oder gar nihilistische Fantasy darauf abzielt, eine Welt zu gestalten, die letztlich dem Gesetz von Gut und Böse untersteht - nur dass das Böse den Leserinnen und Lesern so klar vor Augen steht wie ein wolkenloser Sommerhimmel, wohingegen das Gute innerhalb der Poetik der entsprechenden Werke eher eine ferne Erinnerung, eine unklare Ahnung zu sein scheint: eine Hoffnung, die in ihrer Zweifelhaftigkeit dem Illusionären nahekommt.

In jedem Fall aber sind Kampf und Krieg unabdingbar dafür, dass die Fantasy ihr Pathos realisieren kann. Oder scheint es nur so? Vielleicht ist dieses Genre ja einer Ideologie verfallen, die sich, nach Art der Ideologien, als Naturnotwendigkeit tarnt? Eine Autorin, die es wahrscheinlich so sehen würde, ist Ursula K. Le Guin. Nun hat Le Guin mit dem Earthsea-Zyklus ${ }^{19}$ nicht nur eine der bekanntesten, einfallsreichsten und poetischsten Serien des Genres verfasst; es ist ihr auch in der Tat gelungen, die entsprechenden Geschichten weitestgehend von Schlachtgetöse freizuhalten. Es ist darum angebracht, genau hinzuhören auf ihre Worte - zumal sie sich wie eine Replik auf die Überlegungen lesen, die ich auf den vorangegangenen Seiten entwickelt habe.

Le Guin also schreibt:

I didn't and don't think this way; my mind doesn't work in terms of war. My imagination refuses to limit all the elements that make an adventure story and make it exciting - danger, risk, challenge, courage - to battlefields. A hero whose heroism consists of killing people is uninteresting to me, and I detest the hormonal war orgies of our visual media, the mechanical slaughter of endless battalions of black-clad, yellow-toothed, red-eyed demons.

18 Was César Rendueles für die Gothic Novel, namentlich Mary Shelleys Frankenstein (1818), postuliert, trifft ebenso auf die Fantasy zu: Es handle sich um eine „Auseinandersetzung mit den neuen gesellschaftlichen Verhältnissen, welche der aufstrebende Kapitalismus in der Arbeitswelt Großbritanniens hervorgebracht hat“. Vgl. César Rendueles: Kanaillen-Kapitalismus. Eine literarische Reise durch die Geschichte der freien Marktwirtschaft [2015]. Berlin 2018, S. 145. 19 Bestehend aus den Romanen A Wizard of Earthsea (1968), The Tombs of Atuan (1970), The Farthest Shore (1972), Tehanu. The Last Book of Earthsea (1990) und The Other Wind (2001) sowie etwa zehn Erzählungen. 
War as a moral metaphor is limited, limiting, and dangerous. By reducing the choices of action to „a war against“ whatever-it-is, you divide the world into Me or Us (good) and Them or It (bad) and reduce the ethical complexity and moral richness of our life to Yes/No, On/Off. This is puerile, misleading, and degrading. In stories, it evades any solution but violence and offers the reader mere infantile reassurance. All too often the heroes of such fantasies behave exactly as the villains do, acting with mindless violence, but the hero is on the „right“ side and therefore will win. Right makes might.

Or does might make right?

If war is the only game going, yes. Might makes right. Which is why I don’t play war games.

To be the man he can be, Ged [die wichtigste Figur des Earthsea-Zyklus] has to find out who and what his real enemy is. He has to find out what it means to be himself. That requires not a war but a search and a discovery. The search takes him through mortal danger, loss, and suffering. The discovery brings him victory, the kind of victory that isn't the end of a battle but the beginning of a life..$^{20}$

Zunächst einmal muss man sagen: Le Guin hat völlig recht. Eine Weltsicht, die darauf zielt, immer neue Gräben zu schaufeln und Mauern zu errichten, wird zwangsläufig zerstörerisch, wenn sie die Handlungen von Individuen, Gruppen und Staaten anleitet. Sie bringt Gegensätze hervor, die in die Irre führen, weil sie darauf fußen, das Fremde im Eigenen zu verkennen. Was wohl einer der wesentlichen Gründe dafür ist, weshalb Politik zwar ethischen Prinzipien folgen, niemals aber auf Moral gegründet sein sollte.

In einer Hinsicht greift Le Guins Argumentation aber, so scheint mir, zu kurz. Dort nämlich, wo sie ein Prinzip, das für das Alltagsleben, die Gestaltung von Gemeinwesen und die politische Theorie gilt, umstandslos auf die Kunst überträgt. Umgekehrt könnte man fragen, ob es nicht geradezu das Vorrecht der Kunst ist, uns in zwielichtige bis mitternächtliche Regionen der Seele zu führen, die wir mit gutem Grund nicht betreten wollten, wenn der Einsatz unserer ganzen Existenz, jenseits des ästhetischen Spiels, gefordert wäre? Und ob der spezifische Erkenntnismodus der Kunst nicht auch mit den zutiefst widersprüchlichen Gedanken und Gefühlen zusammenhängt, welche die Ausflüge in jene gefahrvollen Regionen in uns hervorrufen?

Hermann Kappelhoff hat gezeigt, dass die Pathosformel des HollywoodKriegsfilms auf dem unauflöslichen Widerspruch zwischen sacrifice und victim

20 Ursula K. Le Guin: Afterword. In: dies.: The Books of Earthsea. Illustrated by Charles Vess. London/Sydney/New York/Toronto/New Delhi 2018, S. 127-130, hier: S. 129-130. Eine deutsche Übersetzung dieses Nachworts zum ersten Band der Earthsea-Reihe findet sich unter: Ursula K. Le Guin: „Ich beteilige mich nicht an Kriegsspielen“. Ursula K. Le Guin über Konventionen und Originalität in „Erdsee“. In: tor-online.de, 27. Oktober 2018, https://www.tor-online.de/feature/ buch/2018/10/ursula-k-le-guin-ueber-konventionen-und-originalitaet-in-erdsee/ [letzter Zugriff: 12.05.2020]. 
beruht: „dem sinnreichen Opfertod für und dem sinnlosen Sterben Einzelner durch die politische Gemeinschaft“, und zwar als ein „affektgeladener Konflikt“, den eine politische Gemeinschaft, „die sich in ihrem politischen Handeln auf keine höhere Instanz als die des ordinären Lebens vieler Einzelner beruft“, schlichtweg nicht zu lösen vermag. ${ }^{21}$ Die historische und poetologische Verwobenheit beider Genres, Kriegsfilm und Fantasy, zu diskutieren, liegt jenseits der Reichweite dieser Studie. Doch darf man getrost annehmen, dass das, was für den Krieg des Kriegsfilms gilt, mutatis mutandis auf den Krieg der Fantasy zutrifft: dass er nämlich, als Denkfigur und poetologische Gestaltungsform, nicht einfach bruchlos einer reaktionären Ideologie sich andient.

Womit nun nicht behauptet sein soll, dass es harmlos oder unproblematisch wäre, wenn ein Genre in solchem Maße auf den Krieg sich verlässt. Keineswegs. Darum geht es ja gerade: Das konkrete Werk mag die Gewalt auf der Ebene der Figuren und der Handlung verdammen oder zumindest hinterfragen, seine affektpoetische Wirkmacht wird dessen ungeachtet von der mitreißenden Wucht, dem dynamischen Thrill der Kampfszenen abhängen. Das gilt für die allermeisten Kriegsfilme; es gilt ebenso für die allermeisten Fantasyromane. Diese Zerrissenheit betrifft wesentlich die Frage danach, was das Heldentum der Helden ausmacht. Es ist nicht einfach so, dass selbiges darin besteht, andere umzubringen („consists of killing people“). Die großen Krieger der Fantasy - von Aragorn bis Jon Snow - sind Helden, weil sie, wenn es hart auf hart kommt, bereit sind, ihr Leben aus freien Stücken hinzugeben für andere. In gewisser Weise lässt sich das sogar von Conan behaupten, der zwar, ich werde das im folgenden Kapitel ausführen, keineswegs aus edlen Motiven handelt, aber trotzdem immer wieder das Edle tut.

Und dennoch: Die Krieger bleiben Krieger. Und das heißt: Die Leserinnen und Leser werden, wenn sie empfänglich sind für die Verheißungen der Fantasy, darauf brennen, wieder eine jener Szenen lesen zu dürfen, in denen der Held mit der Macht seines Schwertarms einer schier ausweglosen Klemme entrinnt, einen vermeintlich hoffnungslosen Kampf wendet, die Seinen in einer Schlacht gegen einen himmelhoch überlegenen Gegner, jeder Wahrscheinlichkeit spottend, zum Sieg führt. Ich vermute, dass der unwiderstehliche Sog derartiger Szenen (wenn sie gut gemacht sind) vorwiegend mit dem Pathos zusammenhängt, das die Fantasy wesentlich $\mathrm{zu}$ realisieren bestrebt ist: jenem der aufscheinenden Hoffnung inmitten einer unendlichen, lichtlosen Nacht. Was wiederum nichts daran ändert, dass das lustvoll - und womöglich über viele Seiten - ausgebreitete blutige Gemetzel eben auch als blutiges Gemetzel für einen rauschhaften Lektüregenuss sorgt.

21 Kappelhoff: Genre und Gemeinsinn, S. 7. 
Was fängt man damit an? Vielleicht ist es so, dass die (potenzielle) politische Relevanz der Fantasy, ähnlich wie beim Hollywood-Kriegsfilm, gerade mit der Unauflöslichkeit dieses Widerspruchs zusammenhängt. Überträgt man ihn auf die alltägliche Realität der Leserinnen und Leser, die sich wohl tunlichst von blutigen Gemetzeln jeder Art fernhalten werden, so könnte man vermuten, dass uns die Fantasy eine der Aporien des Daseins im Kapitalismus mit seltener Deutlichkeit spürbar macht. Es ist die Lust am agonalen Wettstreit, an der Konkurrenz, daran, den anderen zu übertrumpfen, auszustechen, aus dem Feld zu schlagen - und zugleich das unabweisbare Wissen, dass eine solche Lust, zur grundlegenden Maxime, zum allgemeinen Funktionsprinzip gewendet, die heillosesten Verwerfungen im Leben der Einzelnen wie auch des Gemeinwesens hervorrufen kann und wird. ${ }^{22}$

Ich will also nicht behaupten, dass Le Guin irrt. Wohl aber, dass das Schmerzliche, Widersprüchliche und auch Bitter-Verlogene, das die Fantasy sich durch ihre Obsession mit Krieg und Gewalt einhandelt, dem Schmerzlichen, Widersprüchlichen und Bitter-Verlogenen unseres historischen Standpunkts entspricht. Auch darum wird die kleine Fantasy, von der ich vorhin sprach, wahrscheinlich auf lange Sicht eine, nun ja, Fantasie bleiben. Doch Le Guin hat bewiesen, dass es eine Fantasy geben kann, die nicht (oder nur ganz am Rande) auf martialischen Heroismus, blitzende Klingen und donnernde Hufe setzt - und dass eine solche Fantasy, die entsprechenden Umstände vorausgesetzt, ${ }^{23}$ viele Leserinnen und Leser erreichen und begeistern, mithin eine beträchtliche Wirkung entfalten kann.

Wohin wird es uns führen, wenn wir der Spur folgen, die Le Guin ausgelegt hat? Ich will mich nun von der Literatur abwenden und dieser Frage anhand des Mediums nachgehen, bei dem man wohl am wenigsten erwartet, dass es auf ,the mechanical slaughter of endless battalions of black-clad, yellow-toothed, redeyed demons“ verzichten könnte.

Denn wenn es ein Thema gibt, das beim Videospiel seit Jahrzehnten für Aufregung sorgt, dann ist es dessen offenbar unüberwindliche Vorliebe für Gemetzel jeglicher Sorte.

22 Vgl. Rendueles: Kanaillen-Kapitalismus, S. 236: „Der postmoderne Neoliberalismus ist ein kalter und düsterer Ort, an dem persönliche Güte und die Fürsorge für andere einen zum Verlierer machen. Die Logik des Prekariats besteht nicht nur aus Ausbeutung und Entfremdung wie im klassischen Kapitalismus. Sie läuft auf eine groß angelegte Zerstörung des Sozialen heraus."

23 Es sei daran erinnert, dass der erste Roman des Earthsea-Zyklus im Jahr 1968 erschien. 


\section{Videospiele und Gewalt}

„Violent video games are mass-murder simulators“ - so der Titel eines einflussreichen Artikels, den David Grossmann im Jahr 2000 veröffentlicht hat. ${ }^{24}$ Wer $\mathrm{zu}$ einer solchen Formulierung greift, dem ist es nicht um eine differenzierte Auseinandersetzung mit dem Gegenstand zu tun. An die Stelle des Arguments treten der empörte Furor, die moralische Entrüstung, die pauschale Aburteilung. Das alles fordert zum Widerspruch heraus. Dessen ungeachtet ist es schwer zu leugnen, dass der zitierte Artikel auf deskriptiver Ebene durchaus präzise benennt, worum es in sehr vielen Videospielen geht. Das betrifft zum einen die Beschaffenheit der Welten, in denen Videospiele angesiedelt sind, und die Geschichten, die sie erzählen.

Jonas Linderoth und Torill Elvira Mortensen erläutern:

Digital games seem especially inclined to incorporate controversial themes such as war, disasters, human decay, post-apocalyptic futures, cruelty, and betrayal. Lately, even the most playful of genres are introducing situations in which players are presented with difficult ethical and moral dilemmas. Games frequently provide the opportunity to play as morally doubtful characters. We can be assassins, megalomaniac super villains, mafia members, criminal bikers, vampires, werewolves, and even Nazis. It can even be argued that violent themes are associated with digital games to such a degree that it is one of the traits that constitutes them as an independent form of culture. ${ }^{25}$

Zum anderen betrifft es die Frage, was die Spielerinnen und Spieler innerhalb der jeweiligen diegetischen Anordnung tatsächlich tun, wenn sie sich vor ihren Computerbildschirm oder Fernseher setzen. Ganz gleich, ob das Spiel in der Vergangenheit oder in der Zukunft angesiedelt ist; ganz gleich, ob es etwas mit Orten und Ereignissen zu tun hat, die in einer Beziehung stehen zu dieser Welt und ihrer Geschichte, oder die Spielerinnen und Spieler zu einem Besuch gänzlich fiktiver Schauplätze mit je eigener Historie verlocken möchte; ganz gleich auch, ob man im Rahmen des entsprechenden Abenteuers vorwiegend auf Menschen, Tiere, Monster, Gespensterwesen oder Außerirdische trifft - irgendwie muss man immer jemanden töten.

Wobei der Singular den wahren Sachverhalt verstellt. Denn das Töten im Videospiel vollzieht sich meist in anderem Maßstab. Selbst jene Spieler, die nur

24 David Grossman: Violent Video Games are Mass-murder Simulators. In: Executive Intelligence Review 27 (2000), H. 22, S. 74-79.

25 Jonas Linderoth/Torill Elvira Mortensen: Dark Play. The Aesthetics of Controversial Playfulness. In: dies./Brown (Hg.): The Dark Side of Game Play. New York/Abingdon 2015, S. 3-12, hier: S. 3-4. 
gelegentlich zu Maus und Tastatur oder zum Gamepad greifen, häufen im Lauf der Zeit polygonale Leichenberge an. Wie hoch mögen sie aufragen, diese Leichenberge? Ob es nun tausende, zehntausende oder gar hunderttausende Gegner sind, die den digitalen Feldzügen eines durchschnittlichen Spielers zum Opfer fallen, macht am Ende wohl keinen großen Unterschied.

Zugegeben, es gibt eine Menge Videospiele, und ganze Genres von Videospielen, in denen Gewalt keine oder nur eine sehr untergeordnete Rolle spielt. Das betrifft zahlreiche Geschicklichkeitsspiele und Adventures, die meisten Rätsel- und Sportspiele, ebenso einen Gutteil der Aufbauspiele und (Alltags-)Simulatoren. ${ }^{26}$ Und da die von EA Sports entwickelten FIFA-Spiele (1993-) zu den erfolgreichsten Titeln überhaupt gehören, darf man annehmen, dass viele Spieler nicht, oder nicht ausschließlich, von der Faszination an Kampf, Krieg und Gewalt an die Computer und Spielkonsolen gezogen werden.

Gleichwohl will ich betonen, dass das Töten in Videospielen nicht einfach als konventionalisierter Ausdruck von Spielmechaniken verstanden werden kann, die es geben muss, weil Spielen eben etwas mit dem Austragen von Konflikten, mit Wettstreit und Kräftemessen zu tun hat. ${ }^{27}$ Schon in IKARI WARRIORS (SNK) aus dem Jahr 1986 ist es besonders reizvoll, die anstürmenden Feinde mittels eines gekaperten Panzers zu überrollen. Das hat sicherlich etwas mit dem Gefühl von Macht und Unverwundbarkeit zu tun, welches man genießt, wenn man sich in diesem Spiel eines Panzers bemächtigt. Der Avatar - der offensichtlich in Anlehnung an Sylvester Stallones ikonischen Auftritt in RAMBO: FIRST BLOOD PART II (George Pan Cosmatos, USA 1985) gestaltet ist, jedoch trotzdem bei jedem Treffen das Zeitliche segnet - kann nämlich nicht durch gegneri-

26 Und in den Jump-'n'-Run-Spielen oder Plattformern, in denen dem Kampf eine wesentliche Bedeutung zukommt, ist die Gewalt häufig so weit abstrahiert, dass sie zweifellos in Anführungszeichen gesetzt werden muss. Das betrifft auch Fantasyspiele mit keineswegs unschuldiger Poetik - wie das gleichermaßen putzige und tieftraurige, was das Weltgefühl betrifft offenbar von DARK SOULS inspirierte HOLLOW KNIGHT (Team Cherry, 2017).

27 Marko Siitonen schreibt: „Conflict, at least in an open and relatively abstract sense, lies at the heart of games. Conflict is something that turns a simple challenge, such as being able to jump over a high fence, into something much more engaging.“ Weiter heißt es: „What is it about conflict that motivates players? One way of answering this question is to see solving conflicts as answering a very basic need in players. Players entering a game want to understand it, and ultimately, to be able to control it. In many cases, the final goal of players is to solve the conflict, or somehow find a balance to an unbalanced situation. This need for balancing the conflict can be understood through the universal drive for reaching closure.“ Siitonens Fazit lautet entsprechend: „In essence, opposition, or contest or competition, is necessary for games to be considered games.“ Marko Siitonen: Conflict. In: Wolf/Perron (Hg.): The Routledge Companion to Video Game Studies, S. 166-172, hier: S. 166, S. 167 u. S. 168. 
sche Kugeln getötet werden, solange er sich in einer solchen Kriegsmaschine aufhält. Zu dem Gefühl von Macht und Unverwundbarkeit gehört aber eben auch, dass die Möglichkeiten des Spielers, selbst Gewalt auszuüben, enorm steigen, sowie er einen Panzer kontrolliert, da nun schon die bloße Berührung mit einem feindlichen Sprite für dieses tödlich ist. Was IKARI WARRIORS hier inszeniert, lässt sich durchaus mit jener Pathosszene des Hollywood-Kriegsfilms vergleichen, die auf das „Bild triumphaler Verschmelzung von organischem Körper mit den Geräten und Waffen der Kriegsmaschinerie, von Menschen- und Maschinenkörpern zur physischen Einheit eines Kampfverbundes“ abzielt und darin „die Fantasie einer uneingeschränkten Selbstmächtigkeit“ realisiert. ${ }^{28}$

Nun mag es aus heutiger Sicht eher erheiternd wirken, in Anbetracht der 8Bit Grafik eines über dreißig Jahre alten Spiels von „Macht“ und „Gewalt“ zu sprechen. Die Sache ist aber, dass IKARI WARRIORS exemplarisch ein Prinzip gestaltet, das bis in die Gegenwart hinein wesentlicher Bestandteil der Affektpoetik zahlloser Spiele ist; und zwar umso mehr, so ließe sich vermuten, je weiter die Technik voranschreitet. Es geht um eine lustvolle Aufladung des Tötens, die, wie gesagt, nicht hinlänglich über spielmechanische Notwendigkeiten erklärt werden kann.

Noch in einem Blockbuster wie ASSASSIN'S CREED ODYSSEY (Ubisoft Quebec, 2018) - einem Spiel also, das in jeder Hinsicht dem Mainstream verpflichtet und auf den millionenfachen Verkauf angelegt ist - gibt es eine Unzahl von Waffen, die verschiedentlich verbessert und mit besonderen Eigenschaften ausgestattet werden können. Darüber hinaus gibt es spezielle Angriffe und Fähigkeiten, die sich, je nach Ausrüstung und Entwicklungsstand des Avatars, im Kampf aktivieren lassen. Und vor allem gibt es sogenannte Finisher: spektakuläre und überaus brutale Animationen, mit denen die Spielfigur, Alexios oder seine Schwester Kassandra, ihren jeweiligen Gegner erledigt, indem sie ihn nach allen Regeln der Kunst aufschlitzt, durchbohrt oder zerschmettert, gerne auch in Zeitlupe. Zusätzlich soll das Kampferlebnis durch Vibrationen des Controllers intensiviert werden, die bestimmte Manöver begleiten, sodass die Spielerinnen und Spieler gewissermaßen am eigenen Leib erfahren, welche Wucht hinter den tödlichen Attacken des Avatars steckt.

Wie gesagt: ASSASSIN'S CREED ODYSSEY ist kein radikales Spiel. In der Ausgestaltung des Kampfsystems ähnelt es zahllosen anderen, zum Teil nicht minder erfolgreichen Titeln. Vielleicht könnte man sogar sagen, dass der gegenwärtige Spiele-Mainstream zu einem Gutteil definiert ist über Kampfmechaniken, die

28 Kappelhoff: Genre und Gemeinsinn, S. 139. 
jenen gleichen, die ich am jüngsten Ableger von Ubisofts Meuchler-Reihe beschriebe habe. Vor diesem Hintergrund scheint mir die Vermutung naheliegend, dass die Lust am Videospiel etwas mit der Lust an Fantasien von Verwundung, Gewalt und Tod zu tun hat. Um es geradeheraus zu sagen: Offensichtlich macht es unzähligen Menschen großen Spaß, ein digitaler Krieger, eine digitale Kriegerin zu sein, zu kämpfen, zu töten und Schlachten zu schlagen.

Warum ist das so? Bei aller gebotenen Vorsicht möchte ich annehmen, dass das, was Karin Wenz über den Tod im Videospiel schreibt, auch in diesem Zusammenhang relevant sein könnte:

The experience of death in a safe environment without any serious, lasting consequences and its reversibility gives the impression that we are in control and can live through an experience that in real life is neither controllable nor reversible. It is the fascination and fear of death that seems to be unbearable in real life when we are confronted with the loss of a loved one, but that, when it occurs in-game to one's own avatar, does not have a major impact emotionally. The player is able to interact with a concept that many people do not like to contemplate in real life and observe their „own“ death from the perspective of an observer. Dying in video games is the result of a failure and can be controlled by improving one's own playing skills. ${ }^{29}$

Der Tod ist ja in gewisser Weise die letzte Konsequenz der Gewalt; auch jener Gewalt, die das Leben selbst ist. Und man kann davon ausgehen, dass sich die Angst vor dem Tod - die Drohung der Auslöschung und Vernichtung des Ich regelmäßig einstellt, wenn Menschen Gewalterfahrungen machen; außer vielleicht, es handelt sich um Kampfsportler, Söldner oder sonstige Experten in Sachen Schmerz. Umgekehrt liegt der Gedanke nahe, dass sich die Lust, den Tod im Spiel sozusagen an die Leine zu legen, auf die Gewalt als solche überträgt. Denn eingedenk der oben genannten Ausnahmen, darf man wohl ruhigen Gewissens behaupten, dass die Erfahrung von Gewalt für die meisten von uns mit Gefühlen extremer Ohnmacht und Hilflosigkeit, mit einem existenziellen Ausgeliefert-Sein einhergeht. Im Spiel hingegen beherrschen wir die Gewalt, oder können lernen, sie zu beherrschen. Mehr noch: In den Spielen, in denen Kampf

29 Karin Wenz: Death. In: Wolf/Perron (Hg.): The Routledge Companion to Video Game Studies, S. 310-316, hier: S. 315-316. Vgl. auch Christoph Bareithers ethnografische Studie in welcher er die „teilnehmende Beobachtung in verschiedenen Online-Multiplayer-Games (insgesamt ca. 1200 Stunden reine Spielzeit)“ auswertet, in deren Verlauf er mit „mehreren hundert Spielern Kontakt hatte“; Bareither kommt zu dem Schluss, dass „das Vergnügen an ludisch-virtueller Gewalt als virtuell-körperlich“ bestimmt werden müsse und dass Gewaltspiele „auch der Konfrontation der Akteure mit der nicht-vergnüglichen Seite physischer Gewalt“ dienen „und somit Prozesse der kritischen Reflexion (über physische Gewalt im Allgemeinen und auch den spielerischen Umgang mit ihren Repräsentationen)“ anregen könnten. Christoph Bareither: Gewalt im Computerspiel. Facetten eines Vergnügens. Bielefeld 2016, S. 10, S. 322 u. S. 329. 
und Tod eine wesentliche Rolle spielen, sind es ja üblicherweise die Spieler selbst, oder der von ihnen kontrollierte Avatar, die sich als Meister der Gewalt erweisen und die anderen das Fürchten lehren. ${ }^{30}$ Für gewöhnlich ziehen es die Menschen zweifellos vor, sich keine allzu genaue Rechenschaft darüber abzulegen, wie fragil ihr Leib und ihre Seele in Wahrheit sind - umso verständlicher erscheint der Drang, eine zumindest phantasmatische Kontrolle über das auszuüben, wovor man sich am meisten fürchtet.

Derartige psychologische Dynamiken, wie trivial oder hintergründig auch immer, realisieren sich auf den Bildschirmen freilich in Form von literweise digitalem Blut, abgehackten Gliedmaßen und zerbrochenen Körpern. Vor diesem Hintergrund verwundert es nicht, dass Videospiele, um noch einmal Linderoth und Mortensen zu zitieren, „the latest target for the social processes referred to as moral panic" abgeben. ${ }^{31}$

Das heißt:

Mainstream media coverage of game culture actively seeks spectacular stories about gaming and there is a common understanding that suggests the dark themes of digital play affect the player in negative ways. The stakes of this ongoing issue are extremely high as it is loaded with explanatory value used in political debates. ${ }^{32}$

Auch Jochen Venus stellt fest, dass kaum ein Thema „in der Diskussion um Computerspiele so intensiv debattiert [wird] wie die Frage nach den psychischen und sozialen Gefahren, die von Gewalt darstellenden Computerspielen ausgehen“. ${ }^{33}$

Er führt aus:

In Zeitungsartikeln und auf Online-Foren, in parlamentarischen Anhörungen und vor Gericht werden die Gefahren dieser Spiele beschworen und bestritten. Insbesondere wird diskutiert, ob und in welchem Ausmaß Computerspiele, in denen Tötungshandlungen

30 Eine wichtige Ausnahme stellen sogenannte Survival-Horrorspiele wie die bereits erwähnten OUTLAST und ALIEN: ISOLATION dar, die häufig darauf abzielen, die Spielerinnen und Spieler in eine Position (relativer oder vollständiger) Ohnmacht gegenüber der Gewalt zu bringen.

31 Linderoth/Mortensen: Dark Play, S. 4. Der Begriff „moral panic“ ist Stanley Cohens vielzitierter Studie „Folk Devils and Moral Panics“ entnommen. Cohen definiert „moral panic“ als „[a] condition, episode, person or group emerges to become defined as a threat to societal values and interests; its nature is presented in a stylized and stereotypical fashion by the mass media; the moral barricades are manned by editors, bishops, politicians and other right-thinking people; socially accredited experts pronounce their diagnosis and solutions; ways of coping are evolved or (more often) resorted to; the condition then disappears, submerges or deteriorates and becomes visible.“ Vgl. Stanley Cohen: Folk Devils and Moral Panics. Creation of Mods and Rockers [1972]. Abingdon/Oxon 2002, S. 9.

32 Linderoth/Mortensen: Dark Play, S. 4.

33 Jochen Venus: Gewalt. In: Beil/Hensel/Rauscher (Hg.): Game Studies, S. 331-342, hier: S. 331. 
gegen Menschen und menschenähnliche Fantasiewesen simuliert werden können, zur sozialen Desorientierung junger Menschen beitragen und mitschuldig sind an jugendlicher Gewaltkriminalität. Besorgte Eltern und Pädagogen auf der einen, Computerspielfans und Spielehersteller auf der anderen Seite bemühen sich um eine möglichst stichhaltige Begründung ihrer warnenden beziehungsweise entwarnenden Urteile und verweisen dabei auf empirische Studien der Medienwirkungsforschung, die auf der Basis unterschiedlicher Modelle und Untersuchungsmethoden die Möglichkeit einer Gefährdung durch Computerspiele mehr oder weniger wahrscheinlich erscheinen lassen. ${ }^{34}$

Nun verhält es sich bekanntlich so, dass die jeweils neuen Medien geradezu naturnotwendig den Vorwurf auf sich ziehen, den Verfall der Sitten und die Verderbnis des moralisch weniger gefestigten Teils der Menschheit herbeizuführen, also eine ernste Gefährdung für Kinder, Jugendliche und - im Sinne der patriarchalen Zwangsfürsorge (hoffentlich) vergangener Tage - Frauen darzustellen. Weder die Videothek noch das Fernsehen, weder das Kino noch der Roman entkamen diesem Diskurs. ${ }^{35}$ Gleichwohl vermute ich, dass die Kontroversen um das Videospiel nicht aufgehen in der gewissermaßen reflexhaften Skepsis gegenüber neuen Medien; dass sie vielmehr etwas zu tun haben mit intrinsischen Qualitäten dieses spezifischen Mediums - namentlich mit der bereits beschriebenen, lustvoll-phantasmatischen Energetik, die Videospiele in der Inszenierung von Gewalt entfesseln.

Jedenfalls ist, folgt man Venus, ganz allgemein davon auszugehen, dass es ein „anthropologisches Gewaltpotenzial“ des Menschen gibt, ${ }^{36}$ das sich auch

34 Venus: Gewalt, S. 331.

35 Vgl. Tobias Haupts: Die Videothek. Zur Geschichte und medialen Praxis einer kulturellen Institution. Bielefeld 2014, S. 91-196, v. a. S. 110-128. Vgl. auch Christine Lötscher: Das Zauberbuch als Denkfigur, S. 40-45. Vgl. schließlich die folgenden Überlegungen von Jochen Venus: „So wie der Streit um das Computerspiel den Streit um filmische Gewaltdarstellungen tendenziell verdrängt hat, und so wie ein Jahrhundert zuvor der Streit um die Amoralität des Films den Streit um die Amoralität von Romaninhalten tendenziell verdrängte, so wird vermutlich auch der Streit um die gegenwärtig aktuellen Paradigmen vom Streit um avanciertere Darstellungsformen verdrängt werden.“ Venus: Gewalt, S. 335.

Laut Faltin Karlsen gibt es bereits Anzeichen für diese Entwicklung. Er schreibt: „The proportion of the population acquainted with digital games has gradually increased, and many of those who have grown up with violent digital games are now in their forties or older. This might to some extent explain the milder reception of GRAND THEFT AUTO in 2013 compared to 1997, as more and more people have survived this supposed scourge on society (as Lieberman put it, one that teaches ,children to enjoy inflicting the most gruesome forms of cruelty imaginable ' [Donovan 2010, 225]) without the experience of being turned into rabid thugs when they put down their controllers.“ Faltin Karlsen: Analyzing Game Controversies. A Historical Approach to Moral Panics and Digital Games. In: Mortensen/Linderoth/Brown (Hg.): The Dark Side of Game Play, S. 15-32, hier S. 26.

36 Venus: Gewalt, S. 333. 
dann Bahn zu brechen sucht, wenn die soziale Ächtung der körperlichen Aggression den Rang einer verbindlichen, den Alltag strukturierenden Vorgabe angenommen hat; es findet dann eine Verschiebung ins Mediale und Ästhetische statt:

Je unnachgiebiger und universeller die gesellschaftlichen Erwartungen an die Friedfertigkeit des Einzelnen werden, desto stärker lädt sich die prinzipielle, unberechenbare Gewaltbereitschaft des Menschen mit Imaginärem auf. Diese imaginäre Ladung, die im Prozess der Modernisierung zunimmt, begründet ein zunehmendes Interesse an Gewaltdarstellungen. Dieses Interesse folgt einem Wunsch nach Rationalisierung und Entlastung. Die namenlose, unberechenbare Gefahr, dass urplötzlich, durch spontane Gewalt die situativ geltende Ordnung kollabieren könnte, wird durch die fiktionale Inszenierung, wie Gewalt motiviert sein könnte, wie sie sich materialisieren würde, wie sie aussehen und sich anhören würde, welche Folgen sie hätte, in eine verständliche, fassliche, quasi beherrschbare Form gebracht. ${ }^{37}$

Freilich sind dieser „Rationalisierung“ unüberschreitbare Grenzen gesetzt, die im Wesen des Medialen selbst begründet liegen. Denn „die medial versinnlichten Mythen der Gewalt können die Möglichkeit spontaner Gewaltsamkeit nicht aufheben. Jede Gewaltdarstellung bleibt daher ambivalent.“38 Auf der Grundlage des von Venus umrissenen Arguments ließe sich nichtsdestotrotz behaupten, dass gewalttätige Filme, Bücher und Spiele eine eher stabilisierende Funktion innehaben, da sie einen Raum eröffnen, in dem sich das „anthropologische Gewaltpotenzial“ nicht nur imaginär entladen kann, sondern der den Medienrezipienten darüber hinaus die Möglichkeit bietet, im eigenen Denken und Fühlen die Konsequenzen eines solchen Ausbruchs zu reflektieren.

Im Vergleich zu anderen Medien kommt dem Videospiel in diesem Zusammenhang, so Venus weiter, eine privilegierte, aber auch prekäre Rolle zu. Ein Status, der daher rührt, dass es seinen „ebenso verstörenden wie faszinierenden Darstellungsinhalt“ nicht ,im Rahmen traditionell etablierter, reflexiv beherrschter Medienpraktiken“ entfaltet, sondern - zumindest gegenwärtig noch - als Epitom eines wild wuchernden, für die Einzelperson weder überschaubaren noch verständlichen digitalen Geweses erscheint; einer wahren Flut an „gesellschaftlich relevanten Mediengenres“.39

Die Konsequenzen dieses Zustands sind laut Venus die folgenden:

Das Selbstverständnis der heute bestehenden Medienkultur lässt sich nicht mehr im Bewusstsein absoluter Validität und Reliabilität darstellen, sondern nur im Sinne vage infor-

37 Venus: Gewalt, S. 333.

38 Venus: Gewalt, S. 333.

39 Venus: Gewalt, S. 333-334. 
mierter Spekulation. Die aktuelle Darstellungsmedialität erscheint vor diesem Hintergrund als eine ebenso machtvolle wie eigensinnige und unkontrollierbare Proliferation von Wirklichkeitsinszenierungen, deren Status und soziale Funktion relativ unklar bleiben. ${ }^{40}$

Der besondere Status des Videospiels erklärt sich nun damit, dass die Technik in den „späten 1990er Jahren“ einen Entwicklungsstand erreichte, der es dem Medium fortan ermöglichte, seine „spielerischen Herausforderungen durch Bewegungsbilder [zu] vermitteln, die nahezu fotografisch wirken und in Echtzeit errechnet und manipuliert werden können“. ${ }^{41}$

Mittlerweile sei das Videospiel in der Lage, die Faszination kinematografischer Bewegungsbilder zu überbieten,

indem es erlaubt, in quasi-filmische Simulakren des Lebens einzugreifen und an ihnen teilzunehmen. In Computerspielen kann die Illusion der Lebendigkeit nicht nur beobachtet werden, man kann sie performativ gestalten. Man kann in den Computerspielen lebendig wirkende Figuren laufen, fahren, suchen und sammeln lassen, man kann ihnen Fragen stellen, man kann sie antworten lassen, man kann ihnen Befehle erteilen, sie mit allerlei Werkzeug umgehen lassen, und man kann sie - töten. ${ }^{42}$

Venus vergisst nicht zu erwähnen, dass diese letztgenannten Eigenschaften des Videospiels zur Produktion von „medienkulturellen Angsteffekten“ führen, die wiederum in „bestsellerträchtigen Angstdiskursen“ kultiviert werden. ${ }^{43}$ So etwa in den ebenso erfolgreichen wie zweifelhaften Werken von Manfred Spitzer, der, im Geiste des eingangs erwähnten Artikels, rundweg erklärt, bei Videospielen handele es sich um „Tötungs-Trainingssoftware zum Einüben von Aggression als der einzig möglichen Konfliktlösung“. 44

Derartige Polemiken muss man sicherlich nicht allzu ernstnehmen. Ganz gleich, ob sie von Spitzer, Grossman oder anderen Verfechtern eines analogen Puritanismus verfasst werden. Man sollte allerdings festhalten, dass Venus' Argumentation einen Begründungszusammenhang nahelegt, der nicht aufgeht in der Neigung des Videospiels, sich einer lustvollen und exzessiven Zelebration der Brutalität hinzugeben, sondern vielmehr auf die mediale Positionierung der Spielerinnen und Spieler verweist. Es ist eine Position des Mittendrin; in Rede

40 Venus: Gewalt, S. 334.

41 Venus: Gewalt, S. 334.

42 Venus: Gewalt, S. 334.

43 Venus: Gewalt, S. 334.

44 Manfred Spitzer: Vorsicht Bildschirm! Elektronische Medien, Gehirnentwicklung, Gesundheit und Gesellschaft. München 2006, S. 242. Venus verweist zudem auf zwei weitere Werke Spitzers, die schwungvoll in dieselbe Kerbe hauen. Manfred Spitzer: Digitale Demenz. Wie wir uns und unsere Kinder um den Verstand bringen. München 2014; sowie ders.: Cyberkrank. Wie das digitalisierte Leben unsere Gesundheit ruiniert. München 2015. 
steht also nicht nur das Vermögen, einen Avatar zu kontrollieren, sondern darüber hinaus das leibhafte Eingebunden-Sein in jene quasi-filmischen „Simulakren des Lebens“, das eben mit weitreichender Gestaltungsmacht einhergeht, bis hin zu demiurgischen Omnipotenzfantasien, deren Realisierung - einschließlich der selbstverständlichen Anmaßung, den Tod zuzuteilen - sich wiederum unmittelbar in der Ausgestaltung der wirklichkeitheischenden digitalen Welten niederschlägt.

Hier wäre also der Grund zu suchen für die heikle Stellung, die das Videospiel einnimmt innerhalb der kulturellen Affektökonomie, die sich im Umgang mit phantasmatischer und tatsächlicher Gewalt herausgebildet hat. In dieser Qualität des Mediums - seiner immersiven und interaktiven Kompetenz ${ }^{45}$-, offenbart sich die Möglichkeit, einen proteischen, verlockenden, beängstigenden und gerade darum wirkkräftigen Verhandlungsraum zu eröffnen, wenn es um das „anthropologische Gewaltpotenzial“ unserer Spezies geht. Zugleich verbindet sich mit ihr die Sorge, dass jener Verhandlungsraum unversehens sich transformieren könnte: etwa in ein Labyrinth, worin die Spielerinnen und Spieler sich verlieren, in einen Sumpf, worin sie versinken - oder gar in eine gewaltige Zurichtungsmaschine, die all das verstärkt, was dem Menschen in sich selbst zum Unheil gereicht.

\section{Labyrinth, Sumpf und Zurichtungsmaschine}

Auch jenseits der moralischen Hyperventilation eines Manfred Spitzer ist diese Sorge weitverbreitet. Bis heute findet sie vielfach Widerhall in der Forschung.

45 Gerhard Voorhees erläutert, dass Immersion und Interaktivität als entscheidende Faktoren gelten, wenn es darum geht, das Gefährdungspotenzial von Videospielen einzuschätzen. Er schreibt: „Ultimately, the case for a causal relationship between the representation of violence in games and real violence is not to be found in the empirical research but rather in the theoretical explanations of the data. According to Anderson and Bushman's General Aggression Model (and in the explanations that Thompson and Grossman offer), there are two relevant factors. Interactivity, the player's act of shooting rather than passively watching shooting occur, is conceived as a rehearsal for the real thing and considered impactful in the context of the player's immersion, or sense of being in the game. As Ivory and Kalyanaraman explain, the General Aggression Model assumes that the causal relationship between games and violence is ,mediated by the cognitive, affective, and arousal states induced by dispositional and situational input variables' (2007, p. 536). Of these situational variables, they identify the sense of presence enabled by technological sophistication as vital." Gerald Voorhees: Shooting. In: Wolf/Perron (Hg.): The Routledge Companion to Video Game Studies, S. 251-258, hier: S. 256. 
Tatsächlich gibt es kaum einen Text, der sich dem Zusammenhang zwischen Videospielen und Gewalt widmet, ohne ihr Ausdruck zu verleihen - mal mehr, mal weniger zustimmend, mal mehr, mal weniger differenziert.

Was hat es etwa mit der labyrinthischen Drohung auf sich, die von den Räumen ausgeht, welche die Videospiele in der Spielerfahrung gestalten? Sie scheint sich im Lauf der Zeit zu verstärken. Denn immer höher, undurchsichtiger und wildwuchernder werden die Hecken, die zu beiden Seiten der Irrgänge im Garten von Gut und Böse aufragen.

Zumindest drängt sich dieser Eindruck auf, wenn man die Entwicklung des Videospiels mit Mark Hayse als eine Verfallsgeschichte liest:

The representation and frequency of explicit violent and sexual content gradually accelerate throughout the 1970s, 1980s, and 1990s. Exidy's DEATH RACE (1976) sends players on a demolition-derby mission to run over elusive monochromatic pedestrians.

The gameplay of CUSTER'S REVENGE (Mystique, 1982) and LEISURE SUIT LARRY IN THE LAND OF THE LOUNGE LIZARDS (Sierra On-Line, 1987) focus on pixelated rape and seduction, in turn. The fighting game DOUBLE DRAGON (Taito, 1987) incorporates street violence, male-on-female violence, and S\&M imagery. NIGHT TRAP (Digital Pictures, 1992) utilizes full-motion video and live actors in a slumber party stalker/slasher game. MORTAL KOMBAT (Midway Games, 1992) revels in gratuitous violence through its notorious fatality blows. Id Software's WOLFENSTEIN 3D (1992) and Dо0м (1993) move gratuitous violence into the first-person perspective. Many blamed DOOM - at least in part - for the Columbine High School massacre in 1999. GRAND THEFT AUTO (DMA Design Limited, 1997) launches perhaps the most scandalous video game franchise in terms of violence and sex, including the solicitation and murder of prostitutes. ${ }^{46}$

Ganz allgemein scheinen Videospiele einen „worldview of social conservatism“ $\mathrm{zu}$ befördern, der sich unter anderem in xenophoben, rassistischen und sexistischen Neigungen ausdrückt; wenigstens suggeriert Hayses Zusammenfassung der Diskussion über die politische Positionierung des Mediums diese Schlussfolgerung. ${ }^{47}$ Allerdings räumt er ein, dass sich die Spiele - zumindest ihrem ästhetischen Potenzial nach - der eigenen Neigung zum Reaktionären entgegenstellen können. „Violent and sexual content alone are not morally culpable“, stellt Hayse fest; es gebe so etwas wie ein „ethical video game design“, das ethische Reflektion ermögliche und moralische Wertigkeit vermittle. ${ }^{48}$ „In order to attain this worthy end“, so der Autor,

46 Mark Hayse: Ethic. In: Wolf/Perron (Hg.): The Routledge Companion to Video Game Studies, S. 466-474, hier: S. 467.

47 Vgl. Hayse: Ethic, S. 467.

48 Hayse: Ethic, S. 472. 
video games must leverage the power of the moral economy, ethical dilemmas that surpass merely contrasting choices, the uneasiness of paradox, and a careful balance between consequence, feedback, and opacity. ${ }^{49}$

Einerseits besteht also die Gefahr, dass man die (moralische und ethische) Orientierung verliert in den Welten der Videospiele. Das macht sie zum Labyrinth. Andererseits sind die Spiele in der Lage, einen Ausweg aus dem Irrgarten zu weisen, den sie mit ihren zweifelhaften Lockungen eröffnen - zumindest vermögen sie es, eine Weghilfe an die Hand zu geben. Und zwar indem sie die Spielerinnen und Spieler beizeiten über ihre labyrinthische Natur aufklären und deutlich machen, welche Fährnisse und Herausforderungen diejenigen erwarten, die sich in ihnen verlustieren möchten.

Auch darüber, dass sich die Welten des Videospiels nachgerade in einen Sumpf verwandeln können, ist sich die Forschung wohl bewusst. Peter Krapp etwa erkennt in den gewissermaßen einsaugenden Kräften des Mediums das eigentliche Problem. Zunächst stellt er fest, dass es vielleicht nicht schwer zu begreifen ist, warum so viele Spiele einen hohen Gewaltfaktor aufweisen. Da vor allem Heranwachsende wenig Kontrolle über ihr Leben hätten und ihre eigene Stellung innerhalb der Gesellschaft als ohnmächtig empfänden, sei es naheliegend, dass sie den „transgressive thrills of fighting, shooting, and war“ zuneigen $;^{50}$ demgemäß zählen die entsprechenden Spiele ,in terms of sales figures and hours spent“ zu den beliebtesten Genres sowohl auf dem Computer als auch auf den Konsolen. ${ }^{51}$

In diesem Zusammenhang äußert Krapp die Vermutung, dass es weniger darum gehe, auf welchen Darstellungsmodus die Spiele zugreifen, wenn sie Gewalt inszenieren - „cartoon violence versus photorealism“ -; die entscheidende Frage sei vielmehr, ,whether games can be both deterrent and training, both formative and mere entertainment“.$^{52}$ Er verweist darauf, dass „table-top and floor war games such as Game of Napoleon (Parker Brothers, 1883), Mimic War (Edgar Clark, 1898), and Roosevelt at San Juan (Chaffee \& Selchow, 1899)“ noch im späten 19. Jahrhundert als durchaus für Kinder angemessen betrachtet wurden. ${ }^{53}$ Und zwar präzise aus dem Grund, weil diese Spiele im Ruf standen, nicht nur das historische Verständnis der Spielenden zu vertiefen, sondern

49 Hayse: Ethic, S. 472.

50 Peter Krapp: Violence. In: Wolf/Perron (Hg.): The Routledge Companion to Video Game Studies, S. 345-352, hier: S. 345.

51 Krapp: Violence, S. 347.

52 Krapp: Violence, S. 348.

53 Krapp: Violence, S. 347. 
obendrein deren taktisches und strategisches Denken zu schärfen. ${ }^{54}$ Sie galten also als Vorbereitung auf the real thing - und das wiederum war nach den damaligen Erziehungsmaßstäben offenbar eine gute Sache (aber nur, solange es um männliche Kinder aus dem Bürgertum imperialistischer Nationen ging). ${ }^{55}$

In seiner Auseinandersetzung mit einschlägigen empirischen Studien kommt Krapp freilich zu dem Schluss, dass kein kausaler Zusammenhang zwischen einer Vorliebe für gewalttätige Spiele und einem aggressiven Verhalten im wirklichen Leben bestehe; allerdings gebe es einen nachweislichen Konnex „between a violent or aggressive predisposition and choices in gaming“. ${ }^{56}$ Mit anderen Worten: „When aggression is not pre-existent, playing violent games can raise your pulse and blood pressure, but without raising your levels of real-life aggression. “57 Diese Überlegung führt Krapp zu der Einsicht, dass die Gefahr, die mit Gewaltspielen einhergehe, gar nicht so sehr in der Spielerfahrung selbst begründet liege, sondern darin, dass ein exzessives Spielen die Vernachlässigung anderer sozialer Beziehungen, die sich außerhalb des virtuellen Raums verorten, zur Folge haben könnte:

Dynamic transfer from violent games to one's own social reality is only likely where other relationships that practice empathy give way to gaming in isolation. Children who grow up with healthy relationships to family and friends are unlikely to become psychopaths just because of exposure to violent game content. ${ }^{58}$

Auch der Sumpf ist also eine Verlockung. Und auch diese Verlockung hat etwas damit zu tun, dass der Wanderer nur zu leicht vom Weg abkommen könnte. Er folgt einem zauberischen Irrlicht, bis er plötzlich feststellt, dass er schon bis zum Hals in den fauligen Morast der Einsamkeit, der Isolation und des Schweigens eingesunken ist. Um diesem traurigen Schicksal zu entgehen, sollte man darauf achten, sich nicht allzu tief in den Sumpf hineinzubegeben - oder wenigstens ein paar Mitreisende an der Seite haben. ${ }^{59}$

54 Vgl. Krapp: Violence, S. 347.

55 Vgl. Ginger S. Frost: Victorian Childhoods. Westport, Conn./London 2009, S. 97-120.

56 Krapp: Violence, S. 349.

57 Krapp: Violence, S. 349.

58 Krapp: Violence, S. 351. Ganz ähnlich heißt es bei Faltin Karlsen: „Media content has also generally come to be seen as peripheral in terms of any palpable influence on people's attitude towards violence. Primary socialization through family, school, and friends is much more relevant to the development of norms, and exposure to violence in real life is regarded as more important for shaping people's attitudes towards it than secondary sources such as mediated violence.“ Karlsen: Analyzing Game Controversies, S. 26.

59 Nur am Rande sei vermerkt, dass sich die Frage stellt, inwiefern man Spielerinnen und Spieler, die exzessiv den Online-Multiplayer-Vergnügungen frönen, als vereinsamt und isoliert 
Und wie ist es um die Zurichtungsmaschine bestellt? Vom Labyrinth und dem Sumpf unterscheidet sie sich dadurch, dass sie mit einer gewissen Boshaftigkeit vorgeht. Sie begnügt sich nicht damit, Gewalt und (brutalen) Sex zu inszenieren oder zu einer Vernachlässigung des nicht-virtuellen Lebens zu verführen. Vielmehr ist es ihr darum zu tun, die Spielerinnen und Spieler aktiv zu verwirren, einen unguten Einfluss auf ihre Werte und Überzeugungen auszuüben.

Folgt man Carly A. Kocurek, verbergen sich Zurichtungsmaschinen dieser Art in vielen Videospielen. Und ihre Heimtücke hat etwas damit zu tun, dass sie den Anschein erwecken, die Spiele, in denen sie sich eingenistet haben, seien ganz harmlos und dienten nur dem unschuldigen Zeitvertreib. Kocureks Argumentation zielt nun darauf, einen besonders perfiden Trick der Zurichtungsmaschinen offenzulegen; namentlich geht es um die „aesthetic dehumanisation of in-game victims ${ }^{\text {“60 }}$. Das Perfide besteht darin, dass diese Entmenschlichung vermeintlich dazu dient, die entsprechenden Spiele verträglicher zu machen; ihr angebliches Ziel ist es, „to lessen the impact of on-screen violence, making the games less psychologically dangerous to players“. ${ }^{61}$ Kocurek will das keineswegs gelten lassen. Ihres Erachtens trifft das Gegenteil zu: Wenn in Gewaltspielen das Monströse an die Stelle des Menschlichen tritt, soll damit jedwede Brutalität gerechtfertigt werden: „Many games use literal monstrousness as a defence of on-screen killings“, schreibt Kocurek. ${ }^{62}$ Und sie geht noch weiter. Tatsächlich erkennt sie in dieser „deliberate strategy“ der Spieldesigner eine Parallele zu anderen Strategien; namentlich jenen einer politischen Propaganda, welche auf die radikale Exklusion, die verächtliche Diskriminierung von Minderheiten aller Art zielt. ${ }^{63}$

Kocurek verfolgt die Spur dieser Strategie durch die Geschichte des Mediums. Dabei kommt sie auf zwei Spiele zu sprechen, von denen wir bereits in Hayses Verfallsgeschichte gehört haben, DEATH RACE und DOOM (als ersteres einen Aufschrei der Entrüstung hervorrief, erklärten die Entwickler, der Spieler würde gar keine friedfertigen Fußgänger über den Haufen fahren, sondern gemeingefährliche Monster; ${ }^{64}$ im Fall von letzterem muss man gegen unzählige Dämonen und Untote antreten, „even as those targets looked recognisably, sus-

betrachten kann. Ist eine Kommunikation, die das Internet vermittelt, weniger wirklich und verbindlich als jene, die beispielsweise auf dem Bolzplatz stattfindet?

60 Carly A. Kocurek: Who Hearkens to the Monster's Scream? Death, Violence and the Veil of the Monstrous in Video Games. In: Visual Studies 30 (2015), H. 1, S. 79-89, hier: S. 79 [Herv. i. O.].

61 Kocurek: Who Hearkens to the Monster's Scream?, S. 85.

62 Kocurek: Who Hearkens to the Monster's Scream?, S. 81.

63 Vgl. Kocurek: Who Hearkens to the Monster's Scream?, S. 80.

64 Vgl. Kocurek: Who Hearkens to the Monster's Scream?, S. 79. 
piciously, human“65), bezieht aber auch andere, nicht minder berühmt-berüchtigte Titel in ihre Argumentation ein, etwa CARMAGEDDON (Stainless Software, 1997). Was dieses Spiel betrifft, so interessiert sich Kocurek besonders für den Einsatz von „alternative blood“. Damit hat es Folgendes auf sich: „At its most basic, alternative blood involves the conversion of on-screen blood from red to green; this conversion can be used as a means of claiming that the on-screen victims are something other than human." ${ }^{66}$ Vor dem Hintergrund der Kontroversen um CARMAGEDDON behaupteten die Entwickler etwa, bei gewissen grünblütigen Figuren handele es sich um Zombies, und ,in another iteration of the game, the green zombie blood was replaced with black oil, and the characters became ,robots“". 67

Kocureks Position lässt sich in der These zusammenfassen, dass Spiele, die die Wucht ihrer Gewaltinszenierungen abzumildern suchen, indem sie die zu erledigenden Gegner enthumanisieren oder „alternative blood“ verwenden, nicht nur nicht harmlos, sondern sehr gefährlich, vielleicht gar rundweg verwerflich sind. Machen sie sich doch zum Büttel einer reaktionären Ideologie, die darauf abhebt, alles, was nicht in das jeweilige weltanschauliche Programm passt, aus der (bekanntlich ohnehin sehr brüchigen) Gemeinschaft menschlicher Wesen auszuschließen:

\begin{abstract}
Monsters are frequently coded as social undesirables - as racial or ethnic minorities, as sexual deviants, as those living on the margins of society. While the monstrousness of characters may make the presentation of their persecution and death more palatable to viewers or players or even ratings boards, the dehumanisation of monsters - whether green-blooded zombies or insidious humanoid demons - as a means of justifying onscreen deaths is often reflective of or even a further instance of the dehumanisation of real people. ${ }^{68}$
\end{abstract}

Wenn Kocurek recht hat, liefe die Arbeit der Zurichtungsmaschinen in den genannten und vielen anderen Fällen darauf hinaus, das Denken und Fühlen der Spieler zu vergiften, langsam und unmerklich - bis sie vielleicht bereit sind, das, was in DOOM oder CARMAGEDDON als leicht anrüchige, letztlich aber unbedenkliche Gaudi daherkommt, im Ernstfall der politischen Praxis zu unterstützen.

65 Kocurek: Who Hearkens to the Monster's Scream?, S. 81.

66 Kocurek: Who Hearkens to the Monster's Scream?, S. 81.

67 Kocurek: Who Hearkens to the Monster's Scream?, S. 81.

68 Kocurek: Who Hearkens to the Monster's Scream?, S. 86. 


\section{Leerstellen der Debatte}

Die skizzierten Positionen von Hayse, Krapp und Kocurek scheinen mir bis zu einem gewissen Grad repräsentativ für die neuere Forschung über den Zusammenhang von Videospielen und Gewalt. Das Medium wird nicht rundweg verdammt, sondern durchaus gewürdigt in seinem ästhetischen Potenzial - wobei eher selten Stimmen laut werden, die den medialen Gewaltausbrüchen eine tendenziell stabilisierende Funktion zuweisen, wie sie sich aus Jochen Venus' Überlegungen herleiten ließe. Vielmehr verweist man auf Auswüchse, die bestimmte Designentscheidungen oder eine bestimmte Spielpraxis betreffen. Diese Auswüchse werden kritisiert, weil sich die Spiele in ihnen einer gewaltverherrlichenden, frauenverachtenden oder allgemein diskriminierenden Ideologie andienen - oder weil sie eine Lebensführung begünstigen, die auf eine Art fortwährende digitale Nabelschau hinausläuft und damit dem Zusammenhalt des liberalen Gemeinwesens abträglich ist.

Besonders heikel wird es aus naheliegenden Gründen, wenn beides zusammenkommt; wenn Spieler, und gewiss denkt man hier zuallererst an junge Männer, also in irrealen Welten versinken, die dem Gesetz der machistischen Gewalt gehorchen. Das Schreckensbild des adoleszenten oder ewig spätpubertären Gamers scheint auf: Er ist übergewichtig, hat fahle, verpickelte Haut und fettiges Haar, geht nur aus dem Haus, um koffeinhaltige Softdrinks oder Chips zu kaufen und wundert sich, wenn die Frauen, denen er bei diesen Exkursionen begegnet, weder so aussehen noch sich so benehmen wie Hentai-Figuren. Dass die Frustration über die Defizite alltäglicher Weiblichkeit früher oder später in eine Vorliebe für halbseidene Parteien, rechtsextreme Verschwörungstheorien oder asoziales bis offen destruktives Verhalten umzuschlagen droht, kann beinah als ausgemacht gelten.

Nun geht es mir nicht darum, dem möglichen Wahrheitsgehalt derartiger Schreckensbilder nachzuspüren; ebenso wenig beabsichtige ich, die Debatte über die Gefahren, die von gewalttätigen Videospielen ausgehen, umfassend darzustellen. Tatsächlich wäre eine längere Studie nötig, um die historische Entwicklung dieser Debatte aufzufalten, ihre theoretischen Voraussetzungen und Kurzschlüsse zu diskutieren.

Der knappe Einblick, den ich auf den vorangegangenen Seiten gegeben habe, mag indessen hinreichend sein, um, erstens, eine bemerkenswerte Korrespondenz zwischen der Kritik am Medium Videospiel und am Genre Fantasy aufzuzeigen; und, zweitens, um zu verdeutlichen, dass die Auseinandersetzung mit den dunkleren, vielleicht bedrohlichen Aspekten des Videospiels, obgleich sie viele Dutzend Artikel und Studien hervorgebracht hat, tendenziell zwei Leerstellen aufweist. 
Beginnen wir mit den Parallelen in der Kritik an Videospiel und Fantasy. Diese liegen auf der Hand. Beiden wird - bezogen auf die Fantasy habe ich das bereits ausführlich dargelegt - eine Neigung zur Gewaltverherrlichung und Frauenverachtung, zu Xenophobie und Rassismus, kurzum zu reaktionärem Gedankengut aller Art vorgeworfen. Was man gemeinhin als „Eskapismus“ bezeichnet, liefert gleichsam die Rahmung dieser Vorwürfe: Denn die Vernachlässigung der empirisch gegebenen Realität zugunsten einer ausgedachten, allein den Gesetzmäßigkeiten der literarischen oder programmierenden Fantasie gehorchenden Welt begründet in sich schon ein Verdachtsmoment.

Wie gesagt, die Parallelen liegen auf der Hand. Doch was folgt aus diesem Befund? In Hinblick auf die Fantasy habe ich eine Vermutung geäußert, die auch bezogen auf das Videospiel, so meine ich, zumindest bedenkenswert ist. Der Aufstieg von beidem, Fantasy und Videospiel, ${ }^{69} \mathrm{zu}$ einem weltweiten, populärkulturellen Phänomen hat sich ja in den letzten Jahrzehnten vollzogen, in einer zunehmend utopiearmen Zeit also, in der alle Lebensbereiche unter dem Druck stehen, sich dem TINA-Prinzip zu unterwerfen. Niemand ist restlos gefeit gegen die Macht einer Ideologie, die sich als selbstverständlich, eben als alternativlos geriert. Somit ist es vielleicht nicht verwunderlich, dass viele Intellektuelle der Ansicht sind, die schiere Hinwendung zu ausgedachten Welten komme einer albernen oder unverantwortlichen Kinderei gleich - schließlich haben wir es hier mit Menschen zu tun, die eine höchst prekäre Tätigkeit ausüben (das Denken, nämlich), deren Relevanz sich eigentlich nur innerhalb sozialer und institutioneller Diskurse erweisen kann, die also nicht gerade unabhängig ist vom Status Quo der jeweils herrschenden Meinung. Wenn das zutrifft, wären gewisse Anfeindungen und Abwertungen, denen sich Fantasy und Videospiel ausgesetzt sehen, einer historischen Kontingenz geschuldet - freilich müsste man von einer zukünftigen (oder vergangenen) Warte auf unsere Zeit blicken, sie mit den Augen jener anderen Zeit betrachten, um die Bedingtheit der Voraussetzungen unseres Denkens und Fühlens wirklich verstehen zu können.

Abgesehen von dieser eher spekulativen Kritik der Kritik gibt es aber ganz handfeste Probleme im Umgang mit Fantasy und Videospiel. Bezogen auf die Literatur und den Film hängen sie, auch davon war bereits die Rede, wesentlich mit dem unklaren Status einer Fiktionalität zweiter Ordnung zusammen. Zugespitzt gesagt: Worin besteht der Unterschied, wenn man sich in die fiktive Welt Mittelerde hineinträumt, oder in eine fiktive Welt zur Zeit des sehr realen Ersten

69 In diesem Zusammenhang ist die „Fantasy“ in einem weiteren Sinne gemeint; es geht also nicht nur um Genreprodukte, die in der Tradition von Tolkien stehen, sondern auch beispielsweise um Urban Fantasy à la Harry Potter oder sogenannte Paranormal Romances à la Twilight. 
Weltkriegs? Warum ist es politisch oder sonst wie relevanter, sich beispielsweise auf eine literarische oder kinematografische Reise durch den kriegsversehrten Balkan zu begeben als durch das kriegsversehrte Westeros? Die naheliegende Antwort beantwortet in Wahrheit überhaupt nichts. Denn es geht ja gerade darum, dass erst geklärt werden müsste, auf welcher Ebene sich Fiktion und Wirklichkeit kurzschließen und wie das Referenzsystem funktioniert, das die Imagination mit der gelebten Realität einer Leserin, eines Zuschauers verbindet.

Im Fall des Videospiels stellt sich das Problem insofern anders dar, als bislang noch niemand ernstlich auf die Idee gekommen ist, die digitalen Welten als handfeste Abbildung einer irgendwie vormedialen Wirklichkeit zu deuten wobei möglich scheint, dass sich das demnächst ändern wird; die Rezeption von RED DEAD REDEMPTION 2 deutet darauf hin. Wer die Tests der internationalen Spielepresse liest, könnte mitunter den Eindruck bekommen, als handele es sich bei der Open World von RED DEAD REDEMPTION 2 um eine Zeitmaschine, die die Spielerinnen und Spieler geradewegs in den Wilden Westen befördert. ${ }^{70}$

Einstweilen aber dürfte weitgehend Einigkeit darüber herrschen, dass die Welten des Videospiels zuvörderst und vor allem ihrem eigenen Bauprinzip verpflichtet sind. Das aber macht deutlich, dass die Ubiquität des Themas „Videospiele und Gewalt“ in einem eigenartigen Missverhältnis zu der Ungeklärtheit der Begriffe steht. Wenn ein Spieler allein in seinem Wohnzimmer vor dem Fernseher sitzt und sich daran freut, wie das von ihm gesteuerte polygonale Wesen das Blut anderer polygonaler Wesen vergießt, was heißt dann eigentlich „Gewalt“? Und was heißt „Blut“? Sicherlich könnte man dieselben Fragen stellen, und mit gutem Grund, wenn es um filmische oder literarische Gewalt geht doch beim Videospiel tritt das Problem aufgrund der unzweifelhaften Irrealität

70 Vgl. etwa Martin Woger: Next Level Open World. Wie wir offene Welten 2020 sehen werden. In: www.eurogamer.de, 8. November 2019 [25. Oktober 2018], https://www.eurogamer.de/arti cles/2018-10-24-red-dead-redemption-2-test-next-level-open-world [letzter Zugriff: 12.05.2020]; Jörg Luibl: Die Outlaw Opera. In: www.4players.de, 26. Oktober 2018, http://www.4players.de/ 4players.php/dispbericht/Allgemein/Test/38241/83435/0/Red_Dead_Redemption_2.html [letzter Zugriff: 12.05.2020]; Luke Reilly: A Meticulously Polished Open-world Ode to the Outlaw Era. In: ign.com, 21. April 2020 [25. Oktober 2018], https://www.ign.com/articles/2018/10/25/red-deadredemption-2-review [letzter Zugriff: 12.05.2020]; Martin Robinson: A Peerless Open World, and a Story in the Shadow of its Predecessor. O.K. Corral. In: www.eurogamer.net, 8. November 2019 [26. Oktober 2018], https://www.eurogamer.net/articles/2018-10-25-red-dead-redemption-2-re view_9 [letzter Zugriff: 12.05.2020].

Rolf Nohr hat freilich schon vor Längerem die These aufgestellt, dass das Medium Videospiel immer mehr dazu neige, die eigene Gemachtheit mittels - durchaus im repräsentationalen Verständnis - möglichst realistischer Grafik zu verschleiern. Vgl. Rolf F. Nohr: Die Natürlichkeit des Spielens. Vom Verschwinden des Gemachten im Computerspiel. Münster 2008. 
des Geschehens umso deutlicher zutage; eine Irrealität, die spätestens offenbar wird, sobald die Spielerinnen und Spieler versuchen, etwas zu tun, das nicht im Programmcode vorgesehen ist.

Mit einem Wort: Es stellt sich die Frage, wo die Gewalt im Videospiel eigentlich stattfindet. ${ }^{71}$ Aus Sicht der Theorien von Hermann Kappelhoff, auf denen meine Spielanalysen gründen, ist die Antwort klar: in der leibhaften Erfahrung der Spielerinnen und Spieler. Wenn man sich mit der einschlägigen Forschung beschäftigt, bekommt man den Eindruck, dass diese Antwort als - mag sein, unausgesprochene oder unreflektierte - Voraussetzung gängiger Thesen gelten kann. Schließlich geht es ja meistens darum, dass die Spiele, die man spielt, das eigene Denken und Fühlen beeinflussen; und zwar (so die Befürchtung) nicht zum Guten.

Das führt uns zu den erwähnten Leerstellen. Denn darüber, wie diese Beeinflussung vor sich gehen soll, wie sie etwa mit der Gestaltung und Rhythmik audiovisueller Bilder zusammenhängt, erfährt man wenig bis nichts. Es zählt nur das Faktum des Repräsentierten: der brutale Akt, das abstoßende Monstrum, der zerstörte Körper. Die Poetik einzelner Spiele steht nicht in Rede; ebenso wenig wie die Spielerfahrung der Schreibenden.

Was genau heißt das?

Im Fall der empirischen Psychologie wird deutlich, dass schon das Design der Studien verhindert, dass einzelne Spiele mehr sein können als beinah will-

71 Auch Thomas Hensel fragt, „worauf sich der Gewaltbegriff im Computerspiel eigentlich bezieht?“ - er führt aus: „Bezieht er sich auf die Bildschirmdarstellung, oder bezieht er sich auf das Steuerungsverhalten, also auf das oftmals zeitkritische Drücken von Tastenkombinationen beispielsweise?“ Thomas Hensel: Rohes Entertainment oder raffiniertes Kulturgut? Überlegungen zum Computerspiel. In: Stefan Hradli (Hg.): Der Alltag in digitalen Gesellschaften. Chancen und Risiken. Vorträge des Symposiums vom 28. November 2014. Mainz/Stuttgart 2015, S. 9-15, hier: S. 13. Und Hensel erläutert: „De facto werden die Funktionslogiken von Bildschirmdarstellung und Steuerungsverhalten oftmals verkannt: In der Funktionslogik des Steuerungsverhaltens ,tötet‘ der Spieler mitnichten, sondern drückt lediglich eine Maustaste. [...] Komplementär dazu wäre die Funktionsdarstellung der Bildschirmdarstellung genauer zu betrachten: Hier scheint oftmals alles andere als ein moralisches Einverständnis mit brutalen Metzeleien vorzuliegen, weniger eine Faszination an vor Blut strotzenden Situationen, deren Gewalttätigkeit verherrlicht würde, wie immer wieder insinuiert wird, als vielmehr eine pubertäre Identifikationslust mit einer möglichst ,krassen` Ästhetik, die häufig gepaart ist mit einem Souveränitätsgefühl, das sich einer Beherrschung von Medien verdankt, die Eltern und Lehrern das Blut in den Adern gefrieren lassen.“ Hensel: Rohes Entertainment oder raffiniertes Kulturgut?, S. 13-14.

Die von Hensel angeführten Argumente sollten unbedingt berücksichtigt werden, da sie einen wichtigen Beitrag zur Differenzierung der „Videospiele und Gewalt“-Debatte leisten; zumal, wenn es um die mutmaßlichen Gefährdungen für Jugendliche geht. Allerdings muss ich zugeben, dass es mir dennoch notwendig erscheint, die Frage nach der Lust am digitalen Blutbad ästhetiktheoretisch zu reflektieren. 
kürlich ausgewählte Stimuli. In einer etwas älteren, aber vielzitierten Studie, die von Edward F. Schneider, Annie Lang, Mija Shin und Samuel D. Bradley durchgeführt wurde, wurden die Partizipienten dazu angehalten, vier Spiele für jeweils acht - acht! - Minuten zu spielen: „Eight minutes was selected because it is long enough for experienced game players to make significant progress in these games but short enough to allow all four games to be played in one sitting. “72

Da fragt man sich: Was heißt „significant progress“? Gemessen woran ist der Spielfortschritt, der in acht Minuten erzielt werden kann, „significant“? Und was genau spielt ein Spieler, eine Spielerin eigentlich, der oder die sich nur acht Minuten in einer fiktiven Welt aufhält, wenn ein kompletter Durchgang durch das jeweilige Spiel - im Fall dieser Studie ging es um DOOM 2: HELL ON EARTH (id Software, 1994), QUAKE II (id Software, 1997), OUTLAWS (LucasArts, 1997) und HALF-LIFE (Valve, 1998) - eine Reihe von Stunden in Anspruch nehmen würde? Diese Fragen sind umso dringender, weil die zitierte Studie darauf zielt, die folgenden vier Hypothesen zu überprüfen: „Video game players will identify with characters and their goals to a greater extent when a story is present than when a story is not present“, „Video game players will report greater presence when a story is present than when no story is present “ ${ }^{73}$, „Video game players will report feeling more positive and more aroused when playing story based games compared to nonstory based games“ sowie „Video game players will show greater physiological arousal when playing story based games compared to nonstory based games“74 - und zudem eigens betont wird, dass zwei der ausgewählten Spiele, oUTLAWS und HALF-LIFE, von der Kritik für die „compelling integration of story into game play" gefeiert wurden. ${ }^{75}$

Noch einmal: Welche „story” erleben Spieler, die acht Minuten spielen? Welche Erfahrung können sie im Verlauf von acht Minuten machen, was die „compelling integration“ dieser Story in die Spielmechaniken angeht? Und kann eine Spielwelt in acht Minuten „significant progress“ hinsichtlich der Entfaltung ihrer Gesetzmäßigkeiten erzielen? Kurzum, welche Relevanz hat es von der Warte ästhetischer Theorie aus betrachtet -, wenn eine Studie wie die von Schneider, Lang, Shin und Bradley zu dem Ergebnis kommt, dass „storybased games“ zu einem „higher level of arousal throughout game play“ geführt hätten als „nonstory games“? ${ }^{76}$ Und schlussfolgert:

72 Edward F. Schneider/Annie Lang/Mija Shin/Samuel D. Bradley: Death with a Story. How Story Impacts Emotional, Motivational and Physiological Responses to First-Person Shooter Video Games. In: Human Communication Research 30 (2004), H. 3, S. 361-375, hier: S. 366.

73 Schneider/Lang/Shin/Bradley: Death with a Story, S. 365.

74 Schneider/Lang/Shin/Bradley: Death with a Story, S. 366.

75 Schneider/Lang/Shin/Bradley: Death with a Story, S. 367.

76 Schneider/Lang/Shin/Bradley: Death with a Story, S. 370. 
For the video game marketer, these results suggest that the addition of a story could be a useful sales tool. For those concerned with children potentially modeling aggressive behavior, these results may be disconcerting. These results, coupled with theory on the link between media and aggression, suggest that the addition of narrative could act as a catalyst toward future aggressive behavior. Addition of a narrative functions to provide justification, increase arousal, and therefore increase learning. It provides frequent exposure to violent behavior committed under the direction of the game player by a character with whom the player closely identifies, which is likely to increase facilitation and thus inhibition. It increases the experience of positive emotion, which may further desensitize the viewer to violent behavior. The results reported here suggest that there is reason to be concerned about the possible effects of playing modern immersive narrative-based violent video games on the likelihood of aggressive behavior. ${ }^{77}$

Nun will ich mir nicht anmaßen, die Validität psychologischer Forschung zu beurteilen. Aber wenn sich die Geisteswissenschaften mit dem Vorwurf auseinandersetzen müssen, dass ihre Ergebnisse ebenso luftig wie irrelevant sind, sollte umgekehrt der Hinweis erlaubt sein, dass die empirische Psychologie zwar Ergebnisse hervorbringt, die in unserer positivistischen Zeit als belastbar gelten, dies aber nur um den Preis tun kann, dass die ästhetische Komplexität des Gegenstandes bestenfalls im Ansatz berücksichtigt wird. Das betrifft nicht nur das Videospiel, sondern desgleichen den Film. In beiden Fällen gilt, dass, wie Hermann Kappelhoff schreibt, „eine fachfremde Empirie“ am Werk ist, „die in ihren physiologischen Untersuchungen auf einem Abstraktionsniveau operiert, das unendlich weit entfernt ist von der Möglichkeit, konkrete mediale Rezeptionsprozesse audiovisueller Bilder zu beschreiben“. ${ }^{78}$

Jedenfalls sollte es zu denken geben, wenn ein Aufsatz einschlägige theoretische Modelle diskutiert, die zu einem Verständnis der möglicherweise unguten Folgen gewalttätiger Videospiele herangezogen werden - und dabei klar zu Tage tritt, dass kein einziges dieser Modelle auch nur einen Fingerbreit Raum gibt, die Poetiken konkreter Spiele zu reflektieren; ganz gleich, ob diese Modelle an „longterm effects“ (wie die „Cognitive Neoassociation Theory“, die „Observational Learning and Social Cognitive Theory“ die „Desensitization Theory“ oder die „Cultivation Theory“) oder an „short-term effects“ (wie die „Media Priming Theory“ oder die „Excitation Transfer Theory“) interessiert sind. ${ }^{79}$ Oder wenn für eine andere, gewiss seriöse Studie, die an einem sehr respektablen Ort erschienen ist,

77 Schneider/Lang/Shin/Bradley: Death with a Story, S. 372.

78 Hermann Kappelhoff: Kognition und Reflexion, S. 50.

79 Vgl. René Weber/Ute Ritterfeld/Anna Kostygina: Aggression and Violence as Effects of Playing Violent Video Games. In: Peter Vorderer/Jennings Bryant (Hg.): Playing Video Games. Motives, Responses and Consequences. Mahwah 2006, S. 347-361. 
das als Stimulus verwendete Spiel - dieses Mal HALF-LIFE 2 (Valve, 2004) - kurzerhand umprogrammiert wird, um eine effektivere Prüfung der Hypothesen zu erlauben, ohne dass im Geringsten bedacht wird, dass derart willkürliche Änderungen die Aussagekraft der eigenen Forschung schmälern könnten, was „konkrete mediale Rezeptionsprozesse audiovisueller Bilder betrifft“. ${ }^{80}$

Allerdings ist es keineswegs so, dass dieses Problem auf die empirische Psychologie beschränkt wäre. ${ }^{81}$ Das wird deutlich, wenn wir uns noch einmal dem bereits diskutierten Aufsatz von Carly A. Kocurek, „Who Hearkens to the Monster's Scream?“, zuwenden. Im Rahmen dieses Aufsatzes führt Kocurek drei, wie sie sagt, „close readings“ durch, und zwar von den Spielen LEGO INDIANA JONES: THE ORIGINAL ADVENTURES (Traveller's Tales, 2008), SERIOUS SAM 3: BFE (Croteam, 2011) und RED DEAD REDEMPTION: UNDEAD NIGHTMARE (Rockstar San Diego, 2010). Tatsächlich beschränken sich diese „close readings“ darauf, dass Kocurek jeweils etwa eine Seite darauf verwendet, Aussagen wie die folgenden zu treffen:

While the game boasts literally dozens of playable characters, nonwhite characters often have character names like ,Hovitos Tribesman' and ,Sherpa Gunner'. The minimisation of character-on-character violence in the LEGO INDIANA JONES games may make them less gory than the source films, but it also amplifies the entire franchise's willingness to treat certain lives as inconsequential. ${ }^{82}$

Oder:

While the narrative of SERIOUS SAM justifies the onscreen violence - the aliens are, after all, invaders bent on human extermination - the representation of that violence is simultaneously playful and brutish. The game seems to suggest that violence is not something to be regretted so much as something to be enjoyed, a suggestion only furthered by the irreverent comic blood options. ${ }^{83}$

80 Vgl. Tilo Hartmann/Peter Vorderer: It’s Okay to Shoot a Character. Moral Disengagement in Violent Video Games. In: Journal of Communications 60 (2010), S. 94-119, hier: S. 101. In diesem Fall spielten die Probanden übrigens für zehn Minuten.

81 Übrigens schlagen sich auch Studien neueren und neuesten Datums mit den genannten Problemen herum, ohne dass eine überzeugende Lösung deutlich würde. Vgl. etwa: Jack Denham/Matthew Spokes: Thinking Outside the „Murder Box“. Virtual Violence and Pro-Social Action in Video Games. In: The British Journal of Criminology, 24. Dezember 2018. Gleichwohl ist hier ein Fortschritt zumindest dahingehend zu erkennen, dass die Spiel-Sessions dieser Studie, statt lediglich acht oder zehn Minuten, immerhin eine ganze Stunde umfassten und Gespräche sowohl während wie auch nach dem Spielen mit dem Versuch geführt wurden, konkrete Spielerfahrungen durch die Erzählungen der Probanden nachzuzeichnen.

82 Kocurek: Who Hearkens to the Monster's Scream?, S. 82.

83 Kocurek: Who Hearkens to the Monster's Scream?, S. 83-84. 
Oder:

\begin{abstract}
Marston [der Held aus RED DEAD REDEMPTION: UNDEAD NIGHTMARE] kills Uncle, the Professor, Mr. Nastas and a finely dressed woman from Blackwater in the game's early scenes. While he struggles to save his own wife and son, he has little compunction dispensing with the other infected. The game doubles the rationale for these deaths - the west must as always be won and preserved through violence, and the undead must be eliminated. However, through these early attackers, the game seems to make suggestions about who rightly can and should survive in the West. That Marston, an embodiment of rugged ideals of masculinity, is cast as the hero against zombified academics, women, and "Indians“ echoes and forwards the established values of the Western genre. ${ }^{84}$
\end{abstract}

Die zitierten Passagen verdeutlichen, dass es in Koczureks „close readings“ weder um Bildkompositionen noch um audiovisuelle Rhythmen geht, weder um Genrepoetiken noch um die Modulationen ästhetischer Erfahrung, ja nicht einmal um die Konstruktion einer Figur oder Narration. Stattdessen werden einzelne, isolierte Elemente herausgegriffen und mit Intention und Wirkung des jeweiligen Spiels gleichgesetzt. Der Gedanke ist immer schon gedacht, das Spiel nurmehr Erfüllungsgehilfe einer These.

Das ist umso problematischer, weil Kocureks Überlegungen als solche zweifellos ernstgenommen werden sollten. Wenn Hunderte Millionen Menschen einen Gutteil ihrer Freizeit mit einem Medium verbringen, ist es von großer Bedeutung zu ergründen, wie in den Entwürfen dieses Mediums, auf der Ebene seiner konkreten Realisierungen, das Verhältnis des Einzelnen zur Gemeinschaft, wie Politik und Geschichte, wie Liebe und Sexualität, wie eben auch Kampf und Krieg, Gewalt und Tod gedacht werden. Allerdings werden wir das wohl nie herausfinden, wenn wir, anstatt mit den Spielen zu denken, auf der Höhe ihrer Poetiken, vorgefertigte Thesen applizieren.

Thomas Hensel spricht in Hinblick auf „Risiken und Chancen“ des Videospiels von der „Herausforderung, ja der unbedingten Notwendigkeit, medienkompetener zu werden“ “ ${ }^{85}$ Ich meine, dass die von Hensel geforderte Medienkompetenz sich nicht zuletzt als analytische Kompetenz - durchaus im Sinn eines poetologischen Spürsinns - realisieren muss. ${ }^{86}$ Denn wenn es um die Gewalt im Videospiel geht,

84 Kocurek: Who Hearkens to the Monster's Scream?, S. 85.

85 Hensel: Rohes Entertainment oder raffiniertes Kulturgut?, S. 14.

86 Mir scheint, dass die Argumentation von Bernd Bösel und Sebastian Möring in eine ähnliche Richtung weist, stellen die beiden doch fest, dass „ein Überblick über die charakteristischen affektiven und emotionalen Qualitäten der unterschiedlichen Computerspielgenres“ ein Desiderat der Game Studies sei - wobei sie zugleich betonen, dass die „tentativ so zu nennende ,Affektpoetik des Computerspiels““ gut beraten wäre, „sich nicht auf die vermeintlich sichere neuropsychologische Annahme von Basisemotionen zurückzuziehen, für die dann 
besteht die „Herausforderung“ gerade darin, die verschiedenen Gestaltungsmodi lustvoller Brutalität in der eigenen Spielerfahrung nachzuvollziehen und zu befragen, ohne von vornherein zu wissen, was sie bedeuten. Schließlich ist die Analyse der ästhetischen Erfahrung, die man beim Spielen eines Spiels, beim Sehen eines Films, beim Lesen eines Buchs, beim Hören eines Musikstücks, beim Betrachten eines Gemäldes macht, eine dem Gegenstand angemessene Form von Empirie. Wer sich dieser Form von Empirie rundweg verweigert und trotzdem Aussagen über einzelne Kunstwerke treffen will, läuft Gefahr, zur Karikatur eines Wissenschaftlers zu werden.

Denn wie soll das zugehen? Da gibt es Kriegsfilme, Pornos, Gewaltspiele, die Zuschauerinnen und Zuschauer, Spielerinnen und Spieler mit Macht affizieren, patriotische Aufwallungen, sexuelle Erregung oder latente Blutlust hervorrufen nur die Wissenschaftler, die sich mit diesen Gegenständen beschäftigen, bleiben reiner Geist und können von der Warte der unangefochtenen, in sich ruhenden, absoluten Bewusstheit beurteilen, was im Medienkonsum der anderen geschieht? Und wenn dem nicht so ist, wenn der Wissenschaftler bei der Arbeit, also beispielsweise beim Niedermetzeln einer Horde Westernzombies, das größte Vergnügen empfindet, es gar nicht erwarten kann, wieder mit John Marston und seinem verlässlichen Repetiergewehr loszuziehen - wie passt das dann zum rigorosen ideologiekritischen Urteil?

Also: Entweder der Wissenschaftler ist völlig unberührt von dem Gegenstand der Analyse. Dann kann er keine relevante Aussage über die Wirkung dieses Gegenstands treffen. Oder er ist nicht unberührt. Dann muss er diese seine Berührtheit, die eigene ästhetische Erfahrung, in irgendein Verhältnis zu der politischen Haltung stellen, die er gerne einnehmen möchte.

jeweils ein Genre zuständig wäre; wenn sie nicht hinter die [...] Versuche, zeitgenössische Affekttheorien mit den Ansätzen der Game Studies zu verbinden, zurückfallen will, müsste sie sich der Herausforderung stellen, spielmechanische und prozedurale Aspekte mit somatischen, narrativen, soziokulturellen und auch historischen Aspekten zu verbinden.“ Bernd Bösel/Sebastian Möring: Affekt. In: Feige/Ostritsch/Rautzenberg (Hg.): Philosophie des Computerspiels, S. 193-204, hier: S. 201-202. Auch Stephan Packards Plädoyer für mehr „Virtualitätskompetenz“ - nicht nur in Hinblick auf Videospiele - lässt sich in diesem Sinne verstehen; Packard schließt seine Ausführungen mit der Frage: „Sollen die Fiktionen kontrolliert werden, oder unser Umgang damit? Fordern wir bessere Comics - oder müssen wir nicht vielmehr fordern, dass Comicleser und Nutzer von Virtualitätsmedien selbst bessere, erfahrenere Leser und bessere Virtualitätsreisende werden?“ Stephan Packard: „Choose your fictions well“. Moralische Ansprüche an die mediale Kontrolle virtueller Welten zwischen Fiktion und Spiel. In: Paidia. Zeitschrift für Computerspielforschung, 3. September 2015, http://www.paidia.de/choose-your-fictions-well-moralische-anspruche-an-die-mediale-kont rolle-virtueller-welten-zwischen-fiktion-und-spiel/ [letzter Zugriff: 12.05.2020]. 
Zweifellos ist das nicht einfach. Die Wissenschaftsprosa kommt an ihre Grenzen, wenn sie auf eine Fachsimpelei über Streitäxte und Zweihandschwerter, Schrotflinten und Maschinenpistolen sich einlassen soll. Und erst recht, wenn es darum geht zu beschreiben, wie es sich anfühlt, mit einer Kettensäge Horden von Dämonen zu massakrieren (wie man es in sämtlichen Teilen der DOOM-Reihe tun kann ${ }^{87}$ ). Doch vielleicht gehört das zum Wesen der Sache: dass ein neues Medium nicht unbedingt neue, aber eine andere, ihm angemessene Sprache verlangt. Die sich in ihrer Sinnhaftigkeit wiederum nur einschätzen lässt, wenn man über eine entsprechende Methodik verfügt.

In den Game Studies gibt es Ansätze zu beidem, zugleich jedoch, wie bereits erwähnt, eine große Zurückhaltung und wohl auch Unsicherheit hinsichtlich der Durchführung poetologischer Analysen. Die Probleme, die ich anhand von Kocureks Ausführungen erläutert habe, sind hier durchaus symptomatisch. Alles in allem bestätigt sich bezogen auf das Videospiel - nicht zwar nicht nur, sofern heikle Themen wie die spielerische Affirmation von Gewalt in Rede stehen - die Diagnose, die Kappelhoff hinsichtlich des Films trifft: „Wenn audiovisuelle Bilder als historische Dokumente, als Texte oder Diskurse untersucht oder in Diskursen verortet werden, geschieht dies fast immer mit Blick auf die in den Bildern repräsentierten Sachverhalte - als seien diese selbstverständlich und fraglos gegeben. “88

Ich hoffe, die vorliegende Studie wird ihren Beitrag dazu leisten, dass sich dies ändert. Was dann eben auch den Umgang mit der Frage beträfe, wie die Gewalt in Videospielen einzuschätzen ist. In meinen Analysen zu SHADOw of THE COLOSSUS und DARK SOULS habe ich $\mathrm{zu}$ zeigen versucht, dass Spiele ihre

87 Bei den Spielen der Hauptreihe handelt es sich neben DOOM und DOOM 2: HELL ON EARTH um DOOM 3 (2004, id Software), DOom (2016, id Software) und DOom ETERNAL (2020, id Software).

88 Kappelhoff: Kognition und Reflexion, S. 35. Freilich gibt es Ausnahmen. Eine davon ist der Aufsatz, den Hanns Christian Schmidt über HotLinE MiAmi (Dennaton Games, 2012) geschrieben hat. Nachdem Schmidt die Poetik des Spiels rekonstruiert und eine Spielerposition bestimmt hat, kommt er zu dem Schluss: „Sowohl die Künstlichkeit als auch die Spielhaftigkeit von HOTLINE MIAMI wird vielfach von seinen Figuren thematisiert. Dabei ließe sich das auf diese Weise herausgestellte Motiv der Gewalt durchaus als Kritik am eigenen Spielprinzip lesen - und durch die eigentümliche Geschichte des namenlosen Protagonisten, dessen Welt mit zunehmenden Bluttaten immer groteskere und wahnhafte Züge annimmt, lässt sich für diese Interpretation argumentativ exzellent ins Feld führen. Damit gehört HOTLINE MiAMI einer (bislang) eher seltenen Gattung von Spielen an, die die Darstellung und Simulation von Gewaltakten nicht affirmieren, sondern durch die paradoxe Dissonanz zwischen (ästhetisch zusammenbrechender) Form und (das Spiel nichtsdestotrotz weiter vorantreibenden) Funktion kritisieren.“ Hanns Christian Schmidt: Do You Like Hurting Other People? Retro-Reflexivität in HOTLINE MIAMI. In: Benjamin Beil/Marc Bonner/Thomas Hensel (Hg.): Computer|Spiel|Bilder. Glückstadt 2014, S. 279-302, hier: S. 297. 
Mechaniken, ihre Narration und sogar ihren Weltenbau um den Kampf herum zentrieren können, ohne deshalb ein ungebrochen lustvolles Verhältnis zu der Gewalt einzunehmen, die den Kern der Spielerfahrung bildet. Das qualvolle Sterben der erhabenen und häufig friedfertigen Kolosse kann die Spielerinnen und Spieler ebenso dazu bringen, am Sinn ihres Tuns zu (ver-)zweifeln, wie die schier hoffnungslose Fluchhaftigkeit der sterbenden Königreiche, die alles Kämpfen und Töten nur zu perpetuieren scheint. Dass die schweißtreibenden, adrenalingepeitschten Duelle in DARK SOULS dennoch rauschhafte Glücksgefühle freisetzen, mag etwas damit zu tun haben, dass noch der sinnlosesten Gewalt ein Sinn zukommt, wenn die Möglichkeit ihrer Beherrschung in Reichweite kommt. Vielleicht erwächst in den Spielerinnen und Spielern ein Gefühl für die eigene Widerstandskraft, die sich darin beweist, dass sie nicht in die Knie gehen angesichts der ebenso poetischen wie heillosen Finsternis der gefallenen Königreiche Lordran, Drangleic und Lothric; und vielleicht euphorisiert gerade das Selbstgefühl, das in dieser Widerständigkeit aufblitzt.

Fest steht jedenfalls, dass das Urteil über beide Spiele, SHADOW OF THE COLOSSUS und DARK SOULS, ganz anders ausfiele, wenn die Analyse auf der Ebene der Repräsentation verbliebe. Schließlich sind die Gegner in beiden Spielen monströse, entmenschlichte Kreaturen und die Gewalt gegen sie wird (scheinbar) narrativ motiviert. Im nächsten Kapitel werde ich mit CONAN EXILES auf ein Spiel zu sprechen kommen, das die Spielerinnen und Spieler zu äußerster Brutalität anhält, ja geradezu zwingt, in der vermeintlichen Feier von Rohheit und Gewalt aber die radikale Unfreiheit spürbar werden lässt, die ein erbarmungsloses Weltgesetz all jenen auferlegt, die sich ihm fügen. Hier steht diese Erfahrung von Unfreiheit in einem ebenso unauflösbaren wie unbehaglichen Spannungsverhältnis zu dem Vergnügen, das es bereitet, unter den Unfreien ein Herrscher zu werden, der seine Mit-Sklaven noch weiter unterjocht und in noch brutalere Formen der Sklaverei zwingt. Vielleicht erteilt uns ein Spiel wie CONAN EXILES gerade in der Gestaltung eines derartigen Spannungsverhältnisses eine Lektion über unser Verhältnis zur Gewalt, die wir lieber ignorieren würden: dass das, was im Allgemeinen stets verwerflich ist, nämlich nur zu oft gerechtfertigt erscheint, wenn es den eigenen Interessen dient.

Auf den restlichen Seiten dieses Kapitels soll es jedoch um etwas anderes gehen. Ich will mit analytischen Skizzen zu drei Spielen schließen, die, ohne die digitale Entsprechung zu der von mir erwogenen kleinen Fantasy zu sein, ${ }^{89}$

89 Eine solche kleine Fantasy fände man vielleicht eher in MOONLIGHTER (Digital Sun, 2018), einem Spiel, bei dem man sich nachts durch verschiedene, zu plündernde Dungeons kämpfen muss, tagsüber aber mit der Organisation eines Ladens beschäftigt ist, also beispielsweise die 
vielleicht sogar Ursula K. Le Guin gefallen könnten. Es sind Spiele, die aus ihren Inszenierungen des Kampfes das Bild einer Welt bergen, die gerade nicht, wie man mit Le Guin sagen könnte, ,into Me or Us (good) and Them or It (bad)“ geteilt ist - ein Verdienst, das man vielleicht erst richtig würdigen kann, wenn man sich mit der Diskussion um Videospiele und Gewalt befasst hat.

Was tun diese Spiele, wenn sie nicht die dichotomische Logik reproduzieren, die den politischen, ökonomischen, sexuellen und wohl auch ästhetischen Unterwerfungen zugrunde liegt? Aus meiner Sicht lassen sie sich an ein Projekt anschließen, das Donna Haraway mit der doppelten Aufgabe des „staying with the trouble“ und des „making kin“ verbindet. Sie zielt hier auf eine Haltung, die den „futurism“ - im Sinne einer abstrakten Projektierung zeitgenössischer Bestandsaufnahmen in eine zwangsweise apokalyptische Zukunft - ablehnt, ihr Heil weder in der göttlichen Intervention noch im zynischen Abgesang sucht, sondern nach der „sympoiesis“ strebt: ein Machen, Leben und Sterben, das den Menschen als Teil eines Kontinuums verschiedenster Spezies begreift, die alle auf derselben gepeinigten Erde wohnen, dieselbe offene Zeitlichkeit gestalten. ${ }^{90}$

Haraway führt aus: „In fact, staying with the trouble requires learning to be truly present, not as a vanishing pivot between awful or edenic pasts and apocalyptic or salvic futures, but as mortal critters entwined in myriad unfinished configurations of places, times, matters, meanings. “91 Und weiter: „Kin is a wild category that all sorts of people do their best to domesticate. Making kin as oddkin rather than, or at least in addition to, godkin and genealogical and biogenetic family troubles important matters, like to whom one is actually responsible.“92

Das ist es, glaube ich, womit die Spiele befasst sind, denen ich mich im Folgenden zuwenden will. THE LAST GUARDIAN, PYRE und HELLBLADE: SENUA'S SACRIFICE unterscheiden sich in vielerlei Hinsicht voneinander, was die Prinzipien ihres Weltenbaus, ihre Spielmechaniken und ihre affektpoetische Gerichtetheit betrifft. Worin sie sich gleichen, ist, dass sie die Spielerinnen und Spieler auf je eigene Weise einladen, oder verlocken wollen, etwas abwegige Beziehungen

Beute der nächtlichen Raubzüge ausstellt und die Preise der einzelnen Gegenstände anpasst, um Kunden zu locken.

90 Haraway: Staying with the Trouble, S. 4-5. Vgl. zum Begriff der „sympoiesis“ die folgende Definition: „Sympoiesis is a simple word; it means ,making-with'. Nothing makes itself; nothing is really autopoietic or self-organizing. In the words of the Inupiat computer ,world game', earthlings are never alone. That is the radical implication of sympoiesis. Sympoiesis is a word proper to complex, dynamic, responsive, situated historical systems. It is a word for worlding-with, in company. Sympoiesis enfolds autopoiesis and generatively unfurls and extends it." Haraway: Staying with the Trouble, S. 58.

91 Haraway: Staying with the Trouble, S. 1.

92 Haraway: Staying with the Trouble, S. 2 [Herv. i. O.]. 
und Freundschaften einzugehen, mit Menschen und anderen Wesen, um die sie wahrscheinlich unter weniger spielerischen oder ästhetisch trüberen Umständen einen weiten Bogen gemacht hätten. Und das Mittel, welches THE LAST GUARDIAN, PYRE und HELLBLADE nutzen, um jene merkwürdigen Beziehungen zu entwickeln, ist eben der Kampf. Nicht unbedingt das Duell funkenstiebender Klingen, aber doch Auseinandersetzungen, bei denen, selbst wenn sie völlig unblutig verlaufen (wie es zumindest in PYRE der Fall ist), sehr viel, ja eigentlich alles auf dem Spiel steht: Leben und Tod, Freiheit und Liebe.

„SF is a method of tracing, of following a thread in the dark, in a dangerous true tale of adventure, where who lives and who dies and how might become clearer for the cultivating of multispecies justice." 93 Ich meine, dass diese Worte, die Haraway über die von ihr hochgeschätzte Science-Fiction schreibt, auch auf die genannten Spiele zutreffen - und sogar ein häufig ungenutztes Potenzial der Fantasy allgemein bezeichnen. Etwa in dem Sinn, wie ich vorhin sagte, es sei kein nebensächliches oder randständiges Detail, dass in den Geschichten, die dieses Genre erzählt, oftmals nicht-menschliche oder gerade-noch-menschliche Wesen als selbstlose Helden, große Liebende und, ganz allgemein, Vorbilder in Sachen Menschlichkeit hervortreten. ${ }^{94}$

\section{Der Preis der Freundschaft: THE LAST GUARDIAN}

THE LAST GUARDIAN ist der dritte Teil einer inoffiziellen Trilogie, die von GenDESIGN (vormals Team ICO) unter der Leitung Fumito Uedas entwickelt wurde. Bei den ersten zwei Spielen handelt es sich um ICO (Team ICO, 2001) und um SHADOW OF THE COLOSSUS, von dem wir schon eine Menge gehört haben. ${ }^{95} \mathrm{Im}$ Mit-

93 Haraway: Staying with the Trouble, S. 3.

94 Auch in anderer Hinsicht bleiben THE LAST GUARDIAN, PYRE und HELLBLADE ihrem Genre treu: Man wird in allen drei Spielen eine aus Geschichten gebaute Welt, ein metaphysisch strenggefügtes Weltgesetz und eine Eukatastrophe finden, mal im strengen tolkienschen Sinn, mal als affektive und wertemäßige Verkehrung. Da diese analytischen Skizzen jedoch tatsächlich Skizzen bleiben sollen, verzichte ich im Folgenden darauf, eigens auf jene grundlegenden Elemente des Fantasy-Modus einzugehen. Meine Überlegungen sollten nichtsdestoweniger deutlich machen, dass THE LAST GUARDIAN, PYRE und HELLBLADE in all ihrer Eigenwilligkeit doch auch repräsentative Vertreter des Fantasy-Modus sind.

95 Auf YouTube findet man zahlreiche Videos, die sich den Verbindungen zwischen den Spielen von Fumito Ueda widmen, was die gemeinsame „Lore“ oder den Weltenbau betrifft. In der wissenschaftlichen Auseinandersetzung mit Uedas Werk hat Christian Huberts diesen Verbindungen nachgespürt. Seine Ausführungen beschränken sich zwar - dem Erscheinungsdatum der entsprechenden Studie geschuldet - auf ICO und SHADOW OF THE COLOSSUS, sind im gegebenen Zusam- 
telpunkt von THE LAST GUARDIAN steht die Beziehung zwischen einem kleinen Jungen und einem gewaltigen Monster, das aussieht wie ,a three-storey motley of house cat, pigeon, and other assorted wildlife“. 96

Wie gestalten Fumito Ueda und seine Mitarbeiter diese Beziehung und was hat das mit der Frage nach Gewalt im Videospiel zu tun? THE LAST GUARDIAN zielt darauf, so meine These, eine bestimmte Zeitlichkeit erfahrbar zu machen; es ist die Zeit, in der eine Freundschaft entstehen kann, in der sich Fremdheit, Angst und Unsicherheit langsam wandeln - über tastende, zögernde, brüchige Annäherungen -, bis an ihre Stelle bedingungsloses Vertrauen und Liebe treten. Die Spielerinnen und Spieler sollen sie spüren, diese Zeitlichkeit, sollen jene Beziehung spielend hervorbringen und zugleich als etwas Geschenktes (oder als schicksalhaftes Widerfahrnis) erleben, bis sie selbst eingebunden sind in die merkwürdige Freundschaft zwischen Kind und Ungeheuer; so sehr, dass sie den Schmerz des Verlusts, der beide zwangsläufig treffen muss, als ihren eigenen erleben. Die Gewalt ist Teil dieses Prozesses, ist gewissermaßen der Prüfstein, an dem sich die Freundschaft bewähren muss. Und das betrifft sowohl die Gewalt,

menhang aber dennoch nicht uninteressant. Huberts schreibt: „Doch betrachtet man die mythischen Muster von ICO, ergeben sich viele potenzielle Überschneidungen und Wechselwirkungen. Der kindliche Held von ICo besitzt Hörner. Scheinbar deswegen wird er aus seiner Gemeinschaft verbannt und in einen steinernen Sarkophag innerhalb eines gigantischen Schlosses gesperrt. Die Vielzahl anderer Sarkophage lässt annehmen, dass sich dieses Schauspiel schon seit langer Zeit regelmäßig abspielt. Möglicherweise seit den Ereignissen aus SHADOW OF THE COLOSSUS. Durch ein kurzes Beben gelingt dem gehörnten Jungen die Flucht. Während er durch die Gänge des Schlosses irrt, begegnet er Yorda, die auch gefangen gehalten wird. Gemeinsam suchen sie nach einem Ausweg aus dem Schloss. Dabei werden sie immer wieder von schattenhaften Wesen attackiert, die, scheinbar im Auftrag der Schlossbesitzerin, das Lichtmädchen Yorda gefangen nehmen sollen. Schließlich konfrontiert der Held die Königin des Schlosses. Im Kampf bricht er sich seine Hörner ab, trägt aber letztendlich den Sieg davon. Das Schloss kollabiert, der Held kann fliehen, muss aber Yorda zurücklassen. Am Ende des Spiels erscheint sie ihm im Traum und wirkt, als wolle sie sich für seine Hilfe bedanken. Die Schuld, die der Spieler in SHADOW OF THE CoLOSSUS auf sich geladen hat, wird in ICO wieder gesühnt. Der junge Mann, der den Tod nicht akzeptieren wollte und damit sich selbst und andere ins Unglück stürzte, ist zum kleinen, verfluchten Jungen geworden. Aber schließlich wächst er über sich hinaus, wiederholt nicht die Fehler der Vergangenheit und wird erwachsen. Er hat sich bildwörtlich die Hörner abgestoßen. So verschmelzen ICO und SHADOW OF THE COLOSSUS zu einem großen Mythos über Schuld und Sühne.“ Huberts: Raumtemperatur, S. 83-84.

Es geht mir weniger um Huberts' Interpretation - deren Verbindlichkeit er selbst relativiert -, sondern vor allem um den Konnex, der etwa in Elementen der Bild- und Raumgestaltung aufscheint. Allerdings ist es mir im Rahmen der vorliegenden Studie nicht möglich, der Frage, wie sich THE LAST GUARDIAN an ICO und SHADOW OF THE COLOSSUS anschließt, im Einzelnen nachzugehen. 96 Christian Donlan: The Thing with Feathers. In: www.eurogamer.net, 05. Dezember 2016, https://www.eurogamer.net/articles/2016-12-05-the-last-guardian-review [letzter Zugriff: 12.05.2020]. 
die der Junge und Trico, so der Name des Wesens, ausüben, als auch und vor allem die Gewalt, die ihnen zugefügt wird. Denn die Geschichte, die THE LAST GUARDIAN erzählt, ist, in ihrer märchenhaft anmutenden Archaik, von erschütternder Brutalität und Traurigkeit.

„A robed boy wakes amnesiac on a paved floor far beneath the surface of the earth. His skin is covered in runic tattoos. Besides him is a feathered and mammalian dragon, chained, wounded and stuck with spears." 97 Vom Ende her, nach einigen Rückblenden und einem ebenso schmerzlichen wie rührenden Epilog, versteht man, was es mit dieser rätselhaften Ausgangssituation auf sich hat: Ein Junge wurde, wie es schon vielen Kindern vor ihm geschah, von einem menschenfressenden, geflügelten Ungeheuer entführt. Das Ungeheuer ist Trico, der späterhin zum besten Freund des Jungen wird. Wie die anderen Wesen seiner Art dient er einer bösen Macht - es handelt sich hier um eine lovecraftsche Abstraktion, um grausame und zerstörerische Geometrie ${ }^{98}$-, die sich in einem tiefen Tal, mag sein auf den Überbleibseln einer untergegangenen Zivilisation, ein ebenso himmelsstürmendes wie trostloses Reich aus Ruinen, Stille und Leere geschaffen hat. Nicht nur Trico und Seinesgleichen müssen jener Macht gehorchen; auch ausgehöhlte, von feindseligem Leben angetriebene Rüstungen sind ihre Büttel. Und das ganze megalomane, heil- und sinnlose Konstrukt wird irgendwie angetrieben und am Laufen gehalten von der Lebenskraft geopferter Kinder, ihrem Fleisch und Blut.

Nachdem ein Blitz in seine Rüstung eingeschlagen ist, stürzt Trico mitsamt seiner Beute zu Boden; nunmehr gilt er dem Herrscher des Tals offenbar als wertlos; also wird er von den lebenden Rüstungen in Ketten geschlagen und gemeinsam mit dem Jungen in das höhlenartige Verlies gesperrt, wo das Spiel beginnt.

Das alles wird, wie gesagt, erst nach und nach vollends verständlich. Sehr bald aber begreift man, dass der Junge und Trico aufeinander angewiesen sind, wenn sie überleben und dem Tal entfliehen wollen. Und auch die Helden der Geschichte selbst begreifen dies. Also beginnt der Junge, vom Spieler gesteuert, Trico von den Speeren zu befreien, mit denen sein mächtiger Leib gespickt ist,

97 Don Rowe: Less is More. The Beautiful and Melancholy Minimalism of THE LAST GUARDIAN. In: The Spinoff, 06. Dezember 2016, https://thespinoff.co.nz/games/06-12-2016/less-is-morethe-beautiful-and-melancholy-minimalism-of-the-last-guardian/ [letzter Zugriff: 12.05.2020]. 98 Ich denke hier beispielsweise an das Ende von At the Mountains of Madness (1936), bei dem deutlich wird, dass das ultimative Grauen keiner sprachlich-sinnlichen Konkretion mehr zugänglich ist. Vgl. H. P. Lovecraft: At the Mountains of Madness [1936]. In: ders.: The Thing at the Doorstep and other Weird Stories. London 2001, S. 246-340, hier: S. 339. 
und ihn mit Fässern zu füttern, in denen sich, wie zu befürchten steht, die in eine leuchtende, blaue Substanz umgeformten Überbleibsel anderer Kinder befinden (was zu Beginn von THE LAST GUARDIAN freilich weder der Junge noch die Spielerinnen und Spieler ahnen können). Seinerseits erweist sich Trico bald als unentbehrlicher Helfer für den körperlich schwachen Jungen: Aus seinem Schwanz schießen rötliche Blitze, mittels derer er Hindernisse beseitigen kann - und späterhin auch die lebenden Rüstungen zersprengt -, und er erlaubt seinem Gefährten, an ihm emporzuklettern und sich an seinem Fell festzuhalten. Auf diese Weise vermag der Junge beispielsweise, Abgründe zu überwinden, sozusagen als Passagier Tricos, der über gewaltige Sprungkraft verfügt.

Nachdem die beiden einige Stunden lang durch geheimnisvolle Ruinen gestreift sind und viele kleinere und größere Rätsel gelöst haben, um von Raum zu Raum, von Gebäude zu Gebäude zu gelangen, fasst Trico dann so weit Vertrauen in den Jungen, dass dieser (beziehungsweise die Spielerinnen und Spieler) ihm nunmehr Befehle erteilen kann. Und hier nun offenbart sich die Größe von THE LAST GUARDIAN. Wo die Spielerinnen und Spieler in SHADOW OF THE COLOSSUS lernten, was für ein mühsames Geschäft es ist, ein gewaltiges, fremdartiges Wesen ums Leben zu bringen, sollen sie in diesem Spiel lernen, was es heißt, gemeinsam mit einem solchen Wesen zu leben. Auch das ist mühsam. Denn man erteilt Trico, anders als das Spiel suggeriert, eben keine Befehle. Der Junge kann ihm etwas zurufen, ihm Zeichen geben, auf und ab hüpfen, um seine Aufmerksamkeit zu erregen; und er kann versuchen, Tricos Gemütsverfassung zu lesen, seine Wünsche und Bedürfnisse zu verstehen - wenn er das wasserscheue Tier etwa dazu verleitet, doch den Sprung ins Nass zu wagen, indem er ihn mit einem seiner geliebten Fässer ködert. Aber Befehle erteilen? Nein, ganz und gar nicht. Fumito Ueda und seinen Mitarbeitern gelingt das Kunststück, den Anschein zu erwecken, dass Trico keineswegs den Vorgaben eines wie immer ausgeklügelten Algorithmus gehorcht, sondern tatsächlich ein Wesen aus Fleisch und Blut ist. Ein dickköpfiges, mitunter störrisches Wesen, das seine ganz eigene, rätselhafte Art hat, die Welt zu betrachten und in ihr zu sein. Denn bei Trico handelt es sich um „,[a] wonder of animation and AI smoke-and-mirrors“, um „,a masterpiece of observation".99

Christian Donlan erläutert diesen Gedanken wie folgt:

Given that the beast is a mish-mash of recognisable animal parts, scrambled together in a bizarre manner, it is so odd to discover that the end result feels so entirely convincing. The beast scratches at doors that it can't open, and in that action you briefly forget how

99 Donlan: The Thing with Feathers. 
large or fantastical it is, and you don't think of animation cycles and blending, but of the way that real creatures deal with their frustrations. At one point, I was trying to climb a chain, and I discovered that I was almost being shaken off it by the beast who was batting at the other end of the metal links in a manner I've seen my own cats do a thousand times before with a bit of ribbon or string. ${ }^{100}$

\section{Ganz ähnlich heißt es bei Alexander Bohn-Elias:}

Das Leben Tricos steckt vor allem auch in seinen Unvollkommenheiten. In seinen tollpatschigen Versuchen, eine Kette oder ein Fass mit Nahrung mit seinen überdimensionierten Hühnerklauen zu greifen. Die Federn wehen wüst im Wind, einige stehen imperfekt aus seinem Kleid hervor. Fast möchte man wetten, dass es ein bisschen streng riecht und regelmäßig bekommt man bei einer Kameradrehung sogar seinen alles andere als glamourösen Hinterausgang zu Gesicht. Details wie die feuchten Augen, die tief runtergezogenen Tränenkanäle, die langen Borsten, die aus den Beinen sprießen, die Schrammen und Blutflecken im Pelz - all das kommt zu einem Wesen zusammen, das durch und durch fantastisch, aber doch aus Fleisch und Blut ist. ${ }^{101}$

Darum also kann dieses kuriose Monstrum als die, wie Jörg Luibl schreibt, „faszinierendste Gestalt der Videospielgeschichte“ gelten. ${ }^{102}$ Wenn Trico ein „masterpiece of observation“ ist, ist THE LAST GUARDIAN als Ganzes ein Meisterwerk der Einfühlung. Denn die von Donlan und Bohn-Elias beschriebenen Eigenarten Tricos sorgen dafür, dass man dieses Monstrum sehr bald nicht mehr als Monstrum wahrnimmt, sondern - als was? Als Haustier? Dafür ist Trico dann doch zu fremdartig und auch zu gefährlich. Als wildes Tier? Dafür wiederum erscheint er zu anschmiegsam, zu bedürftig. Als was sonst? Vielleicht ist dieses digitale Geschöpf am ehesten die Verwirklichung einer Kindheitsfantasie, die wohl viele von uns - und möglicherweise gerade diejenigen, die sich in den vermeintlich glücklichsten Lebensjahren selbst als fremdartiges, ungeliebtes Monstrum fühlen mussten - teilen: Es ist die Sehnsucht nach einem großen, starken, treuen Freund; einem Beschützer, der über das eigene, zerbrechliche Dasein wacht und an den man sich in bangen Stunden anschmiegen kann.

Was hat das nun mit Kampf und Gewalt zu tun? Schon in der unpräzisen, hakeligen Steuerung macht THE LAST GUARDIAN die physischen Beschränkungen des Avatars spürbar. Der kleine Junge ist eben ein kleiner Junge; und obgleich er

100 Donlan: The Thing with Feathers.

101 Alexander Bohn-Elias: Und wir haben uns gefragt, was da so lange dauert ... In: www.eu rogamer.de, 05. Dezember 2016, https://www.eurogamer.de/articles/2016-12-05-the-last-guar dian-test [letzter Zugriff: 12.05.2020].

102 Jörg Luibl: Mein Freund die Bestie. In: www.4players.de, 07. Dezember 2016, http://www. 4players.de/4players.php/dispbericht/PlayStation4/Test/16878/73857/0/The_Last_Guardian. html [letzter Zugriff: 12.05.2020]. 
qua seiner Zugehörigkeit zur Spezies der Videospiel-Figuren die erstaunlichsten Kunststücke vollbringt, betont genDESIGN das leicht Fahrige und manchmal Tollpatschige seiner Bewegungen. Die Gigantomanie der Spielwelt tut das Übrige, ein Gefühl für die Hilflosigkeit dieses Kindes zu erwecken. In Anbetracht der schwindelerregenden Türme, die allesamt kurz vor dem Einsturz scheinen, und der Brücken, die sich in aberwitziger Höhe über weites Nichts spannen, möchte man ein ums andere Mal verzagen. Ein kleiner Junge kann doch nur verloren gehen in diesem jedes Maß sprengenden Reich der Verlassenheit! Hier kommen Spieler und Avatar, ich sagte es bereits, Tricos Sprungkraft zugute, und seine Flugfähigkeit, die sich im Verlauf von THE LAST GUARDIAN im gleichen Zug wiederherstellt, wie seine zunächst verstümmelten Flügel wachsen. Und die Momente, wenn man sich an dem Fell des mächtigen Ungeheuers festhält und ansonsten gar nichts tut, Trico einfach seinen Weg suchen und finden lässt, einen unmöglichen, halsbrecherischen Weg über Säulen, Vorsprünge und einstürzendes Mauerwerk - diese Momente zählen nicht nur zu den faszinierendsten und beglückendsten, die man in einem Videospiel erleben kann, sondern erwecken zugleich auch ein seltsames Gefühl der Geborgenheit.

Indessen bleibt es nicht bei den Herausforderungen der Wegfindung. Denn irgendwann treten die ausgehöhlten, feindseligen Rüstungen auf den Plan. Mal sind es nur ein paar wenige, die sich dem Jungen und Trico in den Weg stellen; mal konfrontieren sie die beiden als Kampfeinheit. Indessen genügt ein einziger dieser unheimlichen Gegner, um dem Fluchtversuch des Jungen ein Ende zu setzen. Dieser ist nämlich, auf sich allein gestellt, nahezu völlig wehrlos. Wird er gepackt, kann er sich mittels wilden Zappelns befreien; in einigen wenigen Situationen vermag er, die lebenden Rüstungen in den Abgrund zu stoßen; und zeitweise steht ihm eine Art Spiegel zur Verfügung, der ihm erlaubt, die Blitze, welche aus Tricos Schwanz schießen, auf ein Ziel hin zu lenken. Doch im Grunde hat er der seelenlosen Gewalt, die ihn bedroht, rein gar nichts entgegenzusetzen. Ganz anders sein monströser Freund.

Donlan beschreibt die Kämpfe als Umkehrung des Spielprinzips von ICO:

In ICO, sooty, shifting enemies would advance for your ghostly friend, and drag her away if you didn't knock them aside quickly enough. In THE LAST GUARDIAN, you're in the ghost's role, cast as an innocent little boy while clanking suits of reanimated armour try to carry you off from that beast who will knock them to pieces when asked, but will also have to be soothed back to a childish calm afterwards. You used to protect people; now you need protection yourself. You used to kill monsters; now you depend on one. ${ }^{103}$

103 Donlan: The Thing with Feathers [Herv. i. O.]. 
In dieser Beschreibung wird es deutlich: Verglichen mit den Spielerfahrungen, welche die martialischen Auseinandersetzungen, die das Medium so liebt, für gewöhnlich hervorbringen, erzielt THE LAST GUARDIAN einen geradezu gegenteiligen Effekt: Wir haben es nicht mit den Omnipotenz-Fantasien zu tun, die ein Avatar ins Werk setzt, der Heerscharen von Gegnern mit einem Fingerschnipsen besiegt; ebenso wenig haben wir es mit den unter enormen Anstrengungen errungenen, dafür umso genussvolleren Triumphen zu tun, die man in einem Spiel wie DARK SOULS erleben kann. Stattdessen erzeugen die Kämpfe in THE LAST GUARDIAN die Erfahrung von, wie Donlan sagt, Abhängigkeit. Oder treffender noch: von Beziehung. Hier kämpft jemand anderes an unserer Statt. Trico, das Monster, das uns entführt hat und uns unter ungünstigeren Umständen wohl gerne verspeist hätte. Er kämpft, weil ihn der schiere Anblick der lebenden Rüstungen in Raserei versetzt. Aber er kämpft eben auch für uns. Und umso mehr wird deutlich, dass es ihm darum zu tun ist, den kleinen Jungen, seinen Freund, zu verteidigen, je länger THE LAST GUARDIAN dauert. Die Spielerinnen und Spieler wissen das. Und sollte einer der Feinde sie zu erwischen drohen, wenn sie sich ein Stück entfernt von ihrem gewaltigen Beschützer aufhalten, werden sie zusehen, dass sie eilends zu Trico zurücklaufen, damit er den Rüstungen den Garaus machen kann.

Allein das Ungeheuer, das über uns wacht, jene „three-storey motley of house cat, pigeon, and other assorted wildlife“, ist nicht unbesieglich. Nicht unbesieglich und keineswegs unverwundbar. Auch dies wird im Verlauf von THE LAST GUARDIAN deutlich. Es wird deutlich, wenn Trico doch einmal abstürzt, dutzende, wenn nicht hunderte Meter in die Tiefe fällt und erst langsam wieder zu sich kommt. Vor allem wird es deutlich, wenn Trico schließlich gegen Seinesgleichen antreten muss: Wesen, die noch im Dienst der bösen Macht stehen, die über das Tal herrscht, und darum gepanzert sind, eine mächtige Rüstung tragen, die sie auf ihren Raubzügen beschützen soll. In diesen Kämpfen ist Trico ohne Chance. Und ganz am Ende, wenn er und der Junge es schon fast geschafft haben, steigert sich das Gefühl von quälender Ohnmacht in Anbetracht des unterlegenen, nun selbst hilflosen Riesen beinah ins Unerträgliche. Dann nämlich ruft der Herr des Tales Tricos Artgenossen herbei, eine kleine Herde von ihnen, und als eines dieser Wesen den Jungen angreift, versucht Trico, seinen Freund zu verteidigen. Das bekommt ihm nicht gut. Die anderen, die vermeintlich sind wie er - sein Stamm, seine Familie, sein „kin“ -, fallen über ihn her, alle miteinander, zwingen ihn nieder, drohen, ihn mit ihren Zähnen zu zerreißen und mit ihren Krallen zu zerfetzen. Tatsächlich wird Trico in diesem erbitterten Kampf ein Teil seines Schwanzes abgerissen. Eine merkwürdige Ironie sorgt dafür, dass diese Verwundung zugleich seine Rettung bedeutet. Denn der Junge kann das blitzverschießende Körperteil nutzen, um seinen Freund zu befreien, indem er jene Blitze mithilfe des mysteriösen Spiegels gegen den Herrn des Tals lenkt. Nachdem die böse Macht vernichtet 
ist, sterben Tricos Artgenossen, einer nach dem anderen. Und Trico selbst, wieder zu Kräften gekommen, entschließt sich, den bewusstlosen Jungen zurück in die Heimat zu bringen, aus der er ihn zuvor gestohlen hat - eine Heimat, in der er niemals einen Platz finden wird.

Vor diesem Hintergrund wird greifbar, was der Epilog von THE LAST GUARDIAN bedeutet, den nur diejenigen Spielerinnen und Spieler zu Gesicht bekommen, die bis zum Ende des Abspanns ausharren: Drei Kinder finden den Spiegel, halb im Sand vergraben, der dem Jungen einstmals die Flucht aus dem ebenso geheimnis- wie gefahrvollen Tal ermöglichte. Der Junge selbst ist längst erwachsen geworden; als solcher, ein gereifter Mann, war er im Spielverlauf immer wieder zu hören: ein Erzähler, der in eine ferne Vergangenheit zurückblickt, die doch nie vergangen ist. Nun sieht man ihn: schwarzes Haar und ein leicht ergrauter Bart, ein sanfter, in sich gekehrter Blick, ein ernstes, würdevolles Gesicht. Eine stolze, zugleich irgendwie trauervolle Erscheinung. Man begreift sofort, dass dieser Mann hochangesehen ist in seinem Dorf. Man begreift auch, dass er immer ein Fremder geblieben ist unter Seinesgleichen (obgleich die Kinder, die dort spielen, ihn wie einen Vater betrachten), so wie Trico unwiderruflich zum Feind seiner Artgenossen wurde, als er die Freundschaft eines kleinen Jungen annahm.

Die letzte Szene des Epilogs zeigt den Mann und die drei Kinder, wie sie in der Nacht, von mattem Fackelschein erhellt, beieinanderstehen. Man erfährt nicht, was der Mann den Kindern erzählt hat. Ob sie von Trico wissen und dem Abenteuer, welches ihr Vater - wenn er das denn ist - vor so vielen Jahren erlebt hat. Jedenfalls hebt der Mann den Arm, reckt den Spiegel empor, in einer Geste des Grußes, des Abschieds oder der Würdigung. Nun fliegt die Kamera, auf einem Lichtstrahl schwebend, in den Himmel, fliegt durch sonnenbeschienene, hell leuchtende und dämmerige Wolken, bis sie, es ist wieder Nacht, das Tal erreicht, wo jene böse, fremdartige und unbegreifliche Macht herrschte. Sie sinkt in die Tiefe, immer weiter, gleitet dann durch dunkle Höhlen und zwielichtige Kammern, kommt schließlich an einem Ort zur Ruhe, der jenem Verlies, in dem damals das Abenteuer des kleinen Jungen begann, sehr ähnlich sieht. Dann hört man ein Knurren und in der Dunkelheit leuchten zwei grüne Augen auf - Augen wie Tricos Augen. Und wer ganz genau hinsieht, meint weiter hinten, tiefer in der Dunkelheit, ein zweites Augenpaar zu erkennen.

So wird deutlich: THE LAST GUARDIAN ist ein Spiel über den Preis und die Schönheit einer Freundschaft, die niemals vorgesehen war. Und darüber, dass auch eine solche Freundschaft, trotz allem, fortbestehen und neues Leben, neue Liebe, hervorbringen kann. 


\section{Die Buntheit der Hölle: PYRE}

Auch wenn man viele Stunden in der Welt von PYRE verbracht hat, ist schwer zu sagen, um was für eine Welt es sich handelt - und was für ein Spiel sich in und mit ihr entfaltet. „Eine seltsame Mischung hat Supergiant Games hier gezaubert“, erklärt Matthias Schmid, „stundenlanges Lesen von Textboxen gepaart mit simplen Rollenspielelementen - doch der spielerische Kern ist ein ... Sportspiel!?“104 Rae Grimm beschreibt PYRE als Pelemele ,aus Visual Novel, gruppenbasiertem Rollenspiel und ein bisschen Echtzeit-Strategie mit Fantasy-Handball und kunterbunten Scheiterhaufen“. ${ }^{105}$ Und mit einer gewissen Lakonie erklärt Gita Jackson, das Werk von Supergiant Games sei „,a sports game about starting a revolution““. ${ }^{106}$

Vielleicht erleichtert es die Annäherung an PYRE, wenn man sich klarmacht, was für eine Geschichte das Spiel erzählt. Diese Geschichte ist, in groben Zügen umrissen, tatsächlich einigermaßen stereotyp: Die Spielerinnen und Spieler finden sich wieder als Anführer einer Gruppe von Exilanten, die aufgrund verschiedener Verbrechen - oder sogenannter Verbrechen - aus ihrer Heimat, dem Commonwealth, verbannt wurden. Der Ort ihrer Verbannung ist das „höllenartige Downside“ ${ }^{\text {107}}$, und nach Willen der tyrannischen Elite, die im Commonwealth herrscht, soll es für sie (oder die allermeisten von ihnen) keine Rückkehr geben. Deshalb also plant man im Lager der Exilierten den Umsturz.

So weit, so gut. Doch die Sache wird alsbald vertrackter. Die Vorbereitungen zum Umsturz werden nämlich nicht mit Schwert und Schild durchgeführt, sondern in einer Art Ballspiel. Wie soll das zugehen? Supergiant Games hat eine erstaunlich vielschichtige Mythologie entwickelt, um die Welt von PYRE mit historischer Tiefe und moralischer Komplexität auszustatten. Die Hintergrundgeschichte des Spiels dreht sich um die ersten Exilierten, die sogenannten „Eight Scribes“. In der Verbannung kämpften sie gegen die „Greater Titans“, gigantische Monstren, die vor der Ankunft der „Eight Scribes“ über die Downside herrschten. Nachdem die Eight Scribes den letzten der Titanen bezwungen hatten, begründeten sie die „Rites“ - jenes Ballspiel, das im Mittelpunkt von PYRE steht. Indem sie dies taten, verzichteten die Eight Scribes auf ihre eigene Freiheit, auf dass andere eine Chance bekämen, aus der Verbannung heimzukehren.

104 Matthias Schmid: PYRE - im Test. In: maniac.de, 01. September 2017, https://www.ma niac.de/tests/pyre-im-test-ps4/ [letzter Zugriff: 12.05.2020].

105 Rae Grimm: Flammen der Freiheit. In: www.gamepro.de, 25. Juli 2017, https://www.ga mepro.de/artikel/pyre-flammen-der-freiheit,3317480.html [letzter Zugriff: 12.05.2020].

106 Gita Jackson: PYRE. The Kotaku Review. In: www.kotaku.com, 24. Juli 2017, https://ko taku.com/pyre-the-kotaku-review-1797195264 [letzter Zugriff: 12.05.2020].

107 Schmid: PYRE - im Test. 
Also traten die Exilierten fortan in verschiedenen Teams, den „Triumvirates“, gegeneinander an, und die beiden erfolgreichsten Triumvirate durften sich zu bestimmten Zeiten in sogenannten „Liberation Rites“ miteinander messen. Das Team, das die „Liberation Rites“ gewann, bekam wiederum die Möglichkeit, einen - und nur einen - aus den eigenen Reihen in die Freiheit zu entlassen. Diesen Brauch macht sich der Spieler zunutze, um die Mitglieder der Nightwings, des von ihm geleiteten Triumvirates, nach und nach in den Commonwealth zu schicken, um dort die Revolution vorzubereiten.

Allerdings sind die Einzelheiten der Hintergrundgeschichte im gegebenen Zusammenhang nicht so wichtig; und dasselbe gilt für ihre Funktion als narrative Legitimierung des Spielgeschehens. Mir geht es vor allem darum, inwieweit diese Hintergrundgeschichte - übertragen in Spielmechaniken, Welt- und Figurengestaltung - die Spielerfahrung von PYRE prägt.

Namentlich drei Aspekte wären zu benennen. Zunächst einmal: Der anonyme und gesichtslose Avatar zeichnet sich eigentlich nur dadurch aus, dass er ein Leser beziehungsweise eine Leserin ist (man darf das Geschlecht der Spielfigur wählen). Das Commonwealth hat das Lesen geächtet - das ist in dystopischen Regimes ja so üblich -, in der Downside aber benötigt jedes Team einen „Reader“, der ihm „durch das Entziffern von Sternenkonstellationen sowie im wahrsten Sinne des Wortes per Dechiffrieren eines Buches, nein: DES Buches den Weg zum nächsten Ritual weist““ ${ }^{108}$ Bei DEM Buch handelt es sich um das „Book of Rites“, das die Eight Scribes verfasst haben; im Lauf des Spiels füllt es sich Kapitel um Kapitel auf, und die Spielerinnen und Spieler können viel Zeit damit verbringen, in ihm zu blättern. Wohlgemerkt: Sie können. Es ist durchaus möglich, PYRE zu beenden, ohne auch nur eine einzige Seite im Book of Rites gelesen zu haben. Ebenso, wie es sehr gut möglich ist, als Sieger aus den Wettkämpfen hervorzugehen, die Supergiant Games inszeniert, ohne sich im Geringsten für seine Mitstreiter zu interessieren - ohne also, mit anderen Worten, in die zahlreichen, aber größtenteils optionalen Gespräche einzusteigen, die das Spiel anbietet.

Nun ist es in Rollenspielen üblich, dass man sich über die Lektüre von Büchern, Schriftrollen, Briefen, Tagebucheinträgen und Notizen eine Fülle von Hintergrundwissen erschließen kann, das man nicht unbedingt benötigt, um sich beispielsweise auf den Skellige-Inseln aus THE WITCHER 3 zurechtzufinden. Allerdings geht PYRE, was das betrifft, noch entschiedener vor als andere Titel, insofern die Akquise von Hintergrundwissen hier vollständig entkoppelt ist von

108 Mathias Oertel: Abenteuerspielbuch und Fantasy-Rugby. In: www.4players.de, 31. Juli 2017, http://www.4players.de/4players.php/dispbericht/Allgemein/Test/37700/82682/0/Pyre. html [letzter Zugriff: 12.05.2020]. 
Spielmechaniken und Spielfortschritt. Und dennoch gibt es die Möglichkeit zu „stundenlangem Lesen von Textboxen“, wenn man sich auf das liebevoll gestaltete Book of Rites oder die sorgfältig komponierten Dialoge einlässt.

Es ist also der Willkür des Spielers überlassen, ob und wie viel er liest. Zugleich wird deutlich, dass PYRE - als ästhetisches Konstrukt - die Tätigkeit des Lesens sehr ernstnimmt. Beides ist nicht zufällig. Denn was verbietet das Commonwealth eigentlich, wenn es das Lesen ächtet? Jenes Verbot gilt dem Streben, die Bedeutung der Dinge zu ergründen. Die Spielerinnen und Spieler können somit entscheiden, wer sie in der Welt von PYRE sein wollen: Jemand, der spielt, einfach um zu gewinnen, oder jemand der gewinnen will, weil der Sieg einen Zweck hat - und der obendrein weiß, dass man manchmal verlieren muss, um zu gewinnen.

Noch einmal: Man kann PYRE durchspielen, ohne sich im Geringsten dafür zu interessieren, warum der tyrannische Herrscher Soliam Murr, der Imperator von Sahr, den Weg in die Downside antrat und dort, in einem Moment existenzieller Niederlage, begriff, dass er versagt hatte und dass sein Leben gescheitert war; wie Soliam Murr dennoch die Vergebung seines Generals Gol Golathanian fand und zusammen mit ihm und dem Imp Ha'ub - einer vermeintlich stumpfsinnigen, nur an der eigenen Verfressenheit interessierten Kreatur, die Murr nichtsdestotrotz das Leben gerettet hatte - die späteren Scribes um sich scharte; wie er Ha'ub zu lesen und zu schreiben lehrte, und wie der Imp vielleicht gar zum Tapfersten unter den Scribes wurde, als er den feuer- und pestilenzzeugenden Titan Shax Six Shoulders angriff, während seine Gefährten verzagten; wie schließlich die Stunde des größten Triumphs für die Eight Scribes die Stunde des größten Opfers wurde, da sie, nach ihrem Sieg über den letzten Titan auf Mount Alodiel, den Pakt schlossen, um willen der Freiheit anderer auf ihre eigene Freiheit zu verzichten.

Man muss sich für nichts von alldem interessieren. Aber dann wird man wahrscheinlich nicht begreifen, wie viel Liebe die Entwickler von Supergiant Games ihrem Spiel gegeben haben. ${ }^{109}$ Ebenso wenig wird man begreifen, in welchem Maße die merkwürdige Welt dieses Spiels von Liebe durchdrungen ist.

Das führt uns zum zweiten Aspekt. Bekanntlich werden die Romane, Filme und Spiele, die der Fantasy zugehören, meistens von verschiedenen Rassen bevölkert: Menschen, Elfen (oder Elben), Zwergen, Orks, Goblins - man kennt

109 In diesem Zusammenhang will ich auch einen „spielerisch eigentlich unerheblichen“ Bestandteil des Spieldesigns erwähnen: „Bestimmte Worte der Texte sind rot markiert. Fährt man mit dem Cursor darüber, bekommt man einen kleinen Hilfetext angezeigt, der quasi aus dem ,Unterwelt-Almanach“ stammt und zusätzliche Details über Figuren, Orte und mythologische Hintergründe verrät.“ Vgl. Oertel: Abenteuerspielbuch und Fantasy-Rugby. 
das. PYRE geht einen Schritt weiter. Denn in diesem Spiel haben wir es weniger mit Rassen, vielmehr mit grundverschiedenen Spezies zu tun: „So gibt es unter anderem die hundeartigen Cur, die wurmähnlichen Wyrm-Ritter, die an alternde Medusen erinnernden Crones oder die knuffigen Imps, die aussehen wie eine putzige Version dämonischer Vögel."110 Nicht zu vergessen Harpyien und die sogenannten „Sap“, Baumwesen, die Tolkiens Ents nachschlagen.

$\mathrm{Zu}$ den Dingen, die sich dem Spieler ebenfalls nur beim Studium des Book of Rites erschließen, gehört, dass zu den Eight Scribes je ein Vertreter sämtlicher in der Welt von PYRE vorkommender Rassen beziehungsweise Spezies zählte. Ebenso, wie die Nightwings ihre Reihen nach und nach mit einem Cur, einer Harpyie, einem Wyrm, einem Sap und einer Crone anfüllen. Hier kommt etwas zusammen, was nach gängiger Auffassung vielleicht besser getrennt bliebe, innerhalb der Poetik von PYRE jedoch unbedingt zusammengehört. Auch diesbezüglich ist das Spiel sehr konsequent, begegnet sich selbst mit dem nötigen Ernst. Das wird deutlich, wenn es um die Liebe geht - die Liebe dieses Mal als Teil der erzählten Geschichte. Sie tritt auf mit ebenso pathetischer wie überraschender Wucht. Beides ist dem Umstand geschuldet, dass PYRE die Hoffnung, es sei der Liebe möglich, sämtliche Schranken zu überwinden, gewissermaßen wörtlich nimmt. Der menschliche Nomade Hedwyn wurde aufgrund seiner Liebe zu einer Harpyie namens Fikani Shang in die Downside verbannt. Der winzige Wyrm-Ritter Sir Gilman verguckt sich in die Dämonenfrau Jodariel, welche sich aufgrund ihres allzu langen Exils verwandelte, jetzt riesenhaft, gehörnt und meistens ziemlich übellaunig ist - was Sir Gilman nicht daran hindert, sie, ein ritterlicher Kavalier eben, als „most fair and most spirited“ zu titulieren. Der schnurrbärtige, redselige und etwas stutzerhafte Cur Rukey Greentail wiederum hat einen Narren an der stolzen, kühl-ironischen Harpyie Pamitha Theyn gefressen. Und die Crone Bertrude - ihres Zeichens eine mit einem Geweih und einer Art Pilzbewuchs oder Schneckenhaus versehene, krallenbewehrte Schlange - schließt sich den Nightwings nur aus dem Grund an, weil sie eine unverbrüchliche Liebe zu dem Baummann und Revolutionsführer Volfred Sandalwood hegt, der ihr seinerseits in tiefer Freundschaft verbunden ist. ${ }^{111}$

Wenn man im Hier und Heute von einer erotischen Beziehung zwischen einem Menschen und, sagen wir, einem Hund erführe, würde man wohl günstigstenfalls mit Unverständnis reagieren. Aber es ist das Vorrecht der Kunst, in den entlegenen, abseitigen und vielleicht unansehnlichen Winkeln unseres

110 Grimm: Flammen der Freiheit.

111 Nebenbei bemerkt tragen die häufig schrulligen Namen der Figuren dazu bei, der Welt des Spiels - ungeachtet des schmerzlichen Ernstes, der diese Welt doch auch durchdringt - eine gewisse Vergnügtheit und Verspieltheit einzuflößen. 
Fantasielebens ein brachliegendes Empfindungspotenzial $\mathrm{zu}$ entdecken und aufzuschließen. Genau das tut PYRE. ${ }^{112}$ Das Spiel will die Spielerinnen und Spieler ermutigen, Möglichkeiten ... vielleicht nicht gerade von geschlechtlicher und begehrender Liebe ... aber doch von Freundschaft, von Verbundenheit, von geschwisterlicher Zärtlichkeit und offener, neugieriger Bezugnahme dort zu entdecken, wo man sie nicht unbedingt suchen würde.

$\mathrm{Ob}$ das gelingen kann, hängt freilich von den Spielerinnen und Spielern selbst ab. Ebenso, wie man die Hintergrundgeschichte der Welt von PYRE erst erfährt, wenn man sich die Mühe macht, das Book of Rites zu lesen, wird die Hintergrundgeschichte der einzelnen Figuren nur dann offenbar, wenn man das Gespräch mit ihnen sucht, bereit ist, ihnen zuzuhören - oder vielmehr: ihre Repliken zu lesen. ${ }^{113}$ Es dreht sich darum, in und hinter den spärlich animierten, im Comic-Stil gehaltenen Porträts, die je nach Figur „putzig“ (der Imp Ti’zo), skurril (der Wyrm-Ritter Sir Gilman) oder grotesk (die Crone Bertrude) ausfallen mögen, nach Bedeutung zu suchen. Und da gibt es, wie bereits angedeutet, einiges zu entdecken: bemerkenswert komplexe und in ihrer Verdrehtheit durchaus originelle Figuren, die voller Konflikte, Wehmut, Witz und Heroismus stecken. Wer diese Bedeutungen aufspürt, wer sie zu sehen bereit ist, wird es nicht mehr nur drollig finden, dass der wurmartige Sir Gilman mit seinem überdimensionierten Auge und dem ebenfalls überdimensionierten Helm bereit ist, alles aufzugeben, um seine verlorene Ehre wiederherzustellen. Oder dass das „moon-touched“ Vagabundenmädchen, das seinen Namen vergessen hat und ständig die Stimmen der Eight Scribes hört, und Ti'zo einander schluchzend in die Arme fallen, nachdem dieser, der für sein Leben gern Fische fängt, einmal umsonst ins Wasser getaucht ist. Der wird sogar überlegen, in einem Liberation Rite die Schwester der Harpyie Pamitha gewinnen zu lassen, die das Triumvirat „The Essence“ anführt, um vielleicht irgendwie eine Versöhnung zwischen den beiden zu ermöglichen denn Tamitha, so der Name der Schwester, hält Pamitha für eine verachtenswerte Verräterin, seit sie sich, noch im Commonwealth, vermeintlich gegen die eigenen Leute stellte.

112 Natürlich haben wir es hier mit einem Beispiel für das „Queering“ der Fantasy zu tun. Vgl. Vera Cuntz-Leng: Harry Potter que(e)r. Eine Filmsage im Spannungsfeld von Queer Reading, Slash-Fiction und Fantasyfilmgenre. Bielefeld 2015.

113 Rae Grimm erläutert: „Um die Fremdartigkeit der Charaktere zu unterstreichen, verzichtet PYRE fast vollständig auf verständliche Sprachausgabe. Die Charaktere sagen nur kurze Phrasen in einer Fantasiesprache und lediglich eine Figur namens ,Die Stimme‘ spricht Englisch.“ Grimm: Flammen der Freiheit. In Hinblick auf die hier entwickelten Gedanken wäre zu ergänzen, dass sich die körperlose Stimme, die als einzige verständlich und sozusagen comme il faut spricht, buchstäblich als Stimme der herrschenden Klasse entpuppt. 
Es ist nachvollziehbar, wenn einer Leserin, einem Leser in Anbetracht dieses Beziehungsgewirrs ein wenig der Kopf schwirrt. Doch mir schien es unabdingbar, die vielfältigen Verflechtungen zwischen den Figuren zumindest im Ansatz darzustellen. Denn erst auf dieser Grundlage wird es möglich, und dies ist der dritte Aspekt, vollständig zu erfassen, was bei den Rites selbst auf dem Spiel steht, jenem eigenartigen Ballsport, der das Zentrum von PYRE bildet.

Vergegenwärtigen wir uns zunächst den Ablauf und die Regeln der Begegnungen:

Hier geht es in Echtzeit zur Sache - und zwar in einem Team-Spiel, das am ehesten als ein mit überschaubaren Regeln versehener Mix aus Basketball sowie Rugby definiert werden könnte. Jedes Team muss sein „Pyre“ verteidigen, eine Feuersäule, die als Standard 100 Lebenspunkte hat, wobei diese Zahl auch teamabhängig variieren bzw. anderweitig beeinflusst werden kann. Ziel ist es, die Punktzahl des gegnerischen Pyre auf Null zu bringen. Dazu muss man sich den „Funken” schnappen und diesen entweder auf Distanz ins Pyre zu werfen oder mit der Figur in die Säule zu springen [sic] - quasi die Gegenstücke zum Try beim Rugby, dem Field Goal und dem Slam Dunk.

Aber: Es kann immer nur eine Figur pro Team bewegt werden. Bei den Angreifern ist dies der Träger des Funkens. Bei den Verteidigern kann man frei durchschalten. Als ob dies nicht reichen würde, um für ein spannendes Taktik-Geplänkel zu sorgen, gibt es aber noch weitere Elemente, die beachtet werden müssen. So verfügen alle Figuren z. B. über eine „Aura“, die sie und das Pyre schützt und die vor allem vom Funkenträger nicht betreten werden sollte - denn im Gegenzug für das Privileg, den Funken zu bewegen, muss man seine Aura aufgeben. Zusätzlich kann man Zauber wirken, die in einer direkten Schneise vor einem abgefeuert werden, während andere Figuren z. B. fliegen können, um Schaden auszuweichen oder andere Hilfsmittel einsetzen dürfen. Durch unterschiedlich große Auras, verschiedene Bewegungsgeschwindigkeiten etc. kommen weitere Faktoren hinzu. Und: Wird man ausgeschaltet bzw. schafft es, die Punkte des gegnerischen Pyres zu senken, muss man mitunter ein paar Sekunden warten, bis man wieder auf dem Ritual-Schlachtfeld wieder auftaucht $\left[\right.$ sic]. ${ }^{114}$

Auch, wenn es um die Rites geht, sind die Details des Regelwerks nicht von entscheidender Bedeutung. Wichtig ist vor allem, dass immer nur eine Figur auf dem Spielfeld agieren kann. Hierin drückt sich die Grundidee der Rites aus, ihre „Essential Structure“, wie es in dem von den Eight Scribes verfassten Buch heißt; selbige wird wie folgt definiert: „In each triumvirate the three shall act as one, to demonstrate their trust in one another, not just in themselves." Das heißt nichts anderes, als dass die Figuren, die der Spieler in den Nightwings versammelt hat, jederzeit zusammenarbeiten und sich aufeinander beziehen müssen, nicht trotz,

114 Oertel: Abenteuerspielbuch und Fantasy-Rugby. 
sondern wegen ihrer Verschiedenheit, über die Grenze von Geschlecht, Haut-, Fell-, Schuppen- und Rindenfarbe, Rasse und Spezies hinweg.

Spielmechanisch drückt sich dies - die zitierte Passage aus dem Test von Mathias Oertel macht es deutlich - darin aus, dass die verschiedenen Figuren über je eigene Stärken und Schwächen verfügen, die der Spieler aufeinander abstimmen muss. Dergleichen ist bei einschlägigen Genre-Produktionen durchaus üblich; das gilt sowohl für rundenbasierte Taktik-Spiele wie die X-COM-Reihe (Mythos Games/ MicroProse/Hasbro Interactive/Infogrames/Firaxis Games, 1994-) als auch für die (heutzutage eher seltenen) Vertreter des Subgenres der Echtzeit-Taktik-Spiele wie SHADOW TACTICS: BLADES OF THE SHOGUN (Mimimi Productions, 2016). Dass dieses Pathos des Alle-ziehen-am-gleichen-Strang nicht in konventionalisierten Spielmechaniken aufgeht - und, wichtiger noch, nicht einfach wie hohler Verbrüderungsoder Sportler-Kitsch wirkt -, verdankt sich zum einen der Zuspitzung der Fantasy, die es eben in der Tat erlaubt, Hund, Vogel und Wurm oder Baum, Frau und Schlange in ein- und derselben Mannschaft antreten zu lassen. Es verdankt sich zum anderen, und ganz wesentlich, dem Umstand, dass PYRE die Logik des Gewinnens und Verlierens auf eine bemerkenswerte Weise verdreht. In diesem Spiel gibt es nämlich kein „Game Over“; auch wenn die Nightwings eine, fünf oder zehn Partien verlieren, geht es immer weiter. Dazu passt, dass in den Rites niemand verletzt wird oder stirbt (was allerdings, wie bereits deutlich geworden sein mag, nicht der wesentliche Grund ist, weshalb das Spiel dem Geschmack Le Guins entsprechen könnte). Dazu passt schließlich, dass sich ein Sieg mitunter schmerzlicher anfühlt als eine Niederlage.

Denn im Verlauf von PYRE begreift man langsam, dass sich das Opfer der Scribes in jedem einzelnen Liberation Rite aktualisiert. Immer ist die Befreiung der einen unauflöslich an die Verbannung der anderen gebunden. Immer geht es um die Freiheit dieses oder dieser Anderen; und die Spielerinnen und Spieler müssen je aufs Neue darüber entscheiden, wer in die Freiheit entlassen wird. Wird man Pamithas sehnlichsten Wunsch erfüllen, die Rückkehr ihrer Schwester in den Commonwealth zu ermöglichen - oder wird man ein weiteres Mitglied der Nightwings zwecks Revolutionsvorbereitung nach Hause schicken? Nicht nur im Fall der Harpyien-Schwestern kann es sinnvoll und anständig, oder gar ethisch geboten erscheinen, eine Niederlage der Nightwings in Kauf $\mathrm{zu}$ nehmen, um dem gegnerischen Triumvirat die Möglichkeit zu geben, einen der Ihren $\mathrm{zu}$ befreien. Das gilt gleichfalls, wenn beispielsweise der „alte aufrechte Hund Dalbert“, der Anführer des Triumvirats „Fate“, auf dem Spielfeld steht, „der die Rituale voller Ehrfurcht und Redlichkeit vollführt“ und seinen Sohn dazu anhält, ebenfalls für diese Werte einzutreten. ${ }^{115}$

115 Schmid: PYRE - im Test. 
Freilich weiß der Spieler nie, ob seine Entscheidungen wirklich die erwünschten Folgen zeitigen. Wenn man Dalberts Triumvirat in den Liberation Rites gewinnen lässt, entsendet der alte Hund seinen Sohn Almer in die Freiheit - gegen dessen ausdrücklichen Willen. Das Triumvirat Fate löst sich in der Folge auf, und Dalbert selbst verschwindet auf Nimmerwiedersehen.

Auch bezogen auf die Nightwings ist die Entscheidung darüber, wer in den Commonwealth zurückkehren darf, kein Leichtes. Denn die Figuren müssen einige Erfahrung - oder, im Jargon von PYRE, Erleuchtung - gesammelt haben, ehe sie für würdig befunden werden, ihr Dasein als Exilierter oder Exilierte zu beenden. Nun liegt es in der Natur der Sache, dass man bevorzugt mit Figuren spielt, an denen man besonders viel Freude hat; sei es, weil ihre Fähigkeiten in den Rites gut zum eigenen Spielstil passen; sei es, weil man sie ins Herz geschlossen hat. Gerade diese Figuren werden es aber sein, die als erste für die Befreiung in Frage kommen. Und was innerhalb der Diegese als etwas Gutes und Notwendiges erscheint - verdiente Recken der Nightwings die Heimkehr zu ermöglichen, damit sie für die Freiheit aller eintreten können -, ist aus Spielerperspektive keineswegs so eindeutig zu bewerten.

Denn die Befreiung geht mit dem endgültigen Abschied einher. Zwar wird man noch ein wenig darüber erfahren, wie sich die vormals Exilierten im Commonwealth geschlagen haben. Doch man wird sie nicht mehr spielen können, sodass sich der Abschied etwa von Rukey oder Jodariel als unumkehrbar erweist. In der Konsequenz dieser Spielmechanik vermag PYRE ein Gefühl zu erwecken, das jenem der Trauer erstaunlich nahekommt - vielleicht gerade darum, weil die Spielerinnen und Spieler den Abschiedsschmerz bejahen müssen, ihn sogar in ihrem eigenen Tun und Streben herbeiführen. Gegen Ende von PYRE erhält die Entscheidung, wer in den Liberation Rites befreit werden soll, nochmals größeres Gewicht, sowohl narrativ als auch in der Spielerfahrung; es erweist sich nämlich, dass die Rites zu einem Ende kommen, dass ein ganzes Zeitalter zu einem Ende kommt - und das heißt, den Spielerinnen und Spielern wird es nicht möglich sein, alle Mitglieder der Nightwings in die Freiheit $\mathrm{zu}$ führen. Am Schluss muss man sogar über das eigene Los entscheiden: Kehrt der Avatar in den Commonwealth zurück, um seinen Platz unter den Revolutionären einzunehmen? Oder wählt er das lebenslange Exil und ermöglicht auf diese Weise noch einem anderen Gefährten die Heimkehr?

Völlig zurecht stellt Gita Jackson fest, dass Supergiant Games in dieser Designentscheidung - und dem daraus resultierenden Spielgefühl - ein bemerkenswert komplexes und ernsthaftes Politikverständnis zum Ausdruck bringen. 
Sie schreibt:

The first time I nominated Xae [der Name, den Jackson dem von ihr besonders geschätzten Vagabundenmächen gegeben hat] for liberation I lost the rite. For a brief moment, knowing I'd only have a few more chances to liberate characters, I thought, „Well, guess I'll just start the game over." I pressed on instead, realizing that no matter how many times I play PYRE, I'll always have a moment where I feel like I've doomed my plans. [...] Sometimes, you'll make a choice that feels wrong, although you know it will give your revolution a better chance. Sometimes, there's no right choice, but you'll have to make one regardless. PYRE doesn't frame political action as being dependent on individual choices, however. While you influence the revolution, these plans were set in motion before you and you're just here to drive it home. Although you're in charge of all the decision within the Nightwings, the game makes it clear that the revolution lives or dies on the strength of a community. ${ }^{116}$

„The strength of a community“ - diese Kraft der Gemeinschaft, die PYRE beschwört und feiert, scheint in rätselhafter Weise auf die Downside überzugreifen, hat immer schon auf sie übergegriffen, wie man allerdings erst im Rückblick auf die Spielerfahrung begreift. Mit der Gestaltung der Downside ist die vielleicht merkwürdigste Designentscheidung von Supergiant Games aufgerufen. Die Geschichte des Spiels will uns glauben machen, dass es sich bei der Downside um eine nahezu infernalische Ödnis handelt: lebensfeindlich, gefährlich, harsch und unerbittlich. Wie stellt man sich derartige Gefilde wohl vor? Ungefähr so wie ein durchschnittliches DARK-SOULS-Gebiet, würde ich vermuten. Also düster, in kargen Farben gehalten, voller Ruinen, Nebel und dräuender Erhabenheit. Doch die Downside von PYRE ist gleichermaßen knall- wie kunterbunt. Quietschbunt, möchte man fast sagen. Auch abgesehen von der Farbgebung, haben wir es hier mit einer überaus eigenwillig gestalteten Hölle zu tun. „Atemberaubend schön“, findet Rae Grimm diese Hölle, ${ }^{117}$ und Wes Fenlon erklärt, er habe eine lange Zeit damit verbracht, die Screenshots anzustarren, die er von PYRE gemacht hatte, ehe er ein einziges Wort über das Spiel schrieb, „,because every frame captures a pure fantasy world so creative and otherworldly I envy the minds able to bring it to such vivid life. It's the kind of art that reminds you fiction can be anything, if only you have the power to imagine it. “118

In der Tat: Anders als die allermeisten Fantasy-Spiele (oder -Romane, -Filme und -Serien), die eine im Wortsinn romantisierte Version archaischer Epochen un-

116 Jackson: PYRE.

117 Grimm: Flammen der Freiheit.

118 Wes Fenlon: PYRE Review. In: www.pcgamer.com, 24. Juli 2017, https://www.pcgamer. com/pyre-review/ [letzter Zugriff: 12.05.2020; Herv. i. O.]. 
serer Welt vorstellen, vollzieht PYRE einen radikalen Bruch mit jeglicher Repräsentationslogik. So radikal ist dieser Bruch, so „otherwordly“ die daraus resultierende Bildlichkeit, dass man einen beträchtlichen dichterischen Aufwand betreiben, ja selbst ein kleines Kunstwerk schaffen müsste, um die Anmutung dieser Welt in Sprache zu übertragen. Will man sich auf wenige Worte beschränken, ist es vielleicht am besten, zu einem Vergleich zu greifen, so wie Alexander Bohn-Elias es tut, der meint, diese Welt habe ,sichtlich Inspiration aus den Prog-Rock-Plattencovern der Siebzigerjahre“ gezogen. ${ }^{119}$

Sieht so eine anständige Hölle aus, die ihrem Namen Ehre machen will? Wohl kaum. Der Grund hierfür liegt augenscheinlich darin, dass die Downside nicht annähernd so höllisch ist, wie es uns die Geschichte von PYRE einreden will. Wer mit dem kuriosen Wägelchen der Nightwings (in dem seiner Kleinheit zum Trotz ein umfänglicher Haushalt Platz findet) durch die Downside rumpelt, später fliegt, fühlt sich eher wie in einem Wunderland, ${ }^{120}$ das dem HippieTraum vom Drogenrausch entsprungen ist - bedrohlich mag es sein, dieses Land, vor allem jedoch ist es ein Ort der Überraschungen, des Unerwarteten und Ungeahnten. Dieses Gestaltungsprinzip findet nicht zuletzt einen Ausdruck in dem von Darren Korb komponierten Score, der eine verblüffende, in der Spielerfahrung mitunter sogar ein wenig verwirrende Vielfalt musikalischer Stile kombiniert: ein „mysteriös-verwunschener Reise-Folk“"121, wie man ihn vielleicht erwarten würde, geht Hand in Hand mit barock anmutenden Cembalo-Klängen, Metalriffs und wildem Schlagzeugdonner, Elektro-Pop - ornamental umspielt von orientalisierenden Melodien -, Gothic und Dark Wave, psychedelischem Rock, einer Lounge-Version französischer Musette, Marschmusik und Kinderlied ... und einigem mehr.

So erweist es sich, dass die Hölle in PYRE nicht nur farblich, sondern vor allem ästhetisch bunt ist. Wir müssen sie uns als einen Ort vorstellen, an dem ein verrücktes Vagabundenmädchen und ein „putziger Dämonenvogel“ gemeinsam in den Sonnenuntergang ziehen, nicht als verachtete Außenseiter oder Witzfiguren - sondern als Helden. ${ }^{122}$

119 Alexander Bohn-Elias: Unterwelt-Prog-Rock-Fantasy-Basketball-Rollenspiel für Lesefreunde. In: www.eurogamer.de, 27. Juli 2017, https://www.eurogamer.de/articles/2017-07-27pyre-test [letzter Zugriff: 12.05.2020].

120 Tatsächlich ähnelt die Poetik des Spiels sowohl der von Carrolls Alice-Büchern als auch jener der psychedelischen Adaptionen aus den sechziger und siebziger Jahren. Vgl. Lötscher: Die Alice-Maschine.

121 Bohn-Elias: Unterwelt-Prog-Rock-Fantasy-Basketball-Rollenspiel für Lesefreunde.

122 So gesehen ist die Anekdote aus ihrer Multiplayer-Erfahrung mit PYRE, die Gita Jackson ans Ende ihres Tests zu dem Spiel stellt, vielleicht ein bisschen mehr als nur launig: „When I played against Kotaku editor-in-chief Stephen Totilo in the office, he banished me just as I was 


\section{Ist Liebe stark wie der Tod?: HELLBLADE: SENUA'S SACRIFICE}

„Lege mich wie ein Siegel auf dein Herz, wie ein Siegel auf deinen Arm. Denn Liebe ist stark wie der Tod und Leidenschaft unwiderstehlich wie das Totenreich. Ihre Glut ist feurig und eine gewaltige Flamme.“123

In Salomos Hohelied ist eine Hoffnung ausgedrückt, die über die Jahrtausende hinweg in ungezählten Liedern, Gedichten, Theaterstücken, Romanen und Erzählungen besungen wurde. Auch in den narrativen Leitmedien unserer Tage, in Film, Fernsehserie und Videospiel, erklingt ihr Echo, wieder und wieder. Es ist die Hoffnung, dass der große Abschied, der uns alle erwartet - vielleicht ein Dutzend Mal im Lauf eines Lebens -, in seiner Endgültigkeit doch nicht endgültig sein mag; dass „der dunkle Engel, der die Hände löst und jeden von uns ins Alleinsein mit seinem Nichtsein weist“ nicht in jedem Fall "Gebot und Macht“ habe, „so zu tun“. ${ }^{124}$ Man mag das kitschig, abgeschmackt oder verlogen finden. Man mag auf die historische Wandelbarkeit des Konzepts Liebe verweisen und ihren Warencharakter im Kapitalismus analysieren. Man mag beide Füße fest auf den Boden der Gewissheit stellen, dass das Schicksal unserer Erde, und erst recht des einzelnen Menschen, geschweige denn des einzelnen Tiers, weniger als belanglos ist, wenn man den Maßstab der naturgesetzlichen Prozesse anlegt, die noch die Entropie des Universums in sich schließen.

Doch es kommt der Tag, wo die Katze von einem Auto überfahren wird. Wo der Vater an Krebs stirbt. Wo die Nachricht vom Tod eines alten Freundes, den man seit vielen Jahren nicht gesehen hat, herabfährt wie ein Blitzschlag aus sommerblauem Himmel. Dann stellt sich die Frage: Was bleibt? Oder vielmehr: Bleibt etwas? Ein Andenken? Eine Erinnerung? Eine ferne Stunde, in der die Welt gut war und das Leben so, wie es immer sein sollte?

Kurzum: Gibt es die Liebe, und ist sie wirklich stark wie der Tod? Oder ist das Grab die einzige Wahrheit?

Wie SHADOW OF THE COLOSSUS ist HELLBLADE: SENUA'S SACRIFICE ein orpheisches Lied. Freilich geht es nicht darum, welche Antwort das Spiel auf diese Frage gibt. Sondern darum, wie es sie stellt. Senua lebt im Frühmittelalter, im 8. Jahrhundert; sie ist eine piktische Kriegerin von den Orkney-Inseln. Plündernde Wikinger verheeren ihr Dorf, und auch Dillion, Senuas Geliebter, fällt dem Überfall der Nordmänner zum Opfer. Auf grausame Weise wird er hingerich-

about to score on him and I shouted, ,you motherfucker.' PYRE is good in many ways. It's even good enough that it made me call my boss a motherfucker." Jackson: PYRE.

123 Hohelied 8,6. In: Die Bibel, übers. von Martin Luther. Stuttgart 2017, S. 699.

124 Thomas Mann: [Katja Mann zum siebzigsten Geburtstag]. In: ders.: Über mich selbst. Frankfurt a. M. 1994, S. 180-185, hier: S. 184-185. 
tet. Senua jedoch ist nicht bereit, seinen Tod zu akzeptieren. Sie nimmt Dillions Schädel, bindet ihn an ihre Hüfte, und macht sich auf den Weg nach Helheim, um mit Hela selbst um die Seele ihres Geliebten zu streiten. ${ }^{125}$

Anders ist in HELLBLADE also zunächst, dass hier eine Frau die Reise ins Totenreich antritt. Vor allem jedoch geht es darum, was für eine Frau das ist. Im Lauf des Spiels wird Senuas Hintergrundgeschichte entfaltet, und langsam begreift man, dass sie von Kindheit an zu einem Dasein bitterster Trostlosigkeit verurteilt war. In ihrem Dorf galt sie als verflucht, und im Alter von fünf Jahren musste sie mitansehen, wie ihre Mutter Galena - auch sie eine Verfluchte - von ihrem Vater bei lebendigem Leib verbrannt wurde. Späterhin tat Zynbel, der Vater, alles, um Senua seine Verachtung spüren zu lassen: Er misshandelte sie, körperlich und seelisch, sperrte sie ein.

Kurz gesagt: Die Kriegerin, die man in HELLBLADE spielt, ist ein zutiefst verwundeter Mensch, der früh gelernt hat, sich selbst als einen Haufen Dreck zu betrachten. Aber nicht nur im Mittelalter, auch in unseren Tagen hätte es Senua schwer. Heute würde man sagen: Sie ist schizophren. Oder: Sie leidet an einer Psychose. Tatsächlich war es das erklärte Anliegen der Entwickler von Ninja Theory, in ihrem Spiel eine angemessene, respektvolle und medizinisch stimmige Darstellung psychischer Krankheiten zu realisieren. ${ }^{126}$ Und wenn man die Tests der internationalen Spielepresse liest, stellt man schnell fest, dass HELLBLADE eben dafür gewürdigt, gelobt und mitunter gefeiert wurde: Was immer sie sonst von dem Spiel halten, die Journalisten stellen anerkennend fest, dass Ninja Theory die Mittel des Mediums Videospiel nutzt, um hier ein sehr ernstes Thema auf eindrückliche und überzeugende Weise $\mathrm{zu}$ behandeln. ${ }^{127}$

125 Die Geschichte von HELLBLADE: SENUA'S SACRIFICE trägt sich gänzlich in Helheim zu; selbst die Rückblenden, die Leben und Leiden der Protagonistin greifbarer machen, scheinen noch Teil des Totenreichs. Insofern mag es angemessen sein, auch bezogen auf dieses Spiel von einer Sekundärwelt zu sprechen: Das vermeintliche Jenseits ist als Diesseits der ästhetischen Erfahrung eine für sich bestehende Welt.

126 Vgl. Dom Schott: Duell gegen die Unterwelt. In: www.gamepro.de, 08. August 2017, https:// www.gamepro.de/artikel/hellblade-senuas-sacrifice-duell-gegen-die-unterwelt,3318059.html [letzter Zugriff: 12.05.2020].

127 Als Beispiel für diese Sicht auf HELLBLADE seien im Folgenden einige deutschsprachige Testes genannt. Alexander Bohn-Elias: Hello Darkness, my old friend ... In: www.eurogamer.de, 10. August 2017, https://www.eurogamer.de/articles/2017-08-10-hellblade-senuas-sacrifice-test [letzter Zugriff: 12.05.2020]; Christian Dörre: Ein erzählerischer Meilenstein. In: www.pcgames. de, 11. August 2017, www.pcgames.de/Hellblade-Senuas-Sacrifice-Spiel-56843/Tests/Review-Einerzaehlerischer-Meilenstein-1235560/ [letzter Zugriff: 12.05.2020]; Michael Krüger: Die spielgewordende Wikinger-Hölle. In: www.spieletipps.de, 08. August 2017, https://www.spieletipps. de/artikel/7430/1/ [letzter Zugriff: 12.05.2020]; Benjamin Schmädig: Fluch und Segen. In: www. 4players.de, 10. August 2018, http://www.4players.de/4players.php/dispbericht/Allgemein/ 
In der Spielerfahrung schlägt sich das zum Beispiel so nieder, dass man, während Senua die Unterwelt durchwandert, unentwegt die Stimmen hört, die sie verfolgen. Fast kein Moment der Ruhe wird Senua - und den Spielerinnen und Spielern - gegönnt: Ständig ist da ein Zischen, Tuscheln, Wispern; spottend, höhnend, kritisierend, aber auch bittend, beratend, warnend begleiten die Stimmen, „Furies“ genannt, jeden Schritt, jede Handlung der Kriegerin. Namentlich wenn man mit Kopfhörern spielt, erzeugt diese auditive Belagerung ein überaus bedrängendes und auf Dauer sogar quälendes Gefühl der Gehetztheit und Ohnmacht. Dann gibt es die, je nach Perspektive, Visionen oder Halluzinationen, unter denen Senua leidet: In ihnen zerrinnen die Grenzen von Zeit und Raum, sodass grauenvolle Bilder aus der Kindheit - wie jenes der brennenden Mutter, die ihre Tochter verzweifelt bittet, sie möge die Augen abwenden in die Gegenwart der Kriegerin drängen. Ninja Theory spart hier nicht mit drastischen Inszenierungen von Gewalt, in denen, nicht zuletzt aufgrund des ungeklärten Wirklichkeitsstatus der entsprechenden Bildlichkeit, der körperliche und der seelische Schmerz in eins fließen. Schließlich sollte die Inszenierung von Senua erwähnt werden: In den Filmszenen eröffnet die Darstellerin Melina Juergens nicht nur eine Fantasie der Innerlichkeit dieser gepeinigten Frau, die einer fernen, unbegreiflichen Vergangenheit angehört. Vielmehr verleiht sie Senua eine „einzigartige physische Präsenz“, ${ }^{128}$ die dafür sorgt, dass man geradezu eingesogen wird in die Seele der Kriegerin. Und das heißt auch: auf Tuchfühlung geht mit ihrer Dunkelheit. Vor allem in den Nah- und Großaufnahmen von Senuas Gesicht dringt sie durch. Mehr noch: Das existenzielle Leiden Senuas entfaltet eine solche Wucht, in ihrem Wimmern, ihrem Schreien, im Zerbrechen ihres Gesichts, dass jene Dunkelheit die Hände nach den Spielerinnen und Spielern ausstreckt.

All das legt eine bestimmte Interpretation von HELLBLADE nahe. Unter Berufung auf die mutmaßliche Intention des leitenden Entwicklers Tameem Antoniades schreibt Benjamin Schmädig:

Immerhin kämpft auch Senua gegen mythische Kreaturen und löst Rätsel, um Türen zu öffnen. Sie tut das, um ihren Geliebten zu retten. Seine Seele steckt wohl in dem Schädel, den sie bei sich trägt, und sie reist dafür in die Hölle - oder vielmehr einen Ort, den sie dafür hält. Denn anders als die Widersacher gewöhnlicher Heldinnen scheinen „ihre“ Kreaturen nicht real zu sein: Nach dem Tod lösen sie sich in den Schatten auf, aus denen sie gekommen sind. Und die Tore, durch die Senua gehen muss, sind vermutlich nie ver-

Test/35998/82654/0/Hellblade_Senuas_Sacrifice.html [letzter Zugriff: 12.05.2020]; Dom Schott: Duell gegen die Unterwelt.

128 Schmädig: Fluch und Segen. 
schlossen. Antoniades zeichnet das Bild einer psychisch Kranken, die nur deshalb von einer Dunkelheit spricht, weil zur ihrer Zeit, der Zeit der Wikinger, keine andere Diagnose möglich war. ${ }^{129}$

Diese Interpretation ist sicherlich schlüssig und könnte durchaus dem entsprechen, was man bei Ninja Theory im Sinn hatte, als man die Entwicklung von HELLBLADE vorantrieb. Doch greift sie zu kurz, wenn es um die faktische Spielerfahrung geht. Die Fäulnis, die in Gestalt schwarzer Ranken an Senuas Arm emporwächst, wenn sie stirbt, und mit jedem Tod ein bisschen weiter um sich greift, mag ein Symbol dafür sein, dass die Kriegerin Gefahr läuft, langsam den Verstand zu verlieren. In der sinnlichen Konkretion des Spielerlebens ist hier aber zunächst und vor allem eine boshafte Macht gezeichnet, die von Senua Besitz zu nehmen droht. Die als Stimme des Abgrunds und drohender Schatten gestaltete Dunkelheit, die ebenso zu Senua spricht wie die „Furies“ - und ihr ein ums andere Mal bestätigt, dass sie nichts sei als ein erbärmlicher Schwächling, widerwärtiger Abschaum, der letzte Dreck eben -, lässt sich ohne weiteres als Projektion von Senuas traumatisierter Psyche deuten. Eine Verschiebung, in welcher der wahre Teufel, der Vater, zugleich offenbart und verborgen ist. Das ändert aber nichts an dem metaphysischen Horror, den Senua fühlt, und mit ihr die Spielerinnen und Spieler, wenn dieser Teufel sie mit seinem Hass und seiner Verachtung in die Enge treibt.

Es geht hier schlicht darum, dass HELLbLADE ein Fantasy-Spiel ist. In der Gestaltung der Unterwelt, die Senua bereisen muss, gibt es keinerlei Hinweis darauf, dass etwas an dieser Welt nicht wirklich ist - so wirklich oder unwirklich ist sie, wie die fantastischen Welten des Videospiels eben wirklich oder unwirklich sein können. Und wichtiger noch: Wenn Senua gegen riesige, bullige, maskierte und irgendwie deformierte Dämonenmänner kämpft, die mit grausamen Waffen auf sie eindrängen, dann kämpft sie: Von den Spielerinnen und Spielern gesteuert greift sie an, pariert, kontert, weicht aus, wird getroffen und niedergeschlagen, blutet und stirbt. Was genau heißt es da, dass diese Kreaturen nicht „real“ sind? Real bezogen auf was? In der Realität der Spielerfahrung sind sie zweifelsfrei real; und bedrohlicher und furchteinflößender als die Gegner in vielen Titeln, deren Heldinnen und Helden, nach allem was wir wissen, keinerlei psychische Probleme haben.

Mit anderen Worten: In HELLBLADE überlagern sich zwei verschiedene und letztlich unvereinbare Deutungsmuster. Wo der aufgeklärte Blick des heutigen Spielers eine paranoide Schizophrenie diagnostiziert - was immer das dann heißen soll -, erkennt Senua das Wirken jenseitiger, unseliger Mächte, die sie

129 Schmädig: Fluch und Segen. 
einfach nicht in Frieden lassen wollen. Die Narration des Spiels mag der klinischen Interpretation zuneigen; in der konkret-sinnlichen Weltgestaltung und den Spielmechaniken besteht HELLBLADE hingegen mit Macht auf der Wirklichkeit der Dämonie.

Aus meiner Sicht ist es nicht nötig, und vielleicht auch nicht möglich, hier eine Entscheidung $\mathrm{zu}$ treffen. ${ }^{130}$ Vielmehr sollte man sich klarmachen, dass HELLBLADE seine Intensität, die Wucht seiner Affektpoetik, wesentlich aus dem Zusammenprall der konfligierenden Wirklichkeitssysteme bezieht.

Gerade bei den Kämpfen wird das deutlich. Wären die martialischen Auseinandersetzungen in der Narration, der Weltgestaltung oder den Spielmechaniken eindeutig als „Kampf gegen die inneren Dämonen“"131 markiert, würden sie sehr viel an Wirkung einbüßen. Die Verwundungen, die Senua erleidet, wären rein symbolhaft, ebenso wie das Blut, das sie vergießt; die Bedrohung wäre phantasmatisch und der wirkliche Kampf auf Leben und Tod würde sich ganz woanders zutragen. Hätte Ninja Theory die Kämpfe umgekehrt so angelegt, dass sie umstandslos eine materiell-faktische Wirklichkeit in Senuas Welt bezeichnen sollen, würden daraus Probleme anderer Art folgen. So gibt es ein kaum zu übersehendes Missverhältnis zwischen der zierlichen Physiognomie von Melina Juergens - beziehungsweise der Kriegerin, der sie ihr Gesicht und ihren Körper geliehen hat und dem Schwert, das Senua zu Beginn des Spiels führt, bis es infolge ihrer ersten Konfrontation mit Hela zerbricht. Selbiges ist so groß, man kann sich kaum vorstellen, dass eine Frau dieser Statur in der Lage wäre, es in einer Hand zu halten; geschweige denn, Dutzende Male mit ihm zuzuschlagen oder die vernichtenden Attacken der muskelbepackten Dämonenmänner mit seiner Klinge zu blocken. Und die Feinde selbst? Sie treten gegen Ende von HELLBLADE immer häufiger in solchen Massen auf, dass Senua schon eine kleine Armee im Gefolge haben müsste, um die Kämpfe gegen sie zu bestehen. Davon kann aber keine Rede sein. Im Gegenteil ist sie so alleine wie nur je eine Spielfigur.

Derartige Unstimmigkeiten würden in einer Hack'n'Slay-Sause wie DIABLO III (Blizzard Entertainment, 2012) nicht weiter ins Gewicht fallen; sie würden nicht einmal als solche wahrgenommen werden, da weder die Weltkonstruktion noch die Spielmechaniken irgendeinen Anlass geben, Bezüge zu der physischen Realität menschlicher Wesen herzustellen. Senua aber könnte nicht weiter entfernt sein von dem Fantasy-Klischeebild der Super-Amazone, die ihre üppigen Brüste

130 So gesehen ist HELLBLADE eines der wenigen Spiele, auf die man Todorovs Fantastiktheorie anwenden könnte. Vgl. Todorov: Einführung in die fantastische Literatur.

131 Vgl. Schmädig: Fluch und Segen. 
in ein neckisches Kettenbustier hüllt und die Leichen ihrer erschlagenen Feinde als Laufsteg nutzt. Vielmehr hat man sich bei Ninja Theory offenbar alle Mühe gegeben, in Senua die Körperlichkeit einer schwitzenden, blutenden, schmutzigen, zerzausten Frau spürbar zu machen, die dauernd am Rande der Erschöpfung steht - und schließlich weit über jede Erschöpftheit hinausgeht.

Eben jenes Bildnis eines verwundbaren, leidenden und sterblichen Körpers wandelt sich zum pathetischen Affektbild, wenn man die Kämpfe in HELLBLADE als etwas betrachtet, das eben zugleich phantasmatisch und real ist: ein symbolisches Ringen mit der zerstörerischen Macht der schizophrenen Angst, und ein allzu wirklicher, blutig-brutaler Kampf gegen eine Heerschar von hasserfüllten, mordlüsternen Gegnern, die nicht eher weichen, bis man sie durchbohrt oder niedergehauen hat. In dieser Perspektive bildet die Figur Senua als psychisch kranke Frau und mythische Kriegerin gleichsam einen Konnex zwischen beiden Wirklichkeitsebenen; und wer es so wahrnimmt, der erkennt in der furchtbaren Schlacht, die sie in ihrer Seele und mit ihrem Leib schlagen muss, einen Heldenmut, der aus Liebe und Dankbarkeit eine wahrlich übermenschliche Anstrengung auf sich nimmt, die - gemessen an der Sehnsucht, welche sie befeuert - nur vergeblich sein kann.

Dillion war für Senua, auch das wird im Verlauf von HELLBLADE sehr deutlich, eben ein Licht inmitten eines Lebens voller Schwärze, und sie zieht es vor, ganz buchstäblich durch die Hölle zu gehen, ehe sie dieses Licht verlöschen lässt. Psychologisch könnte man ihre Weigerung, seinen Tod hinzunehmen, sicher als narzisstische Wirklichkeitsverleugnung deuten. Im Modus der Fantasy aber verkehrt sich dieser Befund, da das Genre die Realität nun mal so denkt, dass es durchaus möglich erscheint, in die Hölle selbst vorzudringen, um einen Geliebten zu retten. Umgekehrt wird das Pathos von Senuas Unterweltreise geerdet - und zugleich verstärkt - durch die sehr reale und möglicherweise auch vertraute Anmutung einer Krankheit, die schon für den Einkauf im Supermarkt einigen Heroismus abverlangt.

Wer sich auf HELLBLADE einlässt, kann somit eine Verwandlung erleben, die zum eindrücklichsten und berührendsten zählt, was das Medium zu bieten hat. Anfangs erscheint Senua als eine fremdartige, unglückliche und obendrein verrückte Frau. Als solche ist sie nicht unbedingt attraktiv, keineswegs eine günstige Projektionsfläche für eigene, unbefriedigte Geltungssucht. Zumal sie einem ja nahekommt, allzu nahe, geradezu bedrängend und erstickend nah, mit ihrer Einsamkeit, ihrem Leiden, ihrer Verzweiflung und ihrer Bedürftigkeit. Es mag sein, dass man sich sogar ein wenig für sie schämt. Doch langsam ändert sich etwas in der Beziehung der Spielerinnen und Spieler zu Senua. Voll ungläubigem Staunen erlebt man mit, wie diese Frau immer wieder aufsteht. Ganz gleich, wie viel Schmerz ihr zugefügt wird; ganz gleich, wie viele Niederlagen 
sie hinnehmen muss. Ihre Schwäche und Verletzlichkeit bergen eine erschütternde Kraft. So treten Zuneigung und Bewunderung anstelle des anfänglichen Fremdelns. Schließlich wünscht man nur noch, dass Senua am Ende ihrer grauenvollen Reise ein unmögliches Glück finden wird. Und ist bereit, alles zu tun, was die eigenen Fähigkeiten als Spieler hergeben, um jenes Happy End herbeizuführen, an das man selbst vermutlich längst nicht mehr glaubt. ${ }^{132}$

Natürlich reicht es nicht. Den letzten Kampf gegen Hela und die buchstäblich endlosen Horden, die sie aufbietet, kann Senua nicht gewinnen. Aber einmal mehr ist das Ende nicht das Ende. Das endgültige Ende, in dem Senua Abschied nimmt von Dillions Schädel, ist dann vielfältig ausdeutbar. Fest steht, dass sie im Scheitern etwas gewinnt: die Freiheit zu einem neuen Anfang. Wo und wie sich dieser Anfang zuträgt, was ihn herbeigeführt hat und was aus ihm folgt, ist gar nicht so wichtig. Senua geht, wie wir alle, „als hoffnungsloser Schuldner des Unendlichen“ dahin. ${ }^{133}$ Doch vielleicht wird auch für sie gelten: „Was so gewesen ist, dem bleibt das Sein.“134

132 Um Missverständnissen vorzubeugen, sei darauf hingewiesen, dass die Analyse darauf zielt, eine in HELLBLADE angelegte affektpoetische Kalkulation zu rekonstruieren, die sich nicht unbedingt in der Erfahrung empirischer Spieler realisieren muss. Das wird beispielsweise am Gamers Global-Test von Benjamin Braun deutlich, der Senua „einfach nur uninteressant“ findet. Vgl. Benjamin Braun: Ragnarök und die schizophrene Kriegerin. In: www.gamersglobal. de, 10. August 2017, https://www.gamersglobal.de/test/hellblade-senuas-sacrifice [letzter Zugriff: 12.05.2020].

133 Mann: [Katja Mann zum siebzigsten Geburtstag], S. 184.

134 Mann: [Katja Mann zum siebzigsten Geburtstag], S. 185. 